\title{
1 Der reine Begriff der Realität bei Kant
}

\author{
„Die Kant-Auslegung ist ein unendliches \\ Geschäft - einmal drin, kommt man nicht mehr \\ heraus -, und es ist leicht, das Wesentliche wegen \\ der Einzelheiten aus den Augen zu verlieren.“”
}

Die kantische Philosophie ist noch immer eine gegenwärtige. Angefangen beim Neukantianismus im 19. Jahrhundert, zeigt sie spätestens seit Mitte des 20. Jahrhunderts eine große Wirkungsmacht auch in der sprachanalytischen angelsächsischen Philosophie. Peter F. Strawson legte dementsprechend mit Individuals eine „deskriptive Metaphysik“ vor, welche apriorische Begriffsschemata für die raum-zeitliche Struktur von Einzeldingen in der Welt vorsieht und sich damit beschäftigt, die wirklichen Strukturen unseres Denkens über die Welt zu beschreiben (,to describe the actual structure of our thought about the world“2). Schließlich bahnte er mit The Bounds of Sense. An Essay on Kant's Critique of Pure Reason $^{3}$ der kantischen Philosophie gänzlich den Weg in die anglophone Philosophie. John Rawls hat eine ähnliche Wegbereitung für Kant in den angelsächsischen Raum hinsichtlich der Praktischen Philosophie vollzogen ${ }^{4}$. Und nicht minder steht Kant zu Beginn des 21. Jahrhunderts noch immer und auf neue Weise im Fokus aktueller Debatten (Neurowissenschaft, Evolutionstheorie, Philosophy of Mind, Praktische Philosophie) $)^{5}$.

Die folgende Untersuchung stellt sich der Aufgabe, den reinen Begriff der Realität ${ }^{6}$ in Kants Kritik der reinen Vernunft in seinen Grundzügen herauszuarbeiten. Ihr Ziel ist es nicht, eine Erläuterung von Kants ganzer theoretischer Philosophie zu leisten bzw. deren grundsätzliche Struktur herzuleiten. Vielmehr

1 Charles Larmore: Vernunft und Subjektivität. Frankfurter Vorlesungen, Berlin 2012, S. $24 \mathrm{f}$.

2 Peter F. Strawson: Individuals. An Essay in Descriptive Metaphysics, London/New York 2003, S. 9.

3 Peter F. Strawson: The Bounds of Sense. An Essay on Kant's Critique of Pure Reason, London/ New York 1995.

4 Vgl. John Rawls: A Theory of Justice, Cambridge, Mass. 1971.

5 Vgl. dazu bspw. Warum Kant heute? Systematische Bedeutung und Rezeption seiner Philosophie in der Gegenwart, hg.v. Dietmar H. Heidemann, Kristina Engelhard, Berlin/New York 2004; Kant in der Gegenwart, hg.v. Jürgen Stolzenberg, Berlin/New York 2007. Zu Kant und der zeitgenössischen Philosophie vgl. auch Kurt Mosser: Necessity and Possibility. The Logical Strategy of Kant's Critique of Pure Reason, Washington, D.C. 2008, Kap. 5 („,Kant and Contemporary Philosophy“), S.137-187. 6 ,Reine Realität‘ wird im Folgenden als Oberbegriff für alle kategorialen Realitäts- bzw. Wirklichkeitsbegriffe verwendet. Das stellt noch keine Bewertung des Unterschiedes von „Realität“ und „Wirklichkeit“ dar, sondern ist dem Umstand geschuldet, dass „Realität“ zunächst einmal der umgangssprachlich geläufigere, weitere Begriff ist.

Ә OpenAccess. ( 2021 Claudia Wirsing, publiziert von De Gruyter. (cc) BY Dieses Werk ist lizenziert unter einer Creative Commons Namensnennung 4.0 International Lizenz. https://doi.org/10.1515/9783110730531-002 
soll die Beschränkung auf das begriffliche Moment des Realen - im Sinne des Mottos von Charles Larmore, welches dem Kapitel vorangestellt ist - garantieren, dass vor allem der Problemstand des hier untersuchten kategorialen Begriffs, d.h. seine Widersprüche und selbst unverwirklichten Möglichkeiten, deutlich werden können. Die sich aus dieser methodischen Vorgabe ergebende tendenzielle Isolation des Betrachtungsgegenstandes aus seinem komplexen kantischen Bedingungsgefüge ist deshalb notwendige Voraussetzung und kann dort gerechtfertigt werden, wo allein durch sie die notwendige Trennschärfe und Prägnanz des untersuchten Terminus erzeugt wird. Da es im Rahmen eines solchen Kapitels außerdem nicht nur unmöglich ist, die Fülle der Aspekte der kantischen Ontologie gerade auch in ihrer Aktualität für die Philosophie der Gegenwart - zu benennen ${ }^{7}$, sondern auch, die Forschung zu diesem Thema angemessen zu sichten, beschränke ich mich von vornherein auf eine Auswahl, die nicht repräsentativ für den gesamten Forschungsstand sein soll, sondern einzig exemplarische Geltung für den untersuchten Problemzusammenhang hat.

Die kantischen Voraussetzungen für diese Untersuchung sind durch eine doppelte Trennung gekennzeichnet, deren Folgen für den Realitätsbegriff es zu untersuchen gilt, die aber selbst in ihrer Genese oder Geltung nicht Gegenstand der vorliegenden Untersuchung ist: 1.) die Trennung des begrifflichen Rahmens einer Realität ${ }_{1}$ („Ding an sich“) vom begrifflichen Rahmen einer Realität ${ }_{2}$ („Erscheinungswelt“) als Grundlage der kantischen Metaphysikkritik überhaupt. Sie ist der Schlüssel zur Neubegründung der Metaphysik als Wissenschaft mittels der Beschränkung von Erkenntnisaussagen auf empirische Urteile erster Ordnung und der Unterscheidung dieser Erkenntnisurteile von Selbstbeschreibungen der Vernunft (Reflexionsurteile zweiter Ordnung) mittels transzendentaler Argumente ${ }^{8}$, sowie 2.) die Trennung der Bedeutungen von Realität und Wirklichkeit innerhalb der Kategorien. Die Gründe der ersten Trennung betreffen die Genese der kantischen Transzendentalphilosophie als Projekt der Vereinigung des empiristischen und des rationalistischen Theoriedesigns sowie die sich daraus ergebende Konfiguration von Subjektivität ${ }^{9}$. Die Gründe der zweiten Trennung be-

7 Vgl. dazu Kiyoshi Chiba: Kants Ontologie der raumzeitlichen Wirklichkeit. Versuch einer antirealistischen Interpretation der ,Kritik der reinen Vernunft“, Berlin/New York 2012. Vgl. außerdem Kant and Contemporary Epistemology, hg.v. Paolo Parrini, Dordrecht 1994; Robert Hanna: Kant and the Foundations of Analytic Philosophy, Oxford 2001.

8 Vgl. dazu Eckart Förster (Die 25 Jahre der Philosophie, Frankfurt am Main 2011, S. 45-48, hier: S. 47): „Kants Metaphysikkritik ist in ihrer Radikalität nicht zu überbieten.“

9 Ebenfalls außer Acht gelassen wird hier die Relevanz der historischen Genese von Kants Transzendentalphilosophie nach 1781, wie sie zuletzt Eckart Förster (Die 25 Jahre der Philosophie) 
dürfen einer Untersuchung, welche die Geschichte der kategorialen Unterscheidungen in der von Kant selbst nur dürftig historisch eingeordneten Deduktion der reinen Verstandesbegriffe (KrV, B 107, B 127f.) offenlegt und zeigt, aus welchen Quellen die kantischen Kategorien ihre Intensionen beziehen. ${ }^{10}$

Die Frage meiner Untersuchung ist also nicht, warum Kant diese begriffliche Unterscheidung trifft bzw. ob sie überhaupt oder in bestimmter Hinsicht als sinnvoll betrachtet werden kann (dies betrifft die Fundamente seiner gesamten Erkenntnistheorie), sondern was diese doppelte Trennung für den Realitätsbegriff bedeutet und über dessen systematische Funktion Sinnvolles aussagt. Meine Untersuchung soll dabei zeigen, a) welche begriffliche Form Kant diesen jeweiligen Begriffen von Realität gibt, b) wie er sie funktional (nicht historisch) voneinander unterscheidet, c) wie er ihre Funktionen und Inferenzen im System bestimmt und d) ob sich daraus ein kohärentes Bild des Begriffs des Wirklichen ergibt.

Es ist gleich zu Beginn zu betonen, dass die vorliegende Interpretation keinen Anschluss an die einfache ontologische These von der „Zwei-Welten-Lehre“ in Kants theoretischer Philosophie sucht, die mittlerweile m.E. zu Recht als adäquate Beschreibung der kantischen Voraussetzungen nicht mehr haltbar ist. Vielmehr ist - aus Gründen, die im Folgenden ausgeführt werden - davon auszugehen, dass Kant mit der Unterscheidung von „Ding an sich“ und „Erscheinung(en)“ zwei grundsätzliche, nicht weiter rückführbare transzendentallogische Beschreibungshinsichten des einen kategorialen Begriffs des „Realen überhaupt“ etablieren möchte, die aber zum einen deutliche ontologische Konsequenzen mit sich bringt und zum anderen zwar als komplementäre Struktur gemeint ist, aber zu unauflösbaren inneren Widersprüchen dieses Unterschieds führt. Die Arbeit beschränkt sich somit streng auf die transzendentallogischen Bedeutungsunterschiede, die durch die verschiedenen kategorialen Realitätsbegriffe als Beschreibungsebenen des einen Begriffskomplexes von „Realität überhaupt“ entstehen, und lässt die Frage nach den Referenten dieser Bedeutungsunterschiede, also nach den Unterschieden im Sein, zumindest dort außer Acht, wo diese nicht

für die Argumentation des Realitätsbegriffes nachgezeichnet hat. Wenn nicht anders angegeben, ist deshalb Kants letzte Bearbeitungsstufe der Kritik der reinen Vernunft ausschlaggebend.

10 Zur historischen Kritik an Kants transzendentaler Deduktion vgl. Martin Bondeli: Apperzeption und Erfahrung. Kants transzendentale Deduktion im Spannungsfeld der frühen Rezeption und Kritik, Basel 2006. Für die kategoriale Unterscheidung von Realität und Wirklichkeit verweist Hans Heinz Holz zu Recht auf „die scholastische Bedeutung der Wesenheit (essentia) oder des Was-Seins (quidditas)“ (Hans Heinz Holz: „Realität“, in: Ästhetische Grundbegriffe. Historisches Wörterbuch in sieben Bänden, hg.v. Karlheinz Barck u. a., Bd. 5, Stuttgart/Weimar 2010, S.197-227, hier: S. 211). 
als unmittelbare Konsequenzen aus den kategorialen Beschreibungen fokussiert werden müssen. Kant unterscheidet unleugbar kategorialsemantisch zwischen dem Begriff einer Ding-an-sich-Realität und einer Erscheinungsrealität (gerade deshalb, um sie als die beiden Beschreibungsebenen des einen Begriffs von Realität aufeinander beziehen zu können) und er nimmt unleugbar für beide zumindest partiell verschiedene transzendentallogische Beschreibungen vor. Es geht der vorliegenden Arbeit allein darum, ob die philosophische Semantik dieser beiden Ebenen des kategorialen Realitätsbegriffs in ihrem Verhältnis zueinander sinnvoll und konsistent von Kant bestimmt wird oder nicht, ob sie also einen konsistenten, hinreichend bestimmten und inhaltlich umfassenden kategorialen Begriff des einen Realen ergeben, d.h. ob die kategoriale Semantik von „Realität überhaupt" bei Kant als Set ihrer semantischen Fundamental- und Minimalelemente semantisch und funktional überzeugend, widerspruchsfrei und sachangemessen im Unterschied der Ebenen von „Ding an sich“ und „Erscheinungen“ gedacht werden sollte. Zugleich geht mir in den folgenden Ausführungen darum, die sich möglicherweise aus diesem Ansatz ergebenden systematischen Probleme so $\mathrm{zu}$ beschreiben, dass sie im Zusammenhang einer Problemgeschichte innerhalb der Konstellation „Deutscher Idealismus“ als zu bearbeitende Fragehorizonte erscheinen können.

Kants geläufigste sowie fundamentalste Trennung der Beschreibungssysteme von „Ding an sich“ und „Erscheinungen“ wird also als Ausgangspunkt genommen und der Trennung von „Transzendentaler Ästhetik“ und „Transzendentaler Logik" zugeordnet ${ }^{11}$. Diese Zuordnung ist dabei allerdings rein funktional in Bezug auf den Realitätsbegriff gedacht. Obgleich Kant in der „Transzendentalen Ästhetik“ das „Ding an sich“ nicht erörtert, zeigt sich einzig hier, so meine Behauptung, dessen Beziehung auf den Realitätsbegriff. Gleiches gilt für die Erläuterung der „Erscheinungswelt“ innerhalb der „Transzendentalen Logik“. Denn durch die transzendentale Logik der Begriffe wird die objektive Erfahrungserkenntnis überhaupt erst begründet und vermessen; erst durch die Kategorien werden die Bedingungen objektiver, d.h. allgemeiner und notwendiger Wahrheit von Aussagen begründet. Am Ende schließlich werden die verschiedenen Realitätshinsichten, die sich aus der Analyse des Realitätsbegriffs ergeben haben, zusammengeführt und in Bezug auf die Frage ausgewertet, inwiefern und in welcher Weise Kant den Begriff von Realität transzendentalphilosophisch etablieren kann - und vor allem, welche Schwierigkeiten dabei auftreten, die als

11 Das heißt nicht, dass innerhalb der Erläuterungen der Realitä $t_{1}$ (Transzendentale Ästhetik) und der Realität ${ }_{2}$ (Transzendentale Logik) nicht auch Passagen aus dem jeweils anderen Teil der Kritik der reinen Vernunft verhandelt werden. Die Zuordnung ist also keine strenge, sondern dient einzig der Orientierung. 
Problembestand des Begriffs Lösungen der nachkantischen Philosophie erfordern.

Im Folgenden sollen die Überlegungen zu Kants Realitätsbegriff in drei Schritten durchgeführt werden: Zunächst (in 1.1) möchte ich darlegen, dass Kant in der „Transzendentalen Ästhetik“ den Begriff einer Realität ${ }_{1}$ annehmen muss, um Affektionen der Anschauung erklären zu können, dass aber der Übergang zwischen Realität und Subjekt ein unbestimmbarer, ja sogar undenkbarer bleibt. Daraus ergibt sich paradoxerweise, dass das, was der Realität ${ }_{1}$ ontologisch am nächsten ist (Empfindungen), weder erkenntnis- noch denk- oder sogar objektfähig ist, d.h. eine Gegenläufigkeit von Realität und klarer Präsenz etabliert: Wo man der Realität ${ }_{1}$ im Vermögen des Subjekts am ,nächsten“ (im Sinne unmittelbarer Erfahrung) ist, dort kann sie am wenigsten als etwas Bestimmtes erfasst werden. Damit verbunden ist die Bestimmung der Empfindung als einer „komparativen Unmittelbarkeit“ (1.1.1) und die Idee, dass die Realität $t_{1}$ als ein ereignishafter Einbruch $\mathrm{zu}$ verstehen ist (1.1.2). Zweitens werde ich in einer ersten Zwischenbemerkung (in 1.2) sieben Begriffsunterscheidungen von „Wirklichkeit“ und „Realität“ herausarbeiten, die sich in Kants unterschiedlicher Verwendung aufzeigen lassen. Drittens werde ich mich (in 1.3) der Realität ${ }_{2}$ in der „Transzendentalen Logik“ zuwenden und dabei die Kategorien der Realität und der Wirklichkeit genauer aufzuschlüsseln versuchen. Ich möchte einerseits aufzeigen, dass die Hegel'sche ,Dialektik der Realität‘ in der Struktur des kantischen Schemas der Realität als Feld begrifflicher Zusammengehörigkeit in vielerlei Hinsicht bereits angelegt, jedoch von Kant nicht ausgeführt worden ist. ${ }^{12}$ Andererseits möchte ich darlegen, dass der Begriff der Realität (Realität ${ }_{1}$ und Realität ${ }_{2}$ ) bei Kant die Logik seiner analytischen Aufteilung („Ding an sich“ - Erscheinung, Anschauungsformen - Kategorien, Kategorien untereinander) überschreitet, indem er in mehrfacher Hinsicht transgressiv ist: Denn er tritt als Phänomen eines inferentialistischen Begriffsnetzes wie auch einer begriffsüberschreitenden Erschlossenheit auf.

$12 \mathrm{Zu}$ Interpretationen, die von einer tiefergehenden Gemeinsamkeit zwischen Kant und Hegel ausgehen, vgl. Robert B. Pippin: Hegel's Idealism. The Satisfactions of Self-Consciousness, Cambridge 1989, insb. S. 8-11, und als Rekurs darauf Terry Pinkard: „How Kantian was Hegel?“, in: Review of Metaphysics 43 (1990), S. 831-838. Pippins Lesart versucht zu zeigen, dass Hegels Philosophie ein kantisches Projekt vervollständigt. John McDowell wiederum verweist darauf, dass auch Strawsons Kant-Rezeption v.a. in The Bounds of Sense eine stark von hegelschen Vorgaben geprägte ist: Strawsons Kant sei „more Hegel than Kant“ (John McDowell: Mind and World, Cambridge, Mass. 1996, S. 138, Fußnote 1; vgl. auch McDowell: Mind and World, S. viii). Zur weiteren Auseinandersetzung McDowells mit Strawsons Kant-Leseart vgl. McDowell: Mind and World, Vorlesung 5. 
Es ist heute beinahe zur Raison d'Être bestimmter Teile der Kant-Forschung geworden, die vielfältigen und wesentlichen Kritikpunkte an Kants System, aus denen sich die ,idealistische“ Philosophie bei Friedrich Schlegel, Friedrich Schiller, Johann Gottlieb Fichte, Friedrich Wilhelm Joseph Schelling, Friedrich Heinrich Jacobi oder Georg Wilhelm Friedrich Hegel epistemologisch, ontologisch, sozialphilosophisch, moralphilosophisch und ästhetisch entwickelt hat, zu bloßen „produktiven Missverständnissen“ zu erklären. Demnach seien diese kritischen Perspektiven allesamt und mehr oder weniger am kantischen Denken vorbei entwickelt: entweder weil Kant es ganz anders gemeint habe; oder weil Kant diese Kritik immer schon gesehen und selbst bereits verhandelt habe; oder, noch zugespitzter, weil das Kritisierte bei genauer Lektüre bei Kant überhaupt nicht $\mathrm{zu}$ finden $\mathrm{sei}^{13}$. Es scheint dabei manchmal sogar, als solle die faktische historische Stoßrichtung umgekehrt werden, indem Kant nicht als Vorläufer, sondern, historisch invers, als geheimer Zielpunkt des Deutschen Idealismus begriffen wird, der die Einseitigkeiten, Missverständnisse und Aporien der ihm nachfolgenden Idealisten längst erkannt und gebannt haben soll. Diese manchmal apologetische Tendenz der Kant-Forschung scheint die verspätete Reaktion eben darauf zu sein, dass die Kant-Schüler des 19. Jahrhunderts bis hin zum Neukantianismus oftmals keinen Stein des kantischen Denkens auf dem anderen gelassen haben und Anknüpfung nur noch als weitgehende transformative Kritik durchführten. Anstatt aber dies gerade als Auszeichnung des kantischen Denkens $\mathrm{zu}$ verstehen, produktives Weiterdenken durch die Zugänglichkeit und den Reichtum der eröffneten Perspektiven in besonderem Maße zu ermöglichen, scheint zuweilen der dogmatische Impuls näherzuliegen, Kants Denken gegen Kritik nun besonders immunisieren zu wollen. Die vorliegende Arbeit will einen anderen Weg gehen, indem sie zeigt, wie gerade die aus ihrer Sicht berechtigten Kritikpunkte an Kants theoretischer Philosophie nicht Mängel, sondern eine reichhaltige Reflexion des Problemstandes sichtbar machen, die vor Kant nicht möglich war. Kant soll also nicht einfach bspw. von Hegel aus wegen seiner angeblichen Mängel getadelt werden. Gemäß dem in der „Einleitung“ erwähnten problemgeschichtlichen Paradigma geht es vielmehr eher darum, positiv den besonderen Problemstand sichtbar $\mathrm{zu}$ machen, der in Kants theoretischer Philosophie erstmals in voller Schärfe und Komplexität herausgearbeitet worden ist.

13 Vgl. bspw. die Kritik an der Kritik des kantischen „Ding an sich“, die ich in diesem Kapitel behandele: Bestritten wird, dass Kant jemals irgendwo eine Kausalbeziehung zwischen „Ding an sich“ und mentalem Apparat explizit oder implizit behauptet hätte; bestritten wird, dass das „Ding an sich“ als Rest eines metaphysischen Realismus zu verstehen sei, der den konstruktiven Idealismus Kants aufsprengen würde; bestritten wird, dass das „Ding an sich“ eine derart wichtige Systemstellung einnimmt, wie es die Idealisten behaupteten. 
Versteht man Philosophie nicht szientistisch als das „Lösen“ von Problemen, sondern als die grundlagentheoretische Aufdeckung von Problemen in ihrem vollen Umfang, wie es diese Arbeit vertreten will, wird Kants epochale Leistung durch eine solche Rekonstruktion nicht geschmälert, sondern eher unterstrichen.

\subsection{Die Zustoßung des Realen: Realität ${ }_{1}$ in der „Transzendentalen Ästhetik“}

„Anschauung [...] findet aber nur statt, sofern uns der Gegenstand gegeben wird; dieses aber ist wiederum uns Menschen wenigstens nur dadurch möglich, daß er das Gemüth auf gewisse Weise afficiere. Die Fähigkeit, (Receptivität), Vorstellungen durch die Art, wie wir von Gegenständen afficiert werden, zu bekommen, heißt Sinnlichkeit. Vermittelst der Sinnlichkeit also werden uns Gegenstände gegeben, und sie allein liefert uns Anschauungen; durch den Verstand aber werden sie ged a cht, und von ihm entspringen B e g riffe. Alles Denken aber muß sich, es sei geradezu (directe), oder im Umschweife (indirecte), vermittelst gewisser Merkmale, zuletzt auf Anschauungen, mithin, bei uns, auf Sinnlichkeit beziehen, weil uns auf andere Weise kein Gegenstand gegeben werden kann.“ (KrV, § 1, B 33)

\subsubsection{Die Logik der Empfindung: Komparative Unmittelbarkeit}

Gleich zu Beginn der Kritik der reinen Vernunft erklärt Kant die für ihn einzig mögliche Weise, wie im Voraus zu den subjektiven (allgemeinen) objektförmigen Konstitution einzelne Gegenstände unmittelbar, wenn auch subjekthaft selbstgegeben sein können: nämlich im passiven sinnlichen Affiziertsein durch Gegenstände. Sinnliches Affiziertsein bzw. „Empfindungen“, wie Kant es auch nennt, bilden die einzige „Kontaktstelle“, an der sich das „Ding an sich“, als Welt der Gegenstände jenseits ihres Für-uns-Seins, und das „Subjekt“ berühren: „Alles, was uns als Gegenstand gegeben werden soll, muß uns in der Anschauung gegeben werden. Alle unsere Anschauung geschieht aber nur vermittelst der Sinne; der Verstand schaut nichts an, sondern reflektiert nur.“ (Prol. § 13, Anm. II, S. 48) Die Gegenstände unserer Erfahrung sind „Erscheinungen, deren Möglichkeit auf dem Verhältnisse gewisser an sich unbekannter Dinge zu etwas anderem, nämlich unserer Sinnlichkeit, beruht.“ (Prol. § 13, S. 45) Diese Dinge an sich zu denken, die den Erscheinungen „zum Grunde liege[n]“, ist „unvermeidlich“: „Der Verstand also, ebendadurch daß er Erscheinungen annimmt, gesteht auch das Dasein von Dingen an sich selbst zu“ (Prol. § 32, S. 86). Dieses Verhältnis von solchen für Kant 
unzweifelhaft gegebenen Dingen an sich wird ebenfalls eindeutig als Affektion benannt: „Ich dagegen sage: Es sind uns Dinge als außer uns befindliche Gegenstände unserer Sinne gegeben, allein von dem, was sie an sich selbst sein mögen, wissen wir nichts, sondern kennen nur ihre Erscheinungen, d.i. die Vorstellungen, die sie in uns wirken, indem sie unsere Sinne affizieren.“ (Prol. § 13, Anm. II, S. 49) Die „Behauptung einer realen Affektion durch reale Dinge an sich“14 bei Kant ist - „gegen fichteanisierende Interpretationen“15 der kantischen Kritik der reinen Vernunft - als Grundbehauptung der kantischen Erkenntnistheorie nicht sinnvoll zu eliminieren und, wie gesehen, innerhalb der Kritik der reinen Vernunft sowie in den Prolegomena gut belegt ${ }^{16}$. Kants gesamte „Transzendentale Ästhetik“ ergibt nur von dieser offen herausgestellten Prämisse der Annahme einer „Existenz der Sachen“ (Prol. § 13, Anm. III, S. 55) außerhalb unserer Vorstellungsvermögen und deren Gesetzen her Sinn, von wo sie dann auf diese („Existenz der Sachen“) einwirken. Eben dies ist der bei Kant so ausdrücklich nicht benannte metaphysische Realismus bezüglich der Ebene der Realität $_{1}$ als Bedingung und Voraussetzung eben jenes „empirischen Realismus“, der sich Kant zufolge mit einem „transzendentalen Idealismus“ sinnvoll und konsistent vereinigen lassen soll. Die daraus hervorgehenden „Anschauungen“ sind schon Produkte des Affiziertseins (weshalb Kant auch davon spricht, dass sie uns von der Sinnlichkeit „geliefert“ werden aufgrund des Affiziertseins) und keine Gegebenheiten in der Form der Unmittelbarkeit ${ }^{17}$. Die Anschauungen haben also

14 Ebendies zeigt sehr klar und überzeugend Birgit Sandkaulen: „Das , leidige Ding an sich‘. Kant - Jacobi - Fichte“, in: System der Vernunft. Kant und der Frühidealismus, Bd. 2., hg.v. Wilhelm G. Jacobs, Hans-Dieter Klein, Jürgen Stolzenberg, Hamburg 2007, S. 175-201, hier: S. 187.

15 Sandkaulen: Das leidige Ding an sich, S. 187. Vgl. auch Hartmut Böhme, Gernot Böhme: Das Andere der Vernunft. Zur Entwicklung von Rationalitätsstrukturen am Beispiel Kants, Frankfurt am Main 1985, S. 294.

16 Die Kritik des sogenannten Kausalitätsarguments (vgl. Kap. 1.1.6 im Hauptteil I) sowie die Kritik an der ontologischen Annahme einer „Zwei-Welten-Lehre“ bei Kant (vgl. die Einleitung zu diesem Abschnitt) dürfen nicht verwechselt werden mit der Einsicht in die notwendige Voraussetzung einer realen Affektion. Denn die reale Affektion setzt keine platonische Zwei-WeltenTrennung voraus bzw. impliziert diese notwendig, sondern lediglich einen Ebenenunterschied innerhalb des Konzepts von „Realität überhaupt“ bei Kant als Frage des Begriffsdesigns. Ihr Unterschied zum Kausalitätsargument ist von Sandkaulen (Das leidige Ding an sich) hinreichend und bemerkenswert herausgearbeitet worden.

17 Gerhard Schönrich („Externalisierung des Geistes? Kants usualistische Repräsentationstheorie“, in: Warum Kant heute? Systematische Bedeutung und Rezeption seiner Philosophie in der Gegenwart, hg.v. Dietmar H. Heidemann, Kristina Engelhard, Berlin/New York 2004, S. 126-150, hier: S. 133) übersieht den prozessualen Unterschied von Empfindungen und Anschauungen, wenn er sie als nur verschieden akzentuierte Beschreibungen desselben Gegenstandes bzw. derselben transzendentalen Handlung ansieht. Deshalb mischen sich in die vier Merkmale, die er 
schon keinen reinen unmittelbaren Kontakt zur Realität $t_{1}$ mehr, sondern sind die sinnlichen, unbestimmten, konkreten Formen, die unsere Sinnlichkeit produziert, wenn sie von Gegenständen affiziert wird. Somit ist in den Anschauungen die heterogene Gegebenheit von Dingen bereits transformiert in die zweite subjektive sinnliche Form der heterogenen Gegebenheit von Dingen (denn die erste ist die Empfindung). Anschauungen sind also immer schon durch das Affiziertsein ${ }^{18}$ vermittelt und besitzen als repraesentatio singularis (vor den Begriffen als repraesentatio universalis) bereits einen repräsentationalen Gehalt, indem sie durch die Strukturierung durch begriffsförmige Muster (Form des Raumes, Form der Zeit) „etwas als etwas - wahr oder falsch - vorstellen“19. Empfindungen besitzen

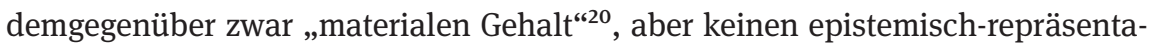
tionalen Inhalt ${ }^{21}$ : Denn erst dort, wo sie nicht mehr im unmittelbaren Kontakt zu ihrem Gegenstand, sondern bereits durch die begriffsförmige Zurichtung des

für die Anschauungen bei Kant angibt, auch ein solches der Empfindung hinein, das Anschauungen nicht mehr im strengen Sinn zukommt: Wo sowohl Empfindungen als auch Anschauungen aufgrund ihrer gleichen Seinsweise als Produkte der sinnlichen Rezeptivität sinnlich, gegenstandsabhängig (d.h. die Existenz eines Gegenstands anzeigend) und singulär (d.h. sich auf genau einen Gegenstand beziehend) sind, gilt das Merkmal der Unmittelbarkeit im strengen Sinn nur für die Empfindungen. Der von mir hier eingeführte Begriff der „komparativen Unmittelbarkeit“ macht es erst möglich, die (im Vergleich zu den Handlungen und Produkten des Verstandes) generelle Unmittelbarkeit der sinnlichen Rezeptivität in Einklang zu bringen mit den innerhalb der Produkte der sinnlichen Rezeptivität von der Anschauung zu unterscheidenden Unmittelbarkeit der Empfindung.

18 Vgl. ein zeitgenössisches Konzept von Wahrnehmung als ,Zudringlichkeit‘ bei Lambert Wiesing, welches das Realismus/Idealismus-Problem folgendermaßen zu vermeiden sucht: Das Subjekt kann sich die sinnlichen Daten der Welt nicht aussuchen, es ist ihnen ausgesetzt, und wird erst durch den Akt der Wahrnehmung als Subjekt konstituiert. Transzendentale Leistungen der Konstitution von Wahrnehmungen müssen demgemäß als abhängig von einem vorgängigen Gegebensein des Subjekts durch und in Wahrnehmungsvollzügen gedacht werden, die so jenseits der Frage von Realismus oder Idealismus bzw. Passivität/Aktivität gedacht werden. (Lambert Wiesing: Das Mich der Wahrnehmung. Eine Autopsie, Frankfurt am Main 2009)

19 Dietmar H. Heidemann: „Vom Empfinden zum Begreifen. Kant im Kontext der gegenwärtigen Erkenntnistheorie“, in: Warum Kant heute? Systematische Bedeutung und Rezeption seiner Philosophie in der Gegenwart, hg.v. Dietmar H. Heidemann/Kristina Engelhard, Berlin/New York 2004, S.14-43, hier: S. 40; zum Unterschied von Empfindung und Anschauung bei Kant vgl. Heidemann: Vom Empfinden zum Begreifen, S. 39-41.

20 Heidemann: Vom Empfinden zum Begreifen, S. 41.

21 Tye allerdings hat in der neueren Forschung zu bestreiten versucht, dass es überhaupt qualitative Bewusstseinszustände, die zugleich nicht-repräsentational sind, gibt (vgl. Michael Tye: Ten problems of consciousness. A representational theory of the phenomenal mind, Cambridge, Mass./London 1995). 
Subjekts in einem anderen Wirklichkeitskontext stehen, beziehen sie sich auf Inhalte als bestimmte Vorstellungsgehalte.

Wenn es um die Gegenstandserkenntnis geht, so ist Kant von Anfang an darauf bedacht, dasjenige, was im Sinne eines strengen Realismus ganz von außen kommt, zu unterscheiden von demjenigen, was im Sinne eines strengen Idealismus ganz von uns als allgemeinen Subjekten erzeugt wird. Daher zeigt schon der Anfang der Kritik der reinen Vernunft, dass jegliche Versuche, den kategorialen Begriff der Realität jenseits der unfruchtbaren Alternative von Realismus und Idealismus zu denken, die jeweils stets einen Aspekt von begrifflicher Realität ignorieren müssen und deshalb selbstwidersprüchlich werden, bei Kant gar nicht erst in den Blick kommen können²2.

Die Wirkung eines Gegenstandes auf die Vorstellungsfähigkeit, sofern wir von demselben afficiert werden, ist Empfindung. Diejenige Anschauung, welche sich auf den Gegenstand durch Empfindung bezieht, heißt empirisch. Der unbestimmte Gegenstand einer empirischen Anschauung heißt Erscheinung. / In der Erscheinung nenne ich das, was der Empfindung correspondirt, die Ma t er i e derselben, dasjenige aber, welches macht, daß das Mannigfaltige der Erscheinung in gewissen Verhältnissen geordnet werden kann, nenne ich die Form der Erscheinung. (KrV, § 1, B 34)

Hier wird die bereits angesprochene Grenze nochmals deutlich, die zwischen „Empfindung“ (erste subjektive Stufe des sinnlichen Gegebenseins von Realität ${ }_{1}$ ) und „Anschauung“ (zweite subjektive Stufe des sinnlichen Gegebenseins von Realität $_{1}$ ) verläuft. Empfindung ist das unmittelbare Produkt des sinnlichen Gegebenseins von dem Subjekt äußerlichen Gegenständen im Subjekt ${ }^{23}$ (es ist das, was uns unmittelbar passiert, und das erste, was in uns als Produkt der Vorstellung entsteht) und stellt somit die einzige als unmittelbar zu bezeichnende Berührung des Subjekts durch die Realität ${ }_{1}$ dar; freilich eine solche, die ebenfalls bereits in der Form von Subjektivität gegeben und damit durch das erkennende

22 Auf diesem Problem basiert die Grundidee Hegels, für welche die vorliegende Arbeit Evidenzen aufzuzeigen sucht: Der Begriff der Realität ist nicht von der Art, dass er im Koordinatensystem der Begriffe „Subjekt“, „Objekt“ und „Relation“ gedacht werden kann, weil er diesen Beziehungen (Abhängigkeit des Objekts vom Subjekt [Idealismus], Abhängigkeit des Subjekts vom Objekt [Realismus]) als Sphäre der Koordination vor- und übergeordnet ist - weil er mithin der Begriff der Sphäre ist, in der Subjekt und Objekt immer schon zugleich und in Einheit getrennt und vermittelt, gegeben und konstituierend sind.

23 Vgl. Förster: Die 25 Jahre der Philosophie, S. 21f. „Sinnlichkeit ist die Empfänglichkeit eines Subjekts, durch die es möglich ist, dass sein Vorstellungszustand durch die Gegenwart irgendeines Objekts auf bestimmte Weise betroffen wird.“ (AA, 2, 392; im Original: „Sensualitas es receptivitas subiecti, per quam possible es, ut status ipsius repraesentativus obiecti alicuius praesentia certo modo afficiatur“.) 
Subjekt konstituiert ist, auch wenn sie noch keine repräsentationale Form im engeren Sinn aufweist ${ }^{24}$. Man müsste hier demnach genauer von einer „komparativen Unmittelbarkeit“ der Empfindung sprechen: Im Vergleich zu den weiteren Modi der Verarbeitung der sinnlichen Data ist die Empfindung am unmittelbarsten. Unmittelbarkeit meint hier externalistisch den Aspekt des realen Kontakts von Bewusstseinsvorkommnissen mit Dingen der Außenwelt ohne weitere Vermittlungsinstanz. Empfindung wie Anschauung allerdings sind gleichermaßen unmittelbar in dem Sinn, dass für beide ,kein anderer Inhalt [...] (durch Über-

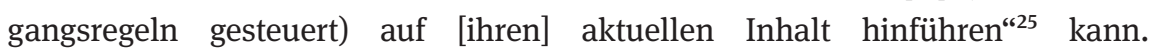
Unmittelbarkeit meint hier internalistisch den Aspekt fehlender regelhafter und begriffsförmiger „inferentieller Beziehungen“ zwischen repräsentationalen Gehalten: Der Inhalt von Empfindungen und Anschauungen steht gleichermaßen nicht in Schluss- und Inklusionsverhältnissen zu anderen sinnlichen Gehalten bzw. kann nur durch solche inferentiellen Regelhaftigkeiten erzeugt werden.

Auf diese Weise kommt in der Wahrnehmung das Andere des Subjekts („Ding an sich") nur als Anderes im Subjekt in den Blick. Deshalb stellt sich notwendigerweise die Frage, welches Kennzeichen des Anderen diese ersten Produkte des Apparats der transzendentalen Subjektivität tragen bzw. mit welchen Markierungen das Andere im Subjekt gekennzeichnet ist.

\subsubsection{Die Leere des Übergangs}

Gemäß dem platonischen Begriff der „Grenze“ aus dem Parmenides, die als Verbindung zweier beziehungsloser Elemente selbst nicht(s) ist und damit die Verbindung überhaupt im selben Maße undenkbar macht, in dem sie diese herstellt $^{26}$, findet der Übergang von der Realität ${ }_{1}$ zur Form des transzendentalen

24 „Direkter jedoch als in Anschauungsvorkommnissen, die einen qualitativen Inhalt haben, ist kein Gegenstandsbezug möglich.“ (Schönrich: Externalisierung des Geistes, S. 138) Wenn Schönrich auch hier erneut in Bezug auf Kant Empfindung und Anschauung unter dem Oberbegriff „Anschauung“ in eins setzt, so ist es doch m. E. zutreffend, die höchste Form der Unmittelbarkeit bezüglich des Gegenstandes bei Kant als immer schon subjektiv gebrochen zu verstehen: „Die denkbare Alternative, in der sich der Gegenstand in nackter Gegebenheitsweise de re repräsentierte, ist [für Kant, C.W.] eine Wunschvorstellung des metaphysischen Realismus.“ (Schönrich: Externalisierung des Geistes, S. 138)

25 Schönrich: Externalisierung des Geistes, S. 134.

26 Platon, Parmenides, Griechisch/Deutsch, hg.v. Hans Günter Zekl, Hamburg 1972, S. 95-99 [155e-157b].Vgl. außerdem den Diskussionszusammenhang der „Grenze“, zumeist in Abgrenzung zur „Schranke“, im idealistischen Diskurs: Kant: Prol. §57, S. 138; KrV, B 600-611; Friedrich Schlegel: Kritische Friedrich-Schlegel-Ausgabe, Bd. XVIII, hg.v. Ernst Behler, München/Paderborn 
Subjekts ohne an sich bestimmbare Vermittlung beider statt. Es gibt damit keinen an sich repräsentierbaren Übergangsbereich, in welchem beide vermittelt anwesend sind oder sogar ein „Drittes“ bilden. Die Inhalte der Realität t $_{1}$ sind plötzlich im Subjekt eine erste subjektive Form (Empfindung), ohne dass der Übergang selbst als eine Form (die dann weder dem Objekt noch dem Subjekt allein angehören dürfte) bestimmbar ist ${ }^{27}$. Ein solches „Drittes“ wie eine zu einem Raum ausgedehnte Grenze, in der das Eine (Realität ${ }_{1}$ ) nicht mehr und das Andere (subjektive Empfindung) noch nicht ist, ist folglich bei Kant nicht denkbar: Also muss das Reale der Realität ${ }_{1}$ als notwendig zu denkender Einbruch (als Ereignis ${ }^{28}$ ) in die Welt der Erscheinungen verstanden werden. Denn die Konfiguration des „Einbruchs“, in der der Übergang in der Form sinnlich-räumlicher Bewegung begriffen wird, fasst ein Dreifaches: 1.) das gänzlich von außen Hinzukommende, nicht aktivisch vom „Innen“ des Subjekts Erzeug- oder Steuerbare der Realität ${ }_{1}$; 2 .) das Wirksam-sein des Einbrechenden innerhalb der Welt der Erscheinungen, d. h. die Zielrichtung des Einbrechens als Anwesend-sein im Raum des Einbruchs (der nicht als bloßer Transitraum erscheint); 3.) die Unmöglichkeit, dem Einbrechenden einen rationalen Grund innerhalb der Welt der Erscheinungen zu geben, d. h. es in Begriffen des Erscheinungsfeldes zu vergegenwärtigen oder zu begründen. Fichtes Begriff der Einbildungskraft wird an dieser Schnittstelle - dem unbefriedigenden Geschehen des Einbruchs der Realität $t_{1}$ - ansetzen, um dieses Dritte innerhalb des Subjekts beschreibbar zu machen (vgl. Kap. 3 im Hauptteil I). Die empirische Anschauung ist dann als zweite subjektive Form des sinnlichen Gegebenseins bei Kant bereits deutlicher als die Empfindung, die bloß noch subjektive Weise, Empfindungen konstitutiv zu gestalten, was sich schon allein daran

1963, S. 521; Fichte: GA I,2, S. 267-282. [§3, Kategorie der Limitation] und GA I,2, S. 350 - 361 [§4, Erster Lehrsatz, y]; GW 21, S. 110-124 [„Grenze“ und „Schranke“]. Es findet sich allerdings im griechischen Denken durchaus der Hinweis darauf, die Dialektik der Grenze im idealistischen Sinne zu denken: in der Art und Weise, wie peras (Grenze) etymologisch der Grund des Praxisbegriffs ist (vgl. dazu erhellend Giorgio Agamben: Der Mensch ohne Inhalt, Berlin 2012, S. 98 f.). Demnach ist nämlich für das Tun bzw. das Handeln seine Grenze zugleich das, was als Zweck in sich selbst fällt (Praxis) und damit zugleich Inbegriff des zu ihm Transzendenten wie Immanenten ist.

27 Fichte (vgl. Förster: Die 25 Jahre der Philosophie, S. 199f.), der zeigt, wie die Grenze des Anstoßes auch ,äußerlich` zu dem durch sie bedingten ist, und Hölderlin, der die Zeitlichkeit des Übergangs selbst als Form des Absoluten denkt (vgl. dazu konzis Jan Urbich: „Poetische Eigenzeiten in Hölderlins ,Brod und Wein“ im Licht seiner Zeitphilosophie“, in: Zeit der Darstellung. Ästhetische Eigenzeiten in Kunst und Wissenschaft, hg.v. Michael Gamper, Helmut Hühn, Berlin 2013, S. 209-244), modifizieren eben dieses Problem des Übergangs bei Kant auf entscheidende Weise und markieren so seine Dringlichkeit für einen angemessenen Begriff des Realen.

28 Zum Begriff des „Ereignisses“ vgl. Jean Baudrillard: Das Ereignis, Weimar 2007. 
zeigt, dass es sehr wohl „reine Anschauungen“ gibt (Raum/Zeit), d.h. Anschauungen selbst reine apriorische subjektive Form sein können, es aber keine vorgängigen „reinen Empfindungsformen“ gibt. Die Anschauungsformen sind also viel deutlicher eine Konstruktionsform des Subjekts, als dies bei der Empfindung der Fall ist. Deren transzendentale Formlosigkeit hingegen trägt der Notwendigkeit Rechnung, Materiales und damit Reales als Stoff der transzendentalen Produktion zuzulassen, das selbst nicht bereits in subjektiver Formung gründet, ohne jedoch dessen ebenso notwendige Art der Bestimmtheit - denn ohne diese ist kein Gegebensein möglich - wirklich denken zu können ${ }^{29}$. Der „Rückfall in den ,Mythos des Gegebenen“"30 bei Kant ist folglich anscheinend unvermeidbar und direkte Konsequenz der begrifflich ungenügenden Bestimmungen des „Einbruchs“: Das Mindestmaß an Kommensurabilität von Gegenstand und subjektiver Registrierung ist nicht gegeben, wo jegliche Ordnung von Identität und Differenz erst in den sensitiven und repräsentationalen Formen subjektiver Ausstattung an dem andersartigen, d.h. an sich unbestimmtem Material hervortritt ${ }^{31}$. Dabei wird vor allem an den bloßen Vorkommnissen der Empfindung, also an der Art und Weise, wie singuläre unmittelbare Empfindungen auf Gegenstände bezogen sind, das Problem eines zu denkenden Übergangs deutlich. Denn die Singularität dieser Vorkommnisse - jede Empfindung ist einzigartig und unwiederholbar - und die Singularität ihres Bezuges - jede Empfindung bezieht sich auf ein bestimmtes Objekt - müssen widerspruchsfrei mit der ebenso notwendigen Allgemeinheit ihres unmittelbaren Beziehens zusammengedacht werden. Denn in verschiedenen Empfindungsvorkommnissen und ihrem Objektbezug muss sichergestellt sein, dass die mögliche Selbigkeit dieses Objekts unmittelbar erfahren werden kann:

29 Tatsächlich hat Kant an manchen Stellen das angedacht, was erst Fichte später systematischexplizit entwickelt hat, um diese Leerstelle füllen zu können: noch den unbearbeiteten Stoff der Empfindung bzw. Wahrnehmung als Modifikation unserer Sinnlichkeit zu begreifen und so auch das Affizierende noch in den Theorieraum des transzendentalen Subjekts zu holen. Mit guten Gründen - um den berkeleyschen Idealismusvorwurf der „Göttinger Rezension“ zu entkräften hat er von diesem Weg abgelassen. Vgl. dazu Sandkaulen: Das leidige Ding an sich, S. $189 \mathrm{f}$.

30 Schönrich: Externalisierung des Geistes, S. 142. Zum Mythos des Gegebenen vgl. Wilfrid Sellars: Empiricism and the Philosophy of Mind, Cambridge, Mass./London 1997, und als umfassende Kritik des Begriffs Wiesing: Das Mich der Wahrnehmung, S. 11-71.

31 Das von Donald Davidson kritisierte „3. Dogma des Empirismus“, der Gegensatz von Begriffsschema und uninterpretiertem empirischem Inhalt, hat hier seinen historischen Ursprung (Donald Davidson: „On the Very Idea of a Conceptual Scheme“, in: Ders.: Inquiries into Truth and Interpretation, Oxford 1974, S. 183-198, hier: S. 189). Überhaupt sind alle drei von Quine und Davidson entwickelten „Dogmen“ des Empirismus, obwohl unmittelbar vor allem auf den ,klassischen ' modernen Empirismus des logischen Positivismus zugeschnitten, deutlich (das 1. Dogma analytischer und synthetischer Urteile) oder untergründiger (das 2. Dogma des Erfahrungsgehalts) letztlich an Kants Erkenntnistheorie orientiert. 
Die verschiedenen und nacheinander ablaufenden Empfindungen bspw. des Essens eines Apfels in Bezug auf die Farbe von verschiedenen Seiten, das haptische Gefühl (rau), das sensorische (Geruch) etc. sollen ohne weitere Zwischenschaltung unmittelbar dasselbe Objekt repräsentieren. Also ist es unumgänglich, dass bereits in die unmittelbare Kontaktstelle des Subjekts zur Außenwelt Normative ihres Zusammenhangs eingeprägt sind, die nicht anders denn als begriffliche oder protobegriffliche Regeln gedacht werden können, auch wenn sie nicht den begrifflichen Formen der Prägung durch das Subjekt zuzurechnen sind ${ }^{32}$. Schönrich hat diese Regeln der Empfindung für die Identität der Objekte als „extensive Größe“ der gleichen „Raumstelle“ und für die Existenzgewissheit der Objekte als „intensive Größe“ der objektabhängigen positiven Graduierung überzeugend bestimmt ${ }^{33}$. Wichtig ist festzuhalten, dass bereits in den noch nicht gehaltsrepräsentationalen, unmittelbaren Kontaktstellen der Empfindung begriffliche Regeln am Werk sein müssen, die einen Proto-Objektzusammenhang der Empfindungen und eine potenzielle Allgemeinheit des Sinns im singulären Wahrnehmungsgehalt ${ }^{34}$ garantieren, ohne die sie nicht durch Anschauungsformen und Kategorien weiterverarbeitet werden könnten. In den allerersten Stufen der Anschauung wirken folglich schon nicht-singuläre Muster begrifflich-repräsenta-

32 Maurice Merleau-Ponty hat diese Eigenbestimmtheit der Realien als das „Unmenschliche“ in den Dingen bei ihrer subjektiven Wahrnehmung markiert: Für gewöhnlich nämlich sind wir in der Wahrnehmung eines Dinges nur auf die dem Menschen zugewandten Aspekte „aufmerksam, da im Zusammenhange unserer Beschäftigung die Wahrnehmung sich gerade so weit der Dinge annimmt, als deren vertraute Gegenwart reicht.“ (Maurice Merleau-Ponty: Phänomenologie der Wahrnehmung (1945), Reprint, Berlin 1966, S. 372 [Zweiter Teil, § 38]) Daneben aber gibt es eine Rückseite der Dinge, der unsere Aufmerksamkeit nicht gilt und die wir dennoch wie einen Schatten - als Bedingung der menschlichen Seite - erfahren, nämlich, „dass diese Rückseite - ein uns eigentümlich verschlossenes und entzogen bleibendes Sein der Dinge an ihnen selbst - da ist. Dieses eigentliche Sein der Dinge ist uns nicht zugekehrt. Es ruft uns nicht, es meint uns nicht, es braucht uns nicht. Es hat weder humane Züge noch eine humane Teleologie.“ (Wolfgang Welsch: Homo mundanus. Jenseits der anthropischen Denkform der Moderne, Weilerswist 2012, S. 320) Insofern meint Merleau-Ponty, dass die Dinge etwas „Unmenschliches bergen“ und „verwurzelt sind in einem Grunde der unmenschlichen Natur“ (Merleau-Ponty: Phänomenologie der Wahrnehmung, S. 372, 374 [§ 38]). Es ist eben diese unmenschliche Kehrseite, die das Ding zum Ding macht (vgl. Merleau-Ponty: Phänomenologie der Wahrnehmung, S. 375), indem sie dessen Selbstbestimmtheit als Grund seiner Realität hält, die uns als Subjekte jedoch vielmehr abstößt als anzieht, weil wir uns in ihr nicht wiedererkennen (vgl. Merleau-Ponty: Phänomenologie der Wahrnehmung, S. 374).

33 Schönrich: Externalisierung des Geistes, S. $140 \mathrm{f}$.

$34 \mathrm{Zu}$ einem m.E. problematischen Versuch, einen rein singulären Sinn der kantischen Anschauungen zu denken, vgl. Peter Rohs: „Bezieht sich nach Kant die Anschauung unmittelbar auf Gegenstände?“, in: Kant und die Berliner Aufklärung, Bd. 2, hg.v. Volker Gerhardt, Rolf-Peter Horstmann u. a., Berlin/New York 2001, S. 214-228. 
tionaler Ordnung: Hegel hat dies später für die deiktischen wie indexikalischen Ausdrücke in der „Sinnlichen Gewißheit“ der Phänomenologie des Geistes offengelegt.

\subsubsection{Formen der Widerständigkeit}

In welchen Formen spielt sich dieser subjektiv-unmittelbare Kontakt mit der Realität $t_{1}$ bei Kant genau ab? Als Beispiele für die „Formen“ der Empfindung erwähnt Kant „Undurchdringlichkeit, Härte, Farbe“ (KrV, § 1, B 35), also Gehalte des Fühlens und Sehens, die die Dinge als Gegen-stand, wörtlich als Wider-stände (siehe auch die affektive Wirkung von Farben), begreifen ${ }^{35}$. Was das „Ding an sich“ also unmittelbar (wenn auch eben schon in der Form des Subjekts, als Form des Formlosen in der Empfindung) ausmacht, sind demnach Gegenkräfte als Impulse, welche dem Subjekt a) zustoßen (vgl. auch später Fichtes „Nicht-Ich“ als Widerstandskraft, vor allem aber Jacobis Konzept gleichursprünglicher, widerständiger Realität des Sinnlichen) und b) es einschränken, d.h. seine Tätigkeit behindern bzw. begrenzen. Daraus ergibt sich ein Begriff von Realität ${ }_{1}$ als Existenzdimension des „Ding an sich“, die als äußerliches Anderes auf das Subjekt treffend bestimmt ist: Wo das Subjekt aufhört, fängt die Realität ${ }_{1}$ der Gegenstände an sich selbst an. Ihre Grenze trennt beide voneinander und wird nur als Widerstand bzw. als Gegeneinander erfahrbar, sodass ihre einzige „Schleuse“ - und dies ist der zentrale implizite Argumentationspunkt bei Kant - eine selbst unbestimmbare Art der Übersetzung der Widerständigkeit in Empfindung bleibt. Zwar sind die Formen der Empfindung, die Kant zur „subjectiven Beschaffenheit der Sinnesart“ (KrV, $\S 2$, B 44) rechnet, also solche „des Gesichts, Gehörs, Gefühls, durch die Empfindungen der Farben, Töne und Wärme“ (KrV, § 3, B 44), quasi die subjektive Form des Nicht-Subjekthaften, aber als solche lassen sie ,an sich kein Object, am wenigsten a priori, erkennen“ (KrV, § 3, B 44). ${ }^{36}$ Die Empfindung ist also noch sehr

35 Hartmut und Gernot Böhme fassen das bei Kant ganz ähnlich, wenn sie diese Widerständigkeit als „Fremdheit“ bezeichnen: „Fremdheit ist geradezu ein Kriterium der Wahrheit, das Merkzeichen dafür, daß man überhaupt den eigenen Kreis verlassen hat.“ (Böhme, Böhme: Das Andere der Vernunft, S. 297) Am Begriff des Widerstands wird später Jacobi in seiner Kritik seinen Beweis von der Notwendigkeit der Annahme einer objektiven, von uns unabhängigen Realität sowie ihrer Erkennbarkeit anknüpfen (Jacobi: David Hume, JWA 2,1, S. 58f.). Ebenso ist Fichtes Begriff des Anstoßes von der Irreduzibilität der Vorstellung eines an sich selbst gegen das Ich Widerständigen her gedacht (vgl. Kap. 3.4 im Hauptteil I).

36 In den Prolegomena spezifiziert Kant hier zweifach: Zum einen wird im programmatischen Anschluss an Locke von sinnlichen Prädikaten wie „die Wärme, die Farbe, der Geschmack“ gesagt, sie kämen nicht „dem Object an sich selbst“ zu, sondern müssten als „Modificationen“ des 
weit davon entfernt, im strengen Sinn erkenntnisfähig zu sein: Vielmehr ist sie in Bezug auf irgendeine Stufe oder Form von Erkenntnis - sieht man selbst von Kants Beschränkung der Erkenntnis auf Aussagenwahrheit $\mathrm{ab}^{37}$ - generell nur als ,Noch-nicht‘ gekennzeichnet, weil ihr die Minimalbedingungen von Repräsentationalität als subjektive Form des Objekthaften überhaupt fehlen. Im Gegenteil:

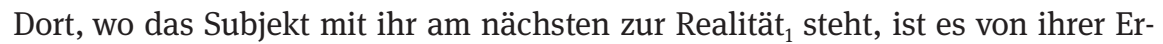
kenntnis, d.h. den psychologischen wie logischen Bestandteilen, die zur Formung einer Erkenntnis notwendig sind, am weitesten entfernt. Das bedeutet erstens: Was am unmittelbarsten als Reflex auf die Realität der Dinge (Realität $_{1}$ ) begriffen werden kann (Empfindungen), d.h. das, was das Nicht-Subjekthafte am nächsten

jeweiligen Sinnes betrachtet werden (Prol. §13, AA, 4, Anm. II, S. 289). Somit wird hier der Realismus der sinnlichen Eigenschaften, wie ihn die Kritik der reinen Vernunft noch unbestimmt ließ, ausgeschlossen: Es gehören „alle Eigenschaften, die die Anschauung eines Körpers ausmachen, zu seiner Erscheinung“ (Prol. § 13, AA, 4, Anm. II, S. 289). Die Fragen jedoch, durch welche apriorischen Konfigurationen dann aber die Intersubjektivität der sinnlichen Eigenschaften gesichert ist - denn schließlich nehmen wir alle, sollte es keine pathologischen Defekte geben, ein Rot zumindest in der Grundeigenschaft des Rotseins als Rot wahr -, warum diese einen anderen Spielraum gegenüber der streng kategorialen Intersubjektivität der Erscheinungen hat, ohne doch subjektiv beliebig zu werden, und welchen Grund diese Erscheinungen in den kausalen Data des Ding an sich haben, bleiben unbeantwortet. Zum anderen spricht Kant nun offensiv von einer „sinnlichen Erkenntniß“ (Prol. § 13, AA, 4, Anm. III, S. 290) und legt damit nahe, dass die Gewahrung sinnlicher Eigenschaften selbst, auch wenn sie vor „dem Zusammenhang der Vorstellungen in dem Begriffe eines Objects“ (Prol. § 13, AA, 4, S. 290) als Form der „Wahrheit“ liegen, auch eine eigenständige Weise des Erkennens bildet. Die sich daraus ergebende Unterscheidung verschiedener Erkenntnisbegriffe bzw. Reichweiten der Erkenntnis bleibt aber im Folgenden bei Kant aus. Für die hier vorliegende Untersuchung ist deshalb einzig die Dramaturgie der Erkenntnis in der Kritik der reinen Vernunft verbindlich, welche Erkennen im strengen Sinn erst auf der Ebene kategorialer Zusammenhänge und damit von apriorischer Objekthaftigkeit ansetzt.

37 Zum wichtigen Unterschied von „Denken“ und „Erkennen“ vgl. KrV, B 94; KrV, B 146; KrV, B 167 (Fußnote); KrV, B 406. Vgl. dazu allgemein Ludger Honnefelder: Scientia transcendens. Die formale Bestimmung der Seiendheit und Realität in der Metaphysik des Mittelalters und der Neuzeit, Hamburg 1990, S. 448f., und Sandkaulen: Das leidige Ding an sich, S. 192; Graeser zeigt in seinem Kommentar zur Einleitung von Hegels Phänomenologie des Geistes sehr überzeugend auf, wie Hegel diesen Unterschied und seine Funktion bei Kant ignoriert, wenn er sein berühmtes Argument vom „Erkennen vor dem Erkennen“ gegen Kant in Stellung bringt (Andreas Graeser: G.W.F. Hegel. Einleitung zur Phänomenologie des Geistes. Ein Kommentar, Stuttgart 1988, S. 21-175, hier: S. 32f.). Es ist eben diese Dichotomie der „anschauungsbezogenen Erkenntnis“ und des „referenzlosen Denkens“, die „schon von Fichte bestritten und seitdem nicht mehr anspruchsvoll rehabilitiert“ worden ist (Reinhard Brandt: „Kant“, in: Sonderheft Information Philosophie 3/4 (2012), S. 27-32, hier: S. 30 f.). Für das sinnvolle Denken des reinen Begriffs des Realen aber, so argumentiert die vorliegende Arbeit, ist die Aufhebung dieser Trennung unumgänglich, denn mit ihrer Reintegration wird die sinnwidrige bloße erkennende Nachträglichkeit des Begriffs für das Reale korrigiert. 
subjektiv registriert, ist selbst das (im ,schlechten“, allgemein nichterkenntnisfähigen Sinn) ,bloß‘ Subjektivste im Subjekt (in der Bedeutung von „nicht-allgemein“, nicht-apriorisch). Das wird am deutlichsten, wenn Kant sagt, dass „nämlich etwa Farben, Geschmack etc. mit Recht nicht als Beschaffenheiten der Dinge, sondern bloß als Veränderungen unseres Subjects, die sogar bei verschiedenen Menschen verschieden sein können, betrachtet werden“ (KrV, § 3, B 45) müssen. Daraus folgt paradoxerweise: Gerade das, was am scheinbar unmittelbarsten auf die Gegebenheit von Dingen im Sinne der Realität ${ }_{1}$ nicht-subjektiv reagiert, ist aufgrund seiner Nicht-Subjektivität im Sinne seiner Nicht-Idealität (keine allgemeine subjektive Form a priori) das im schlechten Sinn Subjektivste und damit gerade nicht fähig, Erkenntnisverhältnisse mit ihrem Fundament in objektiven, d.h. allgemeingültigen Transzendentalformen $\mathrm{zu}$ bilden. Zweitens: Was am unmittelbarsten auf die objektive (im Sinne von objekthafter „Widerständigkeit“) Gegebenheit der Dinge der Realität ${ }_{1}$ im Subjekt antwortet, ist selbst jenseits der Fähigkeit, Objekthaftigkeit zu registrieren. Objekthaftigkeit nämlich entsteht erst im Zusammenspiel der apriorischen Formen auf der Ebene des Verstandes, durch Kategorien und Schemata. Generell gilt drittens: Was die Dinge zu Objekten macht, erfasst sie nicht in ihrer Realität ${ }_{1}$, weil es sie im Sinne transzendentaler Subjektivität erkenntnistheoretisch konstituiert ${ }^{38}$ (Anschauungsformen - Kategorien - Schemata). Was die Dinge noch nicht zu Objekten macht, sondern sie im einzelnen Subjekt unmittelbar als Gegebenheit erfasst (Empfindung), erfasst nicht ihre Realität ${ }_{1}$, weil es unfähig zur Objektivität und Allgemeingültigkeit (als Form der Konstanz von Dingen) ist, sondern nur das bloß Subjektive des wechselnden sinnlichen Eindrucks gebraucht.

Das Paradoxe daran ist also, dass je weiter die sinnlichen Daten der Dinge zu festen Objekten der Realität ${ }_{2}$ werden, desto weiter entfernen sie sich von den Gegebenheiten ihrer Realität $t_{1}$. Sie sind also in dieser Beziehung durch eine tendenzielle Gegenläufigkeit von Realität ${ }_{1}$ und Realität ${ }_{2}$ bestimmt, wo doch hin-

38 Ich danke Anton Friedrich Koch für seine wertvolle Kritik, dass nämlich nicht die Dinge in Raum und Zeit vom Subjekt konstituiert sind, sondern lediglich die Erkenntnis der kategorialen Struktur der Dinge. Die Konstitution, so Koch, die das Subjekt in seinem Verhältnis zu den Dingen leistet, ist nur epistemischer, nicht ontischer Natur. Ich teile diese Ansicht (vgl. Fußnote 95 und Fußnote 189 im Hauptteil I), auf die ich auch bei Fichte aufmerksam mache (vgl. Fußnote 287 im Hauptteil I und Fußnote 5 in der Schlussbetrachtung). Diese epistemische Lesart bestimmt aber trotzdem eine doppelte ontologische Unabhängigkeit der Gegenstände der Erfahrung. Ontologisch unabhängig vom Subjekt ist nämlich in der Tat das Ding an sich, aber eben auch, so Kant, der Gegenstand der Erscheinung. Kant entwirft damit, so die zentrale These des Kant-Kapitels dieser Arbeit, zwei begriffliche Ebenen der einen begrifflich zu beschreibenden Realität, die er als Zusammenhang entwickeln will (als zwei komplementäre Beschreibungen von Realsein), die sich aber zugleich nicht konsistent als Aspekte einer Realität zusammenbringen lassen. 
sichtlich der Genese des Erkennens eine Sukzessivität beider Bewusstseinsinhalte stattfinden soll (denn die kategoriale Formung baut auf den sinnlich gegebenen Daten auf und bewegt sich innerhalb von deren konkreten Vorgaben, welche durch die Schematismen integriert werden). Zugleich aber binhaltet die Eigenschaft der Widerständigkeit, mit der unmittelbare Empfindungen den Impuls der äußeren Realität registrieren und die gerade nicht-objekthaft ist sowie keine Erkenntnis erzeugt, ein wesentliches Merkmal der Objekthaftigkeit überhaupt, durch welches diese überhaupt erst zur Bedingung individueller Objekte wird: die „Undurchdringlichkeit“ von Objekten nämlich. Erst wenn individuelle Objekte als gegeneinander undurchdringlich angenommen werden, ist es möglich, zwei verschiedene Objekte zu denken, die in allen Eigenschaften sowie noch dazu in ihrer Ortseigenschaft identisch sind, ohne doch ontologisch-numerisch identisch zu sein ${ }^{39}$. Kant jedoch sieht nicht, dass die sinnliche Widerständigkeit in der Empfindung bereits unmittelbarer Reflex einer begrifflichen Form ist, die der apriorischen Struktur von „Objektivität überhaupt“ zukommen muss.

\subsubsection{Das Mannigfaltige als reale Bestimmtheit}

Zugleich jedoch muss es notwendigerweise eine reale Bestimmtheit der Dinge in der Empfindung geben, die nicht von den bloß subjektiven Bedingungen von Bestimmtheit als Einheit überhaupt (transzendentale Einheit der Apperzeption) und deren Derivationen in den Kategorien her kommt, sondern die als den Dingen an sich selbst zugehörig betrachtet werden muss. Denn auch das „Mannigfaltige“ (KrV, § 1, B 34) der Empfindung ist in gewisser Weise bestimmt, wenn auch nicht durch die Formen der Einheit des Verstandes (transzendentale Einheit - Kategorien). Genau hier liegt m.E. der unauflösbare und von Kant selbst unbeschreibbare Widerspruch seines Modells: ursprünglich gegebenes Bestimmtsein, das jedem subjektiven Akt der Bestimmung vorhergeht und es ermöglicht, nicht denken zu können. Förster hat deshalb - aus der Perspektive kantischer Programmatik - Recht, wenn er schreibt: „Dieser Einwand ist aber nur gültig aus der Perspektive eines Realismus, demzufolge uns Gegenstände bereits in irgendeiner Weise gegeben sind, bevor der Logiker seine Wahl trifft. Das ist aber gerade für Kant nicht der Fall. Da er vielmehr erklären will, wie auf der Basis von Vorstel-

39 Vgl. hierzu Peter Mittelstaedt: „Der Objektbegriff bei Kant und in der gegenwärtigen Physik“, in: Warum Kant heute? Systematische Bedeutung und Rezeption seiner Philosophie in der Gegenwart, hg.v. Dietmar H. Heidemann, Kristina Engelhard, Berlin/New York 2004, S. 207-231, hier: S. $211 \mathrm{f}$. 
lungen ein Bezug auf etwas vom Subjekt Unterschiedenes überhaupt erst möglich ist, kann für ihn eine Quantifikation über Gegenstände nicht primitiv sein.“40 Försters Schlussfolgerung wird deshalb hier zumindest versuchsweise Ernst genommen: „Eine wirksame Kritik an seinem Verfahren müsste deshalb tiefer ansetzen als bei der Konventionalität gegenwärtiger Logiken: nämlich auf der Ebene der Wahrnehmungstheorie, bei der Frage nach dem Gegebenen bzw. dessen Konstitution. “41

Drei Hinweise sind in dieser Hinsicht anzubringen. Erstens fordert die konstitutive apriorische und aposteriorische Unterbestimmtheit der Gegenstände der Erfahrung ${ }^{42}$ durch den transzendentalen Apparat und seine Formbedingungen, dass den Gegenständen eine Fülle von empirischen Bestimmungen zukommen muss, die sich weder aus transzendentalen Bedingungen ableiten lässt, noch gar mit diesen zusammenfallen kann. Es gibt weder eine Anschauungsform noch eine Kategorie für den Inhalt und die Intensität von Farben: Diese Einsicht zwingt Kant beinahe notwendig einen Realismus bezüglich der Existenz wie auch der empirischen Bestimmtheit von Gegenständen der Realität ${ }_{1}$ auf, die aufgrund der Bipolarität des kantischen Modells (Subjekt und Erscheinungswelt - „Ding an sich“) einzig auf der Seite der Realität ${ }_{1}$ verortet werden können und zugleich verortet werden müssen. „Kann man dieses wohl Idealismus nennen? Es ist ja gerade das Gegentheil davon“ (Prol. § 13, Anm. II, S. 289), sagt Kant in den Prolegomena und verweist damit auf seine eigene Programmatik, transzendentalen Idealismus und empirischen Realismus als notwendige Einheit seiner Theorie zu begreifen, die sich ergänzen und stützen sollen, wollen sie nicht jeweils grund- und bodenlos erscheinen ${ }^{43}$. Damit jedoch stellt er sich nicht dem Folgeproblem, das Paradox der sich jeder Bestimmtheit - auch der Bestimmtheit selbst - entziehenden, zugleich aber als notwendig vorauszusetzenden Bestimmtheit der Dinge an sich aufzulösen. Wann immer Kant die realistische Voraussetzung seiner Transzendentalphilosophie bedenkt, zieht er sich auf die bloße Existenzbehauptung zurück (vgl. Prol. §13, Anm. II und Anm. III, S. 288-294), die den Dingen an sich ,ihre Wirklichkeit lasse[n]“ (Prol. § 13, Anm. III, S. 292) will. Zweitens bereitet bereits der

40 Förster: Die 25 Jahre der Philosophie, S. 36.

41 Förster: Die 25 Jahre der Philosophie, S. $36 \mathrm{f}$.

42 Dieses Problem, dass ,durch die transzendentalen Gesetze unseres Verstandes das Besondere unbestimmt ist und es darum immer zufällig ist, wie verschieden und mannigfaltig die besonderen Naturprodukte sein mögen“ (Förster: Die 25 Jahre der Philosophie, S. 152), beschäftigt Kant in der „Kritik der teleologischen Urteilskraft“ in der Kritik der Urteilskraft erneut.

43 Vgl. zum Problem dieser Einheit in Bezug auf die „Transzendentale Ästhetik“ auch Rolf-Peter Horstmann: „Was bedeutet Kants Lehre vom Ding an sich für seine transzendentale Ästhetik?“, in: Ders.: Bausteine kritischer Theorie. Arbeiten zu Kant, Bodenheim 1997, S. 35-55. 
Begriff des „Mannigfaltigen“ gewisse Schwierigkeiten. Die Daten der Realität ${ }_{1}$ sind nämlich begrifflich als „Mannigfaltiges“ gefasst; d.h. die ursprüngliche, erste Form der Inhalte der Realität ${ }_{1}$ soll eine bestimmte Form der Vielheit sein, nämlich die ohne innere Relation des Vielen, bei der „eine jede einzelne Vorstellung der andern ganz fremd, gleichsam isolirt und von dieser getrennt wäre.“ (KrV, A 97) ${ }^{44}$ Mannigfaltigkeit steht hier deshalb programmatisch noch jenseits der bestimmten Relationen von Identität und Differenz der Elemente des Vielen ${ }^{45}$ : Das wird erst

44 Förster spricht davon, dass bei Kant „die Sinnlichkeit selbst nur unverbundene Eindrücke liefert“ (Förster: Die 25 Jahre der Philosophie, S. 38). Dies könne allerdings genetisch nicht als unüberprüfter Dogmatismus im Rahmen der Vorstellungen über Sinnlichkeit in seiner Zeit gelten, sondern habe konsequent systeminterne Gründe: „Vielmehr folgt für ihn [Kant, C.W.] die Unverbundenheit des sinnlichen Materials allein aus der Passivität der Sinnlichkeit“ (Förster: Die 25 Jahre der Philosophie, S. 39). Zum Vorwurf des „Atomismus“ an Kants Theorie der Sinnlichkeit vgl. Dieter Henrich: Identität und Objektivität, Heidelberg 1976, S. 110, 117. Ein solcher Datensensualismus, wonach „die primären Gegebenheiten von Wirklichkeiten für die Erkenntnis Präsentationen von einfachen Qualitäten in einem diffusen Beieinander im Raume sind“ (Henrich: Identität und Objektivität, S. 17), müsste nach Ronald Harri Wettstein erklären, „daß das Mannigfaltige unserer Vorstellungen von den Gegenständen der Außenwelt bereits als kleinste Einheiten aufgefaßt werden darf“ (Ronald Harri Wettstein: Kritische Gegenstandstheorie der Wahrheit. Argumentative Rekonstruktion von Kants kritischer Theorie, 2. Aufl., Würzburg 1983, S. 96). Wettstein verweist darauf, dass eine solche Überlegung bei Kant nicht aufzufinden ist. Das Problem dabei ist dann aber, wie diese einfachen Qualitäten zu einem geordneten Zusammenhang und damit zu einzelnen Objekte werden. Wettstein schlägt vor, „das Mannigfaltige als Erfahrungskontext zu deuten, dessen Kohärenz dann durch die Grundeinheiten dieses Kontextes, die aber theoretisch zu ermitteln sind, erschlossen wird." (Wettstein: Kritische Gegenstandstheorie der Wahrheit, S. 97) Damit ist zwar möglicherweise eine brauchbare Methodologie bzw. Heuristik entworfen, in der das Mannigfaltige seinen Platz hat, aber keine Aussage über die Art der Zuschreibung der Bestimmungen des Mannigfaltigen im Verhältnis von An-sich und Für-uns getroffen.

45 Kant darf hier als Vorläufer eines begründungstheoretischen Fundamentalismus gelten, wie er in den Rechtfertigungstheorien empirischer Urteile des klassischen logischen Positivismus und der analytischen Philosophie seit Anfang des 20. Jahrhunderts hervorgetreten und später von Quine, Sellars und noch später von McDowell als „klassischer Empirismus“ kritisiert worden ist (ungeachtet der Unterschiede zu einem reinen Empirismus bei Kant, weshalb Kant nach Meinung von Heidemann: Vom Empfinden zum Begreifen, S. $14 \mathrm{ff}$, nicht unter die Kritik bei Sellars falle). Dieser begründungstheoretische Fundamentalismus basiert auf der Idee, dass die letzten Fundamente mit Rechtfertigungsfunktion für empirisches Wissen keine alltäglichen Wahrnehmungen ganzer Gegenstände oder Sachverhalte, sondern nur noch einzelne „Sinnesdaten“ seien, die als Partikel materialer Eindrücke im Subjekt den unmittelbaren, rein auf sinnlicher, ungeformter Wahrnehmung basierenden Kontakt mit der Wirklichkeit ausmachen und noch jenseits jeder intelligiblen, von Begriffs- und Sinnhorizonten bestimmten repräsentationalistischen Aneignung lägen (vgl. die klassische Position bei CIarence Irving Lewis: Mind and the World Order. Outline of $a$ Theory of Knowledge, New York 1929). Bei Kant sind gerade im Begriff des Mannigfaltigen solche Tendenzen klar zu erkennen. 
durch die Synthesis des Verstandes den Daten als Form gegeben. Wir haben es hier also mit einer reinen Vielheit ohne innere Relation des Vielen als Form der Erfahrung der Realität ${ }_{1} \mathrm{zu}$ tun $^{46}$. Die Handlung der „Synthesis überhaupt“ als „Verbindung“ der sinnlichen Anschauungen im Begriff kommt nämlich zuerst und einzig den Verstandesaktivitäten zu (vgl. KrV, § 15, B 129f.). Die direkte sinnliche Materie ist deshalb verbindungslos, d. h. der erste ,Abdruck' der Realität ${ }_{1}$ in der Anschauung besteht für Kant in verbindungsloser Mannigfaltigkeit. Doch ist „Vielsein“ nicht auch schon ein Verhältnis und damit eine Bestimmung von Identität und Differenz? Im Schematismuskapitel spricht Kant von der Zeit als der „formale[n] Bedingung des Mannigfaltigen des inneren Sinnes, mithin der Verknüpfung aller Vorstellungen“ (KrV, B 177) und zeigt damit an, dass die innere Anschauungsform der Zeit das Mannigfaltige in die Ordnung des zeitlichen Nacheinander bringt und damit verknüpft, d. h. als Verschiedene in die Form des Nacheinander setzt und dabei jedes Einzelne mit sich identisch sein lässt. Wie also kann es, kritisch gefragt, eine reine „Vielheit“ ohne das Verhältnis von Identität und Differenz geben? Auch eine „reine“ Vielheit hat das Moment der Differenz begriffslogisch stets an sich selbst, wo sie doch mehr als eins bzw. mindestens eine Zweiheit ist; und wo mindestens zwei sind, muss unterschieden werden können. Und ebenso hat sie das Moment der Identität an sich, da diese Vielen mit sich als Einzelne stets identisch sein müssen ${ }^{47}$. Bereits in der Form des Mannigfaltigen, die Kant kategorial von der Verstandesleistung und den Formen ihrer Vermittlungsprozeduren trennt, ist unausweichlich die differenzierende Verstandesleistung - oder etwas ihr Analoges, aber von den Dingen selbst Herkommendes - und damit ein begriffliches Fundament ${ }^{48}$ schon enthalten. ${ }^{49}$ Man

46 „Kant betont immer wieder, daß das Gegebene als solches keine Einheit enthält, keine Ordnung, kein Gesetz. [...] Das gegebene Mannigfaltige enthält keinerlei Verbindung, Ordnung, Gesetzmäßigkeit.“ (Böhme, Böhme: Das Andere der Vernunft, S. 298)

47 Diese unabweisbare begriffliche Logik der inneren Interdependenz - Hegel würde von „Reflexionsbestimmungen“ sprechen - von Identität und Differenz hat Platon im Sophistes im Rahmen seiner Lehre von den megisté gené bereits entwickelt (Platon: Sophistes, Griechisch/ Deutsch, hg.v. Christian Iber, Frankfurt am Main 2007, bes. S. 137 ff. [256eff.]) und an den „Metakategorien“ der Einheit und Zweiheit im Parmenides ontologisch so fundiert, dass diese so etwas wie eine letztgültige Unhintergehbarkeit von Identität und Differenz für alles Seiende garantieren.

48 Ganz ähnlich hat Sellars implizit gegen Quine argumentiert, dass die empirisch-sinnliche Datenbasis der ,unmittelbaren' Wahrnehmung nicht ein äußerliches, durch fundamentale Unbestimmtheiten geprägtes Anderes zu ihrer Strukturierung durch Theorien darstellt, die deshalb durch ganz verschiedene und sogar widersprüchliche Theorien konsistent erfolgen kann (vgl. Willard Van Orman Quine: „Three Indeterminacies“, in: Perspectives on Quine, hg.v. Robert Barrett, Roger Gobson, Oxford 1993, S.1-16), sondern selbst schon durch und durch begriffs- und 
kann der Mannigfaltigkeit als Form der sinnlich unmittelbaren Empfindungen der Realität $_{1}$ keine Form geben, die nicht immer schon von dem geprägt ist, was Kant einzig dem Verstand als begriffliche Leistung zugesteht. So zeigt also auch die Reflexion auf die Begriffsverhältnisse der Gedankenbestimmungen des „Mannigfaltigen“ als Form der unmittelbaren Gegenwärtigkeit der Realität $t_{1}$ im Bewusstsein, dass eine reale Bestimmtheit ihrer Gegenstände angenommen werden muss, die höchstens in Analogie zu Formen der Bestimmtheit des transzendentalen Apparates stehen kann, aber sowohl aus deren Funktionalität als auch aus deren Dramaturgie bei Kant herausfällt. Schließlich gilt es in diesem Zusammenhang auch noch darauf hinzuweisen, dass eine „radikale Begriffs-Unabhängigkeit"50 der Anschauungen gegenüber Begriffen einen methodischen Selbstwiderspruch Kants zur Folge hätte: Die „Transzendentale Deduktion“ wäre

theorieimprägniert gedacht werden muss (vgl. Thomas Blume: „Sellars im Kontext der analytischen Nachkriegsphilosophie“, in: Wilfrid Sellars. Empirismus und die Philosophie des Geistes, Paderborn 1999. S. VII-XLV, hier: S. XXIIf.). Dass „Alles Factische [...] selbst schon Theorie“ (Goethe: Maximen und Reflexionen, S. 432 [Nr. 488]), also immer schon durch begrifflich-theoretische Formen vermittelt ist, hat Sellars' wirkmächtiger Aufsatz Empiricism and the Philosophy of Mind in der analytischen Diskussion verankert und Wolfgang Welsch zur Grundlage seiner umfassenden historischen wie systematischen Kritik der „Weltfremdheit“ und des Subjekt-ObjektGegensatzes der Philosophie gemacht (Welsch: Homo mundanus). Was dies aber für den kategorialen Begriff der Realität bedeutet, gilt es noch herauszufinden.

49 Die Stufen der Synthesis des Mannigfaltigen, als die „drei Synthesen zur Erkenntnis eines jeden Sinnesgegenstands“ (Förster: Die 25 Jahre der Philosophie, S. 138), welche Kant in KrV A als „Apprehension“, „Reproduction“ und „Recognition“ unterscheidet und den Vermögen sukzessive zuordnet (S. 98-110: Apprehension der Anschauung, Reproduktion der Einbildungskraft und Rekognition dem Verstand), lösen dieses Problem nicht. Zwar scheinen sie zum einen als ursprüngliche Handlungen des Bewusstseins - Verbindungen mehrerer Vorstellungen zu einer Abfolge (Apprehension), Wiedererinnern bzw. Festhalten vergangener Vorstellungen (Reproduktion) und ihr ordnungsgemäßes Zusammenstellen im Begriff (Rekognition) - stets schon am Werk zu sein, wo überhaupt „Etwas“ als Bewusstseinsinhalt vorliegt und demgemäß „selbst die Einheit von Raum und Zeit erst möglich“ (Förster: Die 25 Jahre der Philosophie, S. 42) machend. Zugleich aber gehören sie der Dramaturgie der Vermögen an und beruhen ebenfalls darauf, dass eine vorgängige Weise von „Etwas-sein“ immer schon gegeben ist, um selbst wirksam werden zu können: Die Abfolge der Apprehension in der Anschauung ist die von quantitativ und qualitativ unterschiedenen Elementen in der Form des objektiven „Etwas“. Zur grundsätzlichen subjekthaften Zeitlichkeit der Realität sowie zur transzendentalen Idealität von Raum und Zeit bei Kant vgl. auch präzise Leslie Stevenson: Inspirations from Kant. Essays, Oxford/New York 2011, S. 58 - 62 („The Reality of the Past“) und S. 42-51 („Three Ways in Which Space and Time Could Be Transcendentally Ideal“).

50 Diese Position kritisiert Schönrich (Externalisierung des Geistes, S. 133) in Bezug auf Robert Hannas Behauptung der „logische[n] Priorität von Anschauungen gegenüber Begriffen“ (Externalisierung des Geistes, S. 133; vgl. Robert Hanna: Kant and the Foundations of Analytic Philosophy, Oxford 2001, S. $195 \mathrm{ff}$. .). 
sinnlos, wenn es keine Regelhaftigkeit der Anschauung gäbe, die als Gebrauchswissen der Wahrnehmung rekonstruiert werden könnte. Wie eng aber bei Kant die Normativität eines Regelwissens und Regelgebrauchs mit dem „Begriff des Begriffs“ überhaupt verbunden ist, hat die Kant-Forschung überzeugend dargelegt ${ }^{51}$.

Drittens impliziert schon Kants „kopernikanische Wende“ das in Rede stehende Problem exakt, nimmt man sie mehr beim Wort, als Kant dies in der Kritik der reinen Vernunft in der Formulierung „Umänderung der Denkart“ (KrV, B XVI) tut:

Es ist hiemit eben so, als mit den ersten Gedanken des Copernicus bewandt, der, nachdem es mit der Erklärung der Himmelsbewegungen nicht gut fort wollte, wenn er annahm, das ganze Sternheer drehe sich um den Zuschauer, versuchte, ob es nicht besser gelingen möchte, wenn er den Zuschauer sich drehen und dagegen die Sterne in Ruhe ließ. ( $\mathrm{KrV}, \mathrm{B}$ XVI)

Interpreten haben stets auf die Inversion der Revolution des Kopernikus in dieser Analogie bezüglich des Verhältnisses von Betrachter und Gegenständen aufmerksam gemacht: Kants „kopernikanische Wende“ rücke, gerade entgegengesetzt zu Kopernikus, den Betrachter ins Zentrum der Gegenstandsbeziehung. Bedeutungsreicher aber ist in Kants inverser Analogie seine implizite Hindeutung auf den Grund der Revolution des Kopernikus, nämlich die Erläuterung der „Himmelsbewegungen“. Gerade hier nämlich zeigt sich das eigentliche fundamentale Missverständnis Kants im Hinblick auf seine eigene Analogie. Kopernikus’ „Umkehr der Denkungsart“ war der Versuch, für das Phänomen der retrograden Planetenbewegungen eine plausiblere Erklärung $\mathrm{zu}$ finden, als es Theorien des ptolemäischen Weltbildes anbieten konnten ${ }^{52}$. Im Zuge dieser Neuerklärung des Phänomens des schleifenförmigen Laufs der Planeten am Firmament ermöglicht es das neue Weltbild, scheinbare von wirklichen, d. h. wahren und ansichseienden, Bewegungen der Planeten $\mathrm{zu}$ unterscheiden und den $\mathrm{Zu}$ sammenhang zwischen beiden Modi zu erläutern. Nur für den Betrachter auf der Erde sieht es demnach so aus, als würden die Planetenbahnen am Himmel an

51 Vgl. stellvertretend und konzis Schönrich: Externalisierung des Geistes, S. 127-132.

52 Vgl. zur Theorie des heliozentrischen Weltbildes Kopernikus' Commentariolus (vollständiger Titel: Nicolai Copernici de hypothesibus motuum coelestium a se constitutis commentariolus [Nikolaus Kopernikus' kleiner Kommentar über die Hypothesen der Bewegungen der Himmelskörper, die von ihm selbst aufgestellt wurden]). Die genaue Datierung des Werkes ist unbekannt, jedoch diskutiert die Forschung über die Entstehung des Manuskripts im Zeitraum zwischen 1504 und 1514. Zur Epizykeltheorie, welche die retrograde (rückläufige) Planetenbewegung (Schleifenbahn von Planeten) erklärt, vgl. Kopernikus' Hauptwerk De Revolutionibus Orbium Coelestium (Über die Umschwünge der himmlischen Kreise) von 1543. Den kopernikanischen Hintergrund schlüsselt weitaus detaillierter Jens Lemanski („Die Königin der Revolution. Zur Rettung und Erhaltung der Kopernikanischen Wende“, in: Kant-Studien 4 (2012), Bd. 103, S. 448-472) auf. 
jeweils bestimmten Punkten ihres Laufs eine partielle Rückwärtsbewegung vollführen. Eigentlich jedoch - und die Pointe von Kopernikus ist es, diese Eigentlichkeit evident gemacht und hinreichend begründet zu haben - entsteht der Eindruck retrograder Dynamik durch die unterschiedliche Geschwindigkeit, mit der sich die Erde im Verhältnis zu anderen Planeten um die Sonne bewegt. Eben diese platonische Unterscheidung innerhalb der Phänomene kann Kant nicht oder nur unzureichend treffen ${ }^{53}$ : Zum einen muss er die Erscheinungen als Synthesis von subjekthaften, in transzendentaler Konstruktion gründenden und von ansichseienden, vom „Ding an sich“ herrührenden Eigenschaften begreifen, um ihnen ein fundamentum in re zu geben; zugleich aber kann dieser Unterschied an den Erscheinungen selbst nicht deutlich bestimmt werden. Im Auseinanderfallen von Dass-Sein (quodditas) und Was-Sein (quidditas) der Data des „Ding an sich“54 in der Erscheinung bleibt der Raum der Realität ${ }_{1}$ konstitutiv unbestimmt, ohne als solcher ohne Bestimmung sein zu können. Die Erscheinungen haben mithin einen semantischen Überschuss der Realität ${ }_{1}$ an sich, der sich aber vollständig in den subjekthaften Gegebenheiten der Erscheinungen verbirgt, weil er nur in seiner bloßen, abstrakten Negation bestimmt ist, ohne jedoch wie in Hegels Logik des „Wesens“ deshalb im Schein als seinem Nichtsein bestimmt zu sein (vgl. GW 11, S. 246). Kant kann nicht erklären, wo die erste unmittelbare Bestimmtheit der Dinge an sich selbst herkommt, die sie schon mitbringen müssen, damit sie in der Empfindung bestimmt werden können. Dafür aber hat er keinen Begriff, da alle Bestimmtheit immer nur durch das Subjekt herbeigeführt wird, erst im Subjekt entspringt, nur in der Formatierung von Subjektivität ihren Begriff hat und einzig für derart formatierte Erscheinungen als Gegenstände möglicher Erfahrung gilt ${ }^{55}$ :

53 In den Prolegomena bezieht sich Kant zwar explizit auf die retrograde Planetenbewegung als Grund für die „kopernikanische Wende“ des Kopernikus, verwechselt jedoch eben diese beiden Perspektiven, indem er die objektive Wahrheit des Kopernikus über die Dinge selbst assoziativ mit dem Wahrheitsbegriff der Erscheinungen verbindet, wie er ihn selbst entwirft: „Den Gang der Planeten stellen uns die Sinne bald rechtläufig bald rückläufig vor, und hierin ist weder Falschheit noch Wahrheit, weil, so lange man sich bescheidet, daß dieses vorerst nur Erscheinung ist, man über die objektive Beschaffenheit ihrer Bewegung noch gar nicht urtheilt.“ (Prol. §13, Anm. III, S. 291)

54 Vgl. Manfred Frank: Idealismus und Realismus. Vorlesung im Wintersemester 2009/ 2010, S. 7. Diese großartigen Vorlesungen liegen leider nicht in Buchform vor, sind aber im Internet abrufbar [Abgerufen auf: https://www.scribd.com/document/237151069/Idealismus-Und-Realismus-1 (Stand: 28.2.2021)].

55 Vgl. Förster (Die 25 Jahre der Philosophie, S. 32f.), der auf die wichtige kantische Unterscheidung von „Gegenstände[n] der Erfahrung“ und „alle[n] uns möglichen Erscheinungen“ aufmerksam macht: Es gibt demnach einen kantischen Gegenstandsbereich, der weiter als objekthafte Formen der Erfahrung ist und dafür geeignet sein könnte, Bestimmungen jenseits bloß subjektiver Bestimmtheit zu denken, ohne aus deren Zugriffsbereich gänzlich herauszufallen. 
Klar sagt Kant, dass von diesen apriorischen Formen der „Bestimmtheit überhaupt“ in Bezug auf das „Ding an sich“ „nicht die mindeste Bedeutung mehr übrig bleibt“ (Prol. § 32, S. 87). Hegels Kritik, dass das „Ding an sich“ nicht völlig unbestimmt sei, weil seine Bestimmung eben in seiner Unbestimmtheit liege (vgl. GW 20, S. 80 f., § 44), und deshalb als Konzept an seinem konstitutiven Selbstwiderspruch zugrunde gehe, trifft gewissermaßen den Kern des Problems: Realität - auch die Realität ${ }_{1}$ des „Ding an sich“ - ist von Bestimmtheit nicht zu trennen, auch dort nicht, wo das System diese notwendig als „Noch-Nicht“ von Bestimmtheit bestimmt. ${ }^{56}$

\subsubsection{Inbegriffe der Realität ${ }_{1}$ : „Ding an sich“ und synthetische Einheit des Ich}

Kant entwickelt bekanntermaßen zwei Inbegriffe der Realität ${ }_{1}$, die als Grenzbegriffe das Feld der Unbestimmtheit des stets vorgängig Wirklichen bilden. In ihnen wird das begriffliche Problem einer unbestimmten Bestimmtheit der Realität verdichtet deutlich: zum einen objektseitig das notorische „Ding an sich“, zum anderen subjektseitig das Ich der „synthetischen Einheit der Apperzeption“ ${ }^{\text {“57. }}$ Einige der für unser Anliegen bedeutsamen Passagen zum „Ding an sich“ finden sich im Abschnitt „Von dem Grunde der Unterscheidung aller Gegenstände überhaupt in Phaenomena und Noumena“ (KrV, B 294 ff. $)^{58}$. Kant macht klar, dass das „Dinge an sich selbst“ (KrV, B 310) ein reiner „Grenzbegriff“ (KrV, B $311 \mathrm{f}$.$) ist,$

Leider wird bei Kant nirgends sichtbar, dass dieser Unterschied in dieser Hinsicht worden begriffen sein könnte.

56 Aristoteles' dichotomische Unterscheidung von zwei Weisen des Hervorgegangenseins von Seiendem in der Physik darf als Folie der hier vorgeschlagenen Korrektur an Kant gelten: „Unter den vorhandenen Dingen sind die einen von Natur aus, die anderen sind auf Grund anderer Ursachen da.“ (Aristoteles: „Physik“, in: Ders.: Philosophische Schriften, Bd. 6, hg. u. übers. v. Hans Günter Zekl, Hamburg 1995, S. 25 [Buch II,1, S. 192b]) Denn „Naturbeschaffenheit“ (Aristoteles: Physik, S. 26 [Buch II,1, S. 192b]) markiert den Aspekt eines vorgängigen Selbstbestimmtseins von Dingen, der im Unterschied zur produktiven Bestimmtheit durch den Menschen als ursprünglicher Wechselgrund mit dieser gedacht werden muss.

57 Vgl. die Forschungsdiskussionen bei Karl Ameriks („Apperzeption und Subjekt. Kants Lehre vom Ich heute“, in: Warum Kant heute? Systematische Bedeutung und Rezeption seiner Philosophie in der Gegenwart, hg.v. Dietmar H. Heidemann, Engelhard, Berlin/New York 2004, S. 76-100) und, immer noch grundlegend, Konrad Cramer („Über Kants Satz: Das: Ich denke, Kristina muß alle meine Vorstellungen begleiten können“, in: Theorie der Subjektivität, hg.v. Konrad Cramer, Hans Friedrich Fulda, Rolf-Peter Horstmann, Ulrich Pothast, Frankfurt am Main 1987, S. 167-203). 58 Vgl. zur problematischen Unterscheidung von Noumena und Phenomena James Van Cleve: Problems from Kant, New York/Oxford 1999, insbes. Kap. 10 („Noumena and Things in Themselves“), S. 134-171, sowie Appendix D („Unperceived Phenomena“), S. 233-235. 
d.h. einzig in „negativer Bedeutung“ (KrV, B 309) gemeint ist, weil seine „objective Realität aber auf keine Weise erkannt werden kann“ (KrV, B 310). Er ist deshalb nur von „negativem Gebrauche“ dahingehend, dass er als „Einschränkung der Sinnlichkeit“ zu fungieren und zugleich eine Selbsteinschränkung des Verstandes zu sein habe:

Unser Verstand bekommt nun auf diese Weise eine negative Erweiterung, d.i. er wird nicht durch die Sinnlichkeit eingeschränkt, sondern schränkt vielmehr dieselbe ein, dadurch daß er Dinge an sich selbst (nicht als Erscheinungen betrachtet) Noumena nennt. Aber er setzt sich auch sofort selbst Grenzen, sie durch keine Kategorien zu erkennen, mithin sie nur unter den Namen eines unbekannten Etwas zu denken. (KrV, B 312)

Diese Passage ist der Versuch, die Paradoxie des Begriffs des „Ding an sich“ durch die analog paradoxe, metabegriffliche Beschreibung „negative Erweiterung“ zu erfassen. Denn sehr wohl erkennt Kant hier, dass der Verstand sich selbst überschreitet, indem er das „Ding an sich“ postuliert und so paradoxerweise genau das macht, was er zugleich für sich bestreitet: nämlich das zu definieren, was sich der Definition gemäß gerade nicht definieren lässt. Kant sieht also, dass die Definition einer Grenze zugleich auch ihre Überschreitung bedeutet ${ }^{59}$, kommt jedoch deshalb trotzdem nicht an die Hegel'sche Konsequenz heran, sie aus diesem Selbstwiderspruch eines Wissens vom Nicht-Wissbaren bzw. der Verkennung des abstrakten Wissens vom „Ding an sich“60 deshalb als falschen, weil einseitigen Verstandesbegriff zu begreifen. ${ }^{61}$ Vielmehr hält er daran fest, dass der Verstand negativ über sich hinausgehen kann, indem er ein Jenseits seiner selbst postuliert (und sich so über sich selbst hinaus erweitert), dieses Jenseits aber für gänzlich unbekannt erklärt (und so in seinen Grenzen bleibt). So wird das „Ding an sich“,

59 Vgl. Friedrich Schlegel: „Man kann keine Gränze bestimmen, wenn man nicht diesseits und jenseits ist. Also ist unmöglich die Gränze der Erkenntniß zu bestimmen, wenn wir nicht auf irgend eine Weise (wenn gleich nicht erkennend) jenseits derselben hingelangen können. “Kritische Friedrich-Schlegel-Ausgabe, Bd. XVIII, S. 521 [23]. Vgl. dazu Manfred Frank: Einführung in die frühromantische Ästhetik, Frankfurt am Main 1989, S. 288 f.

60 Vgl. GW S. 20, 80 f., § 44. Das Problem, ob sowohl Hegels Argumente der Grenzüberschreitung jeder Grenzsetzung als auch das angebliche Wissen vom Nicht-Gewussten am „Ding an sich“ valide sind, diskutiert, mit Verweis auf Inwood, Graeser: Kommentar zur Einleitung zur Phänomenologie des Geistes, S. 54.

61 Wie Förster überzeugend gezeigt hat, kennt Kant in Bezug auf den Begriff der Antinomie durchaus ein nicht nur grenzensetzendes, sondern platonisch-dialektisch grenzenüberschreitendes, den vorherigen ausschließenden Gegensatz in einen höheren Begriff integrierendes antinomisches Verfahren - nämlich in der Antinomie der praktischen Vernunft (Förster: Die 25 Jahre der Philosophie, S. 130-132) -, nur kommt es eben in Bezug auf den Begriff des „Ding an sich“ nicht zum Tragen. 
wie Hegel geschrieben hat, „die leere Form der Entgegensetzung, objektiv ausgedrückt“ (GW 4, S. 5): also die Bestimmtheit des „Anderen überhaupt“, die zugleich die einzige Bestimmung der Nicht-Bestimmtheit in sich trägt, weil sie als gänzlich unerkennbar markiert ist ${ }^{62}$. Es sind dabei drei Hauptargumente, die bei Kant dafür zu finden sind, ein „Ding an sich“ als Unerkennbares trotzdem annehmen zu müssen:

1) „[D]ie Vorstellung von etwas Beharrlichem im Dasein ist nicht einerlei mit der beharrlichen Vorstellung; denn diese kann sehr wandelbar und wechselnd sein, wie alle unsere und selbst die Vorstellungen der Materie, und bezieht sich doch auf etwas Beharrliches, welches also ein von allen meinen Vorstellungen unterschiedenes und äußeres Ding sein muß“ (KrV, B XLI, Anm.). Da die einzelnen Vorkommnisse der Empfindung und Anschauung, so Kant, per definitionem nicht beharrlich, sondern ,in den Sog der Rekurrenz hineingezogen“63 sind, d. h. ständig auftauchen und verschwinden (weil sie zeitlich strukturiert sind), ein Beharrliches jedoch im Prozess des Objektbezuges vorhanden ist, wo wir bspw. demselben Gegenstand nacheinander verschiedene Eigenschaften zuschreiben, muss das Beharrliche jenseits der Repräsentationsvorkommnisse zu finden sein. Auch wenn man laut Kant also ,zu solchen Objekten keinen anderen Zugang als den repräsentationalen über die Inhalte in Anschauungsvorkommnissen“"64 finden kann und sie deshalb nur von innen als Externes markiert werden können, ist ihre Annahme als unabhängig existierende absolut notwendig, um das interne Funktionieren des transzendentalen Apparates, wie er faktisch vorliegt, erklären zu können. Dass „dieser Begriff [...] für Gegenstandserkenntnis ganz unverzichtbar“65 ist, folgt somit daraus, dass ein Etwas als „Correlatum [...] zur Einheit des Mannigfaltigen in der sinnlichen Anschauung“ (KrV, B 306/KrV, A 250) gedacht

62 Horstmann (Was bedeutet Kants Lehre vom Ding an sich für seine transzendentale Ästhetik?, S. 38 -44) diskutiert eine These der Kant-Forschung (Paul Guyer), die aufzuzeigen versucht, dass Kant darüber hinaus bei der Begründung des subjektiven Charakters der Raumvorstellung Aussagen über Eigenschaften des „Ding an sich“ macht: nämlich indem die Nicht-Räumlichkeit und die Nicht-Zeitlichkeit der Dinge an sich nicht als nur denknotwendiger Schluss aus dem subjektivapriorischen Charakter von Raum und Zeit abgeleitet würden, sondern umgekehrt der subjektive Charakter der Schluss aus der Nicht-Räumlichkeit und der Nicht-Zeitlichkeit der „Dinge an sich“ sei; damit aber würde sich Kant auf eine Erkenntnisaussage bezüglich der „Dinge an sich“ und ihrer Eigenschaften festlegen. Horstmann kritisiert diese These zwar aus gutem Grund, jedoch macht ihre prinzipielle Anerkennbarkeit als Position in der Kant-Forschung klar, dass das nachkantianische Unbehagen an der kategorialen Ambivalenz des „Ding an sich“-Begriffs bis heute nicht verstummt ist.

63 Schönrich: Externalisierung des Geistes, S. 147.

64 Schönrich: Externalisierung des Geistes, S. 145.

65 Honnefelder: Scientia transcendens, S. 453. 
werden muss, damit die Erscheinung selbst nicht zu einem bloß Gedachten verkommt, von dem sie sich vielmehr in der Differenz von Denken und Erkenntnis als Gegenstand ja gerade unterscheidet. Zugleich jedoch ist dieser letztgenannte Aspekt der intentionalen Differenz von Vorstellung und Inhalt natürlich essenziell: „Denn sonst würde der ungereimte Satz daraus folgen, daß Erscheinung ohne etwas wäre, was da erscheint.“ (KrV, B XXVIf.) ${ }^{66}$ In der Auflage A heißt es weiterhin:

Dies war das Resultat der ganzen transzendentalen Ästhetik, und es folgt auch natürlicher Weise aus dem Begriffe einer Erscheinung überhaupt: daß ihr etwas entsprechen müsse, was an sich nicht Erscheinung ist, weil Erscheinung nichts vor sich selbst, und außer unserer Vorstellungsart sein kann, mithin, wo nicht ein beständiger Zirkel herauskommen soll, das Wort Erscheinung schon eine Beziehung auf Etwas anzeigt, dessen unmittelbare Vorstellung zwar sinnlich ist, was aber an sich selbst, auch ohne diese Beschaffenheit unserer Sinnlichkeit, (worauf sich die Form unserer Anschauung gründet), Etwas, d.i. ein von der Sinnlichkeit unabhängiger Gegenstand sein muß. (KrV, B 308/KrV, A 251f.)

In dieser Hinsicht fungiert der „Ding an sich“-Ausdruck in doppelter Semantik: Zum einen sichert er den „stofflichen Affektionsgrund“67 der Erscheinungen, d.h. die Dimension ihrer genetisch-kausalen Situiertheit in den materialen Tatsachenverhältnissen der Welt sowie die intentionale Gefülltheit der Vorstellungen als nicht bloß zufällige, von bloßen Einbildungen nicht zu unterscheidende Zustände. Zum anderen bildet er als „identische Substanz hinter den individuell verschiedenen und veränderlichen Wahrnehmungsobjekten“ (essentia) die „Totalität der Bedingungen“68 des Wissbaren vom einzelnen Gegenstand, d.h. den vollständigen, wahrhaften Erkenntniszusammenhang der Erscheinungen und damit deren „substantiale Wesenheit“69: die epistemische Norm dafür, dass das vom Einzelnen Gewusste zumindest prinzipiell einem Wesen der Sache entspricht. Schon von diesen Funktionen her ist klar, dass der „Ding-an-sich“-Ausdruck

66 Vgl. Sandkaulen: Das leidige Ding an sich, S. 196. Vgl. auch die klaren Aussagen in der Grundlegung zur Metaphysik der Sitten, wo es heißt: „Es ist eine Bemerkung, welche anzustellen eben kein subtiles Nachdenken erfordert wird [...], daß alle Vorstellungen, die uns ohne unsere Willkür kommen (wie die der Sinne), uns die Gegenstände nicht anders zu erkennen geben, als sie uns afficiren, wobei, was sie an sich sein mögen, uns unbekannt bleibt [...]. Sobald dieser Unterschied [...] einmal gemacht ist, so folgt von selbst, daß man hinter den Erscheinungen doch noch etwas anderes, was nicht Erscheinung ist, nämlich die Dinge an sich, einräumen und annehmen müsse [...]. Dieses muß eine, obzwar rohe, Unterscheidung einer Sinnenwelt von einer Verstandeswelt“ (Grundlegung, AA, 4, S. 450 f., dazu auch Prol. AA, 4, S. 337) abgeben.

67 Gerd Irrlitz: Kant-Handbuch. Leben, Werk, Wirkung, Stuttgart/Weimar 2002, S. 176.

68 Irrlitz: Kant-Handbuch, S. 173.

69 Irrlitz: Kant-Handbuch, S. 176. 
notwendigerweise nicht bloß ein semantischer Überschuss des Erscheinungsbegriffs sein kann, sondern tatsächlich die Realität seines Begriffsinhalts als $B e$ dingung der Erscheinungen meinen muss. Dass dafür die Kategorie der Substanz über die Grenzen ihres Gebrauchs in der Welt der Erscheinungen hinaus auf die Welt der Dinge an sich erweitert werden muss, ist ebenso notwendige Konsequenz des gesamten Arguments - doch bei Weitem nicht das größte Problem. Birgit Sandkaulen hat nämlich en détail vorgeführt, dass zur „Rettung“ der Affektionslehre durch das „Ding an sich“ eben nicht auf bestimmte explizite und implizite Vorschläge Kants zurückgegriffen werden kann, die das Sprengpotenzial des affizierenden „Ding an sich“ gegen den Theorierahmen wieder kassieren könnten, indem sie das affizierende Ding mit Instanzen oder Vorkommnissen innerhalb der transzendentalen Subjektivität identifizieren. Erstens können „die als affizierend behaupteten Gegenstände“70 nicht identisch sein mit der „Vorstellung vom Gegenstand = X“, die Kant in der „A-Deduktion“ als „Einheit von Gegenständlichkeit überhaupt“ (analog zur transzendentalen Einheit der Apperzeption) kennzeichnet: Als ,gänzlich unbestimmte[r] Gedanke von Etwas überhaupt“ (KrV, B 309/KrV, A 253) ist ihnen eine bestimmte Affizierung bestimmter Empfindungen und Wahrnehmungen auch als Selbstaffektion nicht sinnvoll abzugewinnen ${ }^{71}$. Zweitens aber - und in der Forschung als „Verteidigungsversuch“ weitaus prominenter ${ }^{72}$ - kann auch der Bezug auf Kants Aussagen zum „Noumenon“ hier nicht weiterhelfen. Zwar bezeichnet Kant in der Tat mit dem Begriff des „Noumenon“ in der „Amphibolie der Reflexionsbegriffe“ ausdrücklich einen Begriff des Verstandes, der nicht in der Gefahr steht, ,sein eigenes Feld zu erweitern“, weil Kant mit diesem Begriff nicht ,auf Dinge an sich selbst zu gehen“ wagt, sondern lediglich „einen Gegenstand an sich selbst [meint, C.W.], aber nur als transzendentales Objekt, das die Ursache der Erscheinung (mithin selbst nicht Erscheinung) ist, und weder als Größe, noch als Realität noch als Substanz etc, gedacht werden kann“ (KrV, B 344). Dieser Begriff des Verstandes ist rein funktional dafür da, innerhalb der Grenzen des Verstandes dessen Innen auszumessen: „Da wir aber keine von unseren Verstandesbegriffen darauf anwenden können, so bleibt diese Vorstellung doch für uns leer, und dient zu nichts,

70 Sandkaulen: Das leidige Ding an sich, S. 190. Verwirrenderweise fasst Kant sowohl diese Einheit von „Gegenständlichkeit überhaupt“, das Noumenon und auch das eigentlich-reale „Ding an sich“ gelegentlich unter dem Begriff „transzendentaler Gegenstand“ bzw. „transzendentales Objekt“" zusammen. Umso wichtiger ist die Differenzierung, die Sandkaulen herausgearbeitet hat. 71 So wird freilich Fichte dann argumentieren; vgl. Sandkaulen: Das leidige Ding an sich, S. 196 201.

72 Vgl. die Hinweise auf die so verfahrende Forschung bei Sandkaulen (Das leidige Ding an sich, S. 192). 
als die Grenzen unserer sinnlichen Erkenntnis zu bezeichnen, und einen Raum übrig zu lassen, den wir weder durch mögliche Erfahrung, noch durch den reinen Verstand ausfüllen können.“ (KrV, B 345) Noumena sind so bloße Funktionen des reinen Denkens und nirgends des Erkennens: Man würde wohl heute von „Gedankenexperimenten“ sprechen. In Bezug auf sie wird von den Kategorien nur ein rein transzendentaler Gebrauch gemacht (Kant spricht vom „reine[n] Gebrauch der Kategorien“, KrV, A 253), der als unschematischer Gebrauch derselben diese nicht auf Anschauungen oder sinnliche Vorstellungen bezieht, sondern bloß die Denkmöglichkeiten der Grenzen des Denkens durchreflektiert. Doch auch dieser Begriff des Noumenon kommt für den Affektionsgrund der sinnlichen Empfindungen als tragendes Konzept nicht infrage: Denn in diesem Begriff wird die Wirksamkeit eines affizierenden Gegenstandes zu einer bloß logischen Möglichkeit eines in sich selbst hochproblematischen Grenzbegriffs ${ }^{73}$. Die reine Denkmöglichkeit einer Ursache aber kann nicht selbst die Rolle realer Affektionsursachen einnehmen: Notwendige wirkliche Affektionsursachen können nicht in der Beschreibung reiner Möglichkeiten gedacht werden. Den affizierenden Dingen an sich kommen mithin Bestimmungen zu, die weder die „Vorstellung vom Gegenstand = X“ noch das „Noumenon“ integrieren können; mit der Berufung auf diese Begriffe lässt sich das Problem des „Ding an sich“ also nicht lösen.

So widerlegt sich m. E. auch der Versuch, gegen die freilich falsche Fassung der „transzendental-metaphysische[n] [...] Position [...] als ,Zwei-Welten-Sicht [...] der Dinge an sich“74 den Unterschied von Erscheinungen und „Dingen an sich“ als einen rein funktionalen, bloß logischen oder gar $\mathrm{zu}$ vernachlässigenden innerhalb der Frage nach dem Zusammenhang von sinnlicher Anschauung und Denken zu verstehen, der keine systemsprengenden Kräfte freisetzen würde. Denn es ist gerade durch das Ausschlussverfahren hinsichtlich der Kandidaten für das „Ding an sich“ sichtbar geworden, dass der begriffliche Unterschied nicht als völlig beziehungslos auf einen notwendigen Unterschied der entsprechenden Verhältnisse des Denkens auf ein außerhalb seiner gelegenes Reales gedacht werden kann - auch wenn diese Denkverhältnisse selbst nicht das Thema der kantischen Erörterungen sind ${ }^{75}$. „Dinge an sich“ müssen als außerhalb der Gel-

73 Vgl. Sandkaulen: Das leidige Ding an sich, S. $191 \mathrm{f}$.

74 Horstmann (Was bedeutet Kants Lehre vom Ding an sich für seine transzendentale Ästhetik?, S. 44-48, hier: S. 44) argumentiert für eine solche Beschränkung der Lesart des „Ding an sich“ und verweist auf weitere Literatur zum Thema.

75 Es ist hier also nochmals darauf hinzuweisen, dass Kants Lehre vom „Ding an sich“ nicht einfach ontologisch-metaphysisch im Sinne einer Zwei-Welten-Lehre verstanden wird. Gesagt wird nur, dass die Bedeutungsunterschiede, die Kant zwischen „Ding an sich“ und „Erschei- 
tungsbedingungen der transzendentalen Subjektivität gleichwohl existierende Korrelate der sinnlichen Erfahrung gedacht werden, d.h. die Annahme ihrer Realität ist selbst denknotwendig für den Begriff des Gehalts sinnlicher Erfahrung, damit dieser nicht selbstwidersprüchlich wird. Kant argumentiert epistemologisch: Es gibt zu diesen „Dingen an sich“ keinen erkennenden Zugang, der die für Erkenntnisaussagen notwendigen transzendentalen und empirischen Elemente hinreichend verknüpft; gleichwohl müssen sie gedacht werden als unerkennbar. Es ist zuzugestehen, dass Kant sicher darauf abzielte, seine ontologischen wie epistemologischen Aussagen zum „Ding an sich“ einer Programmatik des nicht-metaphysischen und nicht-epistemologischen Denkens des „Ding an sich“ als bloß funktionalem Ausdruck einer negativen Beschreibung des Erkenntnisvorgangs unterzuordnen bzw. diese Aussagen darin aufgehen - oder wenigstens verschwinden - zu lassen. M. E. gelingt dies jedoch nicht: Deshalb ist die Anwendung einer eigenständigen Dimension der Realität auf die Welt des „Ding an sich“ nicht nur gerechtfertigt, sondern aus der Logik der grundbegrifflichen Unterscheidungen Kants heraus sogar denknotwendig. Diese Denknotwendigkeit jedoch ist selbst noch keine positive ontologische Behauptung und droht daher auch nicht, von sich aus in eine einfache ontologische Zwei-WeltenLehre abzurutschen: Sie betrifft einzig den Begriffszusammenhang dessen, was als Verbindung von Realität ${ }_{1}$ und Realität ${ }_{2}$ als Komplex des „Realen überhaupt“ gefasst wird. Kant sagt klar, dass seine Kritik der reinen Vernunft „das Object in zweierlei Bedeutung nehmen lehrt, nämlich als Erscheinung oder als Ding an sich selbst“ (KrV, B XXVII), die als „zwei Seiten“ (KrV, B 566) desselben Wesens zu verstehen sind. Die sich daraus ergebende Kritik der These einer Zwei-WeltenLehre bei Kant und das Beharren auf der „one-world interpretation“76 darf jedoch nicht dazu führen, diese eine Welt als notwendig geschlossen und begrifflich kohärent anzunehmen. Das ist sie bei Kant eben nicht: Die Beschreibungen und Funktionszusammenhänge von $\mathrm{R}_{1}$ und $\mathrm{R}_{2}$, obwohl sie grundsätzlich als „Teile“ (KrV, B 574) des einen Realitätsbegriffs gefasst sind, fügen sich nicht zu einer kohärenten und konsistenten Beschreibung zusammen. Dies liegt, wie bisher gesehen, vor allem an den Problemen der Affektionstheorie der $\mathrm{R}_{1}$-Ebene und den sich aus ihr ergebenden Problemen des Begriffs der realen Bestimmtheit. Ich plädiere also dafür, das Aufgeben der veralteten „Zwei Welten“-Kritik an Kant nicht mit dem Verschwinden der Probleme zu verknüpfen, die in dieserKritik auch artikuliert worden sind.

nungen“ entwickelt, als korrelativ-referenziell auf Unterschiede im Bereich der korrespondierenden Gegenstände bezogen gedacht werden müssen.

76 Colin Marshall: „Kant's One Self and the Appearance/Thing-in-itself Distinction“, in: KantStudien 4 (2013), Jg. 104, S. 421-441, hier: S. 422. 
2) Kant knüpft in diesem Zusammenhang die „Erfahrung“ der Selbstgewissheit des Ich als Existenzgewissheit „[m]eines Daseins in der Zeit“, d.h. die Selbstgegenwart des „empirischen Bewußtsein[s] meines Daseins“ (KrV, B XL, Anm.), an die sich daraus notwendig ergebende Gewissheit eines „Wirkliche[n] außer mir“ (KrV, B XL, Anm.). „[D]ie Realität desselben, zum Unterschiede von der Einbildung“ (KrV, B XL, Anm.), beruht dann darauf, dass die empirische Daseinsgewissheit des Ich als Faktum jeder Erfahrung einzig in Bezug auf ein Anderes, das dafür ebenfalls existieren muss, um dieses Andere zu sein, gegeben sein kann. Zwar ist bei Kant, wie Dieter Henrich gezeigt hat, das Bewusstsein der eigenen Subjektidentität eine ganz eigenständige „Art von Wirklichkeit, die weder die der Gegebenheit von Vorstellungen noch die der Objekte der Erkenntnis ist" ${ }^{\text {"77, }}$ trotzdem aber ist das Ich nur in ursprünglicher Wechselwirkung mit Anderem wirklich; Selbstbewusstsein ist keine selbstgenügsame, sich selbst erzeugende Wirklichkeit, sondern Grund wie zugleich Folge einer ursprünglichen Wechselkonstitution mit einem Anderen außer ihm. Aus der vorliegenden Wirkung, der empirischen Gewissheit der eigenen Existenz, wird auf die notwendige Wirklichkeit der Ursache, nämlich eines existierenden Anderen außer dem Ich, geschlossen. Dass dies aber auch dann noch im Rahmen von Kants System im Positiven undenkbar bleibt, obwohl es positiv gedacht wird, wenn auf diese Weise aus der Logik der Genese des Ich auf seine Notwendigkeit geschlossen worden ist, wird hier und auch an anderer Stelle bei Kant nicht thematisiert.

3) Gerhard Schönrich hat einen interessanten Vorschlag gemacht, um aus der Zeichenlogik von Kants Theorie des Selbstbewusstseins einen weiteren Beleg für die Existenz des „Ding an sich“ abzuleiten, der bei Kant angelegt, aber nicht ausformuliert sei. „Die Repräsentation eines Repräsentierten ist immer auch eine Selbstrepräsentation“78: Denn die auf Objekte bezogenen Vorkommnisse der Anschauung repräsentieren in diesem Bezug nicht nur die Objektinhalte, sondern auch immer - diese Selbstbezüglichkeit ist Ausdruck der Form des Selbstbewusstseins („Ich denke“), die alle Repräsentationen an sich tragen - sich selbst als repräsentierende. Folglich unterscheiden alle Repräsentationen an sich selbst ihre Objektinhalte und die Art und Weise ihrer Repräsentation. „Nur eine Repräsentation, die sich selbst als Repräsentation von dem unterscheidet, auf das sie sich bezieht, die also zur Selbstrepräsentation wird, kann diesen Bezug auch als ein dem Repräsentiertsein externes Etwas anzeigen“"79: Damit ist gesagt, dass

77 Dieter Henrich: Das Ich, das viel besagt. Fichtes Einsicht nachdenken, Frankfurt am Main 2019, S. 294.

78 Schönrich: Externalisierung des Geistes, S. 148.

79 Schönrich: Externalisierung des Geistes, S. 148. 
die Repräsentation an sich selbst anzeigt, dass sie mehr sei als nur eine Repräsentation. „Daß es ein externes Etwas gibt, kann so immerhin von der Innenseite der Repräsentation aus angezeigt werden“80: Das aber löst das Problem, ob und wie dieses Externe widerspruchsfrei zu denken ist, in keiner Weise, sondern erhöht im Gegenteil die Dringlichkeit, es als unabweisbare Evidenz des Denkens auch wirklich zu denken. Dem schon von den Zeitgenossen (Fichte, Schelling, Jacobi, Hegel) immer wieder kritisierten Problem des Verstoßes gegen die eigene Systemlogik entkommt Kant also nicht (vgl. dazu näherhin die Kapitel zum „Ding an sich“). Denn einerseits behauptet Kant, dass „der Gebrauch der Kategorien keinesweges über die Grenze der Gegenstände der Erfahrung hinausreichen“ (KrV, B 308) darf. Andererseits wird das „Ding an sich“ zum einen (wie bereits gezeigt wurde) als Beharrliches in der Art der Substanz gedacht, ohne das der Wechsel der Empfindungsvorkommnisse nicht denkbar ist, zum anderen als notwendig zu denkender Anstoß (Affektion) für die Empfindung und so die Logik des Verstandes „negativ erweitert“, ohne dafür wiederum begriffliche Regeln bezüglich des Gesamtzusammenhangs von $R_{1}$ und $R_{2}$ anbieten zu können. Dass etwas mit Beziehung auf unsere Vermögen nicht zugleich als es selbst in Unabhängigkeit von unseren Vermögen erscheinen kann, wenn beide Beziehungen sich unvermittelt gegenüberstehen, erscheint demnach als Zentralproblem dieser Argumentation. Kants verschwiegener, unüberbrückbarer (d.h. i.S. Hegels: abstrakter) Grundgegensatz von „An-sich“ und „Für-uns“81 wird deutlich, wenn er davon spricht, dass die „Gegenstände[] an sich selbst“ zu denken bedeutet, „ohne ihr Verhältniß auf unsere Anschauung“ (KrV, § 6, B 52). Dass etwas aber an sich im Raum des epistemologischen Für-Andere sein kann, dass sich also ein Ansichsein für Andere öffnen bzw, geben' kann, ohne durch dieses Andere, dem es sich als repräsentationaler Gehalt gibt, immer schon vollständig geformt, überformt und überschrieben zu sein, wäre ein adäquater Begriff von Realität. Denn dieser nimmt den Überschreitungsvektor der notwendigen inneren Unterschiede des Begriffs von Realität ernst, den Kant jedoch aus der Formation seiner terminologischen Grundunterscheidungen heraus nicht konsequent denken kann und

80 Schönrich: Externalisierung des Geistes, S. 148.

81 Darin liegt das platonische Erbe Kants: Die von Platon als „Charaktere“ eingeführten Metabestimmungen der megisté gené, „Ansichsein“ (auta kata auta) und „Beziehung auf Anderes“ (pros heteron), die bei Platon gebraucht werden, um das Problem der kategorialen Eigenständigkeit der Kategorie des „Verschiedenen“ zu lösen, sind auch bei Kant als abstrakter Gegensatz und damit als unvermittelbarer wechselseitiger Ausschluss (Hegel würde dies „seinslogisch“ nennen) definiert (Platon: Sophistes, S. 133 [255c-d]). 
folglich stets auf $\ddot{a} u ß e r e$ Unterschiede begrenzt ${ }^{82}$. In Kants Gebrauch der Formulierung des „An-sich“ wird der „Reflexionsausdruck“, der das „An-sich“ eigentlich - auch gemäß seiner scholastischen Quelle des „res per se spectata“ - sein soll, immer wieder auf nicht-reflektierte Weise mit dem ontologischen Gebrauch ineinandergeschoben oder zumindest auf diesen hin geöffnet, d.h. an entscheidender Stelle dort unterbestimmt, wo er die ontologische Lesart positiv ausschließen sollte ${ }^{83}$. Das Ding ,an sich selbst betrachtet ${ }^{\star}$, d.h. nur unter der Perspektive seines Unabhängigseins gedacht, korrespondiert nämlich stets mit einem Seinsaspekt, der das reale Gegebensein dieses Betrachteten als ebenfalls notwendig zu denken mitführt und sogar als Bedingung dieses Gedacht-werdenKönnens impliziert. Hegel hat in der Logik diesen Aspekt bei Kant, gemäß der von ihm entwickelten Logik des Scheins, als eine „leere Bestimmung“ (GW 11, S. 246) der Erscheinung bezeichnet: Weil Kant die notwendig zu denkende reale Beziehung der Erscheinungswelt auf ein in ihr erscheinendes Wesentliches nicht widerspruchsfrei denken kann, lädt er stattdessen die Erscheinung mit den Charakteristika des Seins auf, um ihr eine logische Stabilität zu verleihen, ohne die sie sonst gänzlich haltlos wäre. So ist die Logik der Erscheinung „nur aus dem Seyn in den Schein übersetzt worden“ (GW 11, S. 247), um durch die Charakteristika einer

82 Adorno hat in seiner Kant-Vorlesung das Grundproblem des „Ding an sich“ konzise, wenn auch in der Terminologie der alten „Zwei-Welten-Theorie“-Lesart umrissen: „[I]n der ,Kritik der reinen Vernunft heißt ,Ding an sich“ zunächst einmal soviel wie: die uns gänzlich unbekannte und unbestimmte Ursache unserer Erscheinungen, die Ursache der Affektionen, die Ursache der sinnlichen Daten, - von denen ich Ihnen gesagt habe, daß sie selber auch noch als ein ganz Unbestimmtes gefaßt würden, die aber bei Kant als durch ein solches unbekanntes Ding verursacht aufgefaßt werden. Wie Kant dazu kommt, überhaupt ein solches unbekanntes Ding zu postulieren und gar zwischen ihm und unseren Erlebnissen Kausalität zu postulieren, während die Kausalität bei ihm doch lediglich eine immanente Kategorie, also eine Kategorie der Ordnung unserer Phänomene ist und nicht etwa eine Kategorie, die sich auf Tranzendentes, der Erfahrung Unzugängliches bezieht, - das möchte ich Ihnen jetzt nicht noch einmal sagen. Ich glaube, ich habe Ihnen darüber bereits genug gesagt, indem ich Ihnen gezeigt habe, daß die scheinbar dogmatische Voraussetzung des Dinges bei Kant keinen anderen Grund hat als den, daß er gewissermaßen der Reduplikation der Erkenntnis mit sich selbst entgehen wollte; daß er festhalten wollte an einem Begriff von Wirklichkeit, der nicht identisch ist: der also nicht einfach mit dem Bewußtsein selber zusammenfällt.“ (Theodor W. Adorno: „Kants Kritik der reinen Vernunft“ (1959), in: Ders.: Nachgelassene Schriften, Bd. IV, 4, hg.v. Rolf Tiedemann, Frankfurt am Main 1995, S. $141 \mathrm{f}$.)

83 Vgl. dazu und zum ontologischen, reflexionslogischen, definitorischen und epistemologischen Sinn von „An sich“ Graeser: Kommentar zur Einleitung in die Phänomenologie des Geistes, S. 40 f. Auch Otfried Höffe (Immanuel Kant, 8. Auflage, München 2014) betont die irreduzible Doppelperspektive Kants sowohl einer Zwei-Welten-Lehre als auch einer Zwei-Welten-Perspektive. Irrlitz (Kant-Handbuch, S. 168-176) klärt über die Traditionshorizonte der „Ding an sich“Vorstellung auf. 
durch sich bestehenden seienden Substanz, „un mittelbar bestimmtes“ (GW 11, S. 247) zu sein, eben die Festigkeit als Raum des Realen zu gewinnen, die ihr durch ihre unsichere Beziehung auf das „Ding an sich“ wegzubrechen droht ${ }^{84}$.

Gerade an Kants eigener Begründung der subjektiven Idealität der Anschauungsformen wird dieses Problem sichtbar. Denn wie Kant sinnvollerweise argumentiert, kann der Raum nichts von den Dingen Abstrahiertes sein, weil die Rede von Gegenständen, also der rein formelle Begriff von „Gegenständlichkeit überhaupt“, Räumlichkeit bereits voraussetzt. Raum ist das Prinzip des Andersseins und des Unterscheidens von Gegenständen an sich: „Die Möglichkeit also der äußeren Wahrnehmung als solcher setzt den Begriff des Raumes voraus und erzeugt ihn nicht“ (AA, 2, § 15, S. 402). ${ }^{85}$. Fichte hat die Logik dieser Einsicht aufgenommen und wiederum als Prinzipienhaftigkeit des Ich für das Nicht-Ich überhaupt gefasst ${ }^{86}$. Das aber bedeutet, dass sich die Ausschließlichkeit der transzendentalen Idealität des Raumes selbst negiert bzw. auf ihr Anderssein überschreitet: dort nämlich, wo Kant von „Dingen an sich“ bzw. von an sich gegebenen Dingen in räumlichen Begriffen, $d$.h. im Unterschied zueinander und zum Subjekt, spricht - in seiner Theorie der Affektion. Denn so macht er selbst deutlich, dass die Bestimmtheit des Raumes bzw. die Bestimmtheit des Unterschiedenseins gegenständlicher Entitäten notwendig als das Subjekt und das Ding an sich übergreifend zu denken ist (als An-sich im und zugleich gegen das Für-uns ${ }^{87}$ ): Sie macht einen Unterschied aus, der jedem anderen Unterschied (auch dem von Subjekt und „Ding an sich“, Für-uns und An-sich) notwendig vorgelagert ist und diesen erst ermöglicht. Ob diese inferentialistische Überschreitungsbewegung des

84 Vgl. dazu Christian Iber: Metaphysik absoluter Relationalität. Eine Studie zu den beiden ersten Kapiteln der Wesenslogik, Berlin 1990, S. $78-82$.

85 Im Original Latein: „Possibilitas igitur perceptionum externarum, qua talium, supponit conceptum spatii, non creat.“ Vgl. Förster (Die 25 Jahre der Philosophie, S. 77-85), der zeigt, wie die Konstruktion eines Raumschematismus in den Anfangsgründen die Transzendentalphilosophie vollendet, wegen ihrer Aporien (Förster: Die 25 Jahre der Philosophie, S. 85) bei Kant aber unvollendet bleibt.

86 „Es ist die gewöhnliche Meinung, daß der Begriff des Nicht-Ich ein diskursiver, durch Abstraktion von allen Vorgestellten entstandner Begriff sey. Aber die Seichtigkeit dieser Erklärung läßt sich leicht darthun. So wie ich irgend etwas vorstellen soll, muß ich es dem Vorstellenden entgegensetzen. Nun kann und muß allerdings in dem Objekte der Vorstellung irgend ein X. liegen, wodurch es sich als rein Vorzustellendes, nicht aber als das Vorstellende entdekt: aber daß alles, worin dieses X. liege, nicht das Vorstellende, sondern ein Vorzustellendes sey, kann ich durch keinen Gegenstand lernen; vielmehr gibt es nur unter Voraussetzung jenes Gesetzes erst überhaupt einen Gegenstand.“ (GA I,2, S. 267)

87 Vgl. Förster (Die 25 Jahre der Philosophie, S. 22f.): Kants Begründung, warum der Raum nicht auch wirklich-objektiv sein kann, hat das Problem, dass sie innerhalb der Logik der Ideen und damit innerhalb der Bedingungen eines subjektiven Vermögens vollzogen wird. 
Realen als dinghaftes Anderssein nun im Paradigma „Raum“ gedacht wird oder nicht, spielt demgegenüber sogar eine untergeordnete Rolle. Dass allerdings in diesem Kontext eben die Logik des Raumes notwendig transgressiv ist, zeigt auch Kants „Widerlegung des Idealismus“ (KrV, B 274ff.), welche den „Skandal der Philosophie und der allgemeinen Menschenvernunft, das Dasein der Dinge außer uns (von denen wir doch den ganzen Stoff zu Erkenntnissen, selbst für unseren inneren Sinn her haben,) bloß auf Glauben annehmen zu müssen“ (KrV, Vorrede, B XL, Fußnote), beseitigen will. Das transzendentale Argument gegen diesen „materialen“ Idealismus - sowohl in seiner „problematischen“ (Descartes) als auch in seiner „dogmatischen“ (Berkeley) Form (vgl. KrV, B 274) - koppelt nun gerade die Gleichursprünglichkeit und Wechselbegründung von Selbstbewusstsein und Weltbewusstsein, wie sie in der großen Fußnote zur Vorrede B erstmals klar entworfen worden war (KrV, Vorrede, B XL, Fußnote), an ein letztes, beharrliches Substrat der Außenwelt:

Ich bin mir meines Daseins als in der Zeit bestimmt bewußt. Alle Zeitbestimmung setzt etwas Beharrliches in der Wahrnehmung voraus. Dieses Beharrliche aber kann nicht etwas in mir sein, weil eben mein Dasein in der Zeit durch dieses Beharrliche allererst bestimmt werden kann. Also ist die Wahrnehmung dieses Beharrlichen nur durch ein Ding außer mir und nicht durch die bloße Vorstellung eines Dinges außer mir möglich. (KrV, B 275)

„Beharrlichkeit“ und „Außer-uns-sein“ als dessen notwendige Begriffsbestimmungen verorten das „Ding an sich“ in einer Realität des Raumes, die gemäß dem Argument Bedingung für die subjektive Realität der Erscheinungen in den Anschauungsformen Zeit und Raum ist. Damit aber ist die Notwendigkeit angezeigt, dem Verhältnis von Subjekt und Realgrund seiner Vorstellungen („Ding an sich“) eine selbst realbestimmte Form räumlichen Gegebenseins zu geben, die der Form seiner transzendentalen Ausstattung (Anschauungsformen - Kategorien) immer schon vorhergeht.

Wie problematisch diese kantische Konstruktion angelegt ist, lässt sich sehr gut an den neueren Lösungsversuchen dieses Problems und ihrer selbst problematischen Argumentation ablesen. Wilfrid Sellars wirkungsmächtige Auseinandersetzung mit Kants Erkenntnistheorie in Empiricism and the Philosophy of Mind (1956), vor allem aber in Science and Metaphysics. Variations on Kantian Themes $(1967)^{88}$ ist von der Idee getragen, Kant gerade vor der Anklage des „myth of the given“ in Schutz zu nehmen. Anders als der traditionelle Empirismus verfalle Kant nicht in den logischen Fehler, als Rechtfertigungsinstanz unseres Wissens ein

88 Wilfrid Sellars: Science and Metaphysics. Variations on Kantian Themes, Atascadero 1992. Vgl. dazu Dietmar H. Heidemann: Vom Empfinden zum Begreifen, S. 14-44. 
bloß sinnlich Gegebenes, nicht-epistemisch Empfundenes anzunehmen. Denn wo Kant konstatiere, dass ,der Verstand [...] nichts anzuschauen und die Sinne nichts zu denken“ (KrV, B 75) vermögen, weil „Gedanken ohne Inhalt [...] leer, Anschauungen ohne Begriffe [...] blind“ (KrV, B 75) sind, da sei ersichtlich, dass erkennender Weltbezug immer schon auf begriffliche Strukturen zurückgreife und nicht auf ein bloß unmittelbar-sinnlich Gegebenes („naturalistic fallacy“). Doch damit wird in Bezug auf den Begriff der Realität das Problem bei Kant mehr verdeckt als kenntlich gemacht oder gar gelöst. Sellars bemüht sich, vor allem in Science and Metaphysics, die Stufen zwischen der unbegrifflichen, unmittelbaren Empfindung und dem Urteilswissen bei Kant mittels Unterscheidungen wie „sinnliche Vorstellungen - anschauliche Vorstellungen“ etc. derart weiter auszudifferenzieren, dass sich der Gegensatz von Sinnlichkeit und Verstand einem Kontinuum ihrer jeweiligen Verschränkung annähert. Dadurch aber bleibt das hier beschriebene normative Gefälle zwischen den Dimensionen von Genese und Geltung in Bezug auf einen verlässlichen Realitätsbezuge unberührt. Der Übergang von Realität $t_{1} \mathrm{zu}$ Bewusstsein, wo er möglichst unverzerrt gegeben ist in der Empfindung, bleibt der Transformation der Empfindungen in Wissen durch Anschauungsformen und Kategorien in gewissem Maße äußerlich. Der letzte (bzw. erste) Schritt, die letzte (erste) Vermittlung zwischen unmittelbaren Sinnesdaten und Proto-Wissen, d.h. durch begriffliche Strukturen vermittelte Anschauung, bleibt unbeeinflusst von den komplexen begrifflichen Formen auf sie folgender vermittelter Anschauung, weil sie weiter als erster Übergang vom Begriffslosen zum schwach Begrifflichen gedacht werden muss ${ }^{89}$. Wo Kant kein Anderssein des Begrifflichen bereits im unmittelbar Sinnlichen und damit im Realen selbst denken kann, weil sein „Begriff des Begriffs“ es nicht zulässt, Begrifflichkeit als etwas das Subjekt und das Reale in verschiedenen Formen Überspannendes zu denken, kann keine subjektive begriffliche Regel gedacht werden, die ,in ihrer Anwendbarkeit auf konkrete Anschauungen zugleich offen und spezifisch genug ist, um das durch den Begriff intendierte Objekt zu treffen. " ${ }^{\circ 0}$ John McDowells Auseinandersetzung mit Kant, die in gleicher Weise die protobegrifflichen

89 Deshalb sind die Argumente Kants, welche die Funktion der „Synthesis“ in Anschauung und Verstand als dieselbe bestimmt (KrV, B 104f.) bzw. Anschauung und Verstand aus einer gemeinschaftlichen „Wurzel“ hervorkommen sieht (KrV, B 863), keine Lösungen des Problems, weil diese Einheitsbegriffe nicht als primäre Verschränkungen, die immer schon wirksam sind, in Funktion gezeigt werden. Vgl. Heidemann (Vom Empfinden zum Begreifen, S. 40 f.), der genau diese von der Realität ${ }_{1}$ her unvermittelte Schwelle zwischen Empfindung und Anschauung markiert und zeigt, dass die Verschränkungen von Sinnlichkeit und Verstand bei Kant erst ab der zweiten Stufe der Anschauung komplett greifen.

90 Heidemann: Vom Empfinden zum Begreifen, S. 26. 
Strukturen unmittelbaren sinnlichen Weltbezuges zu denken versucht, bleibt ebenfalls an dieser hegelianischen Grenze stehen. Nur wenn man zeigen kann, wie das Zusammenspiel von sinnlichen Daten und begrifflichen Formen als Genese von realitätshaltiger Erkenntnis selbst im Objekt vorhergeht, ohne doch damit den Unterschied von objektivem Gehalt und subjektiven Erkenntnisstrukturen aufzuheben, ist die Chance gegeben, eine sinnvolle Realitätsnähe des Erkennens zugleich mit dem partiellen Unabhängigsein dessen, was man mit „Realität“ meint, zu denken. Es ist also zwar richtig, darauf hinzuweisen, dass Kants „kopernikanische Wende“ lautet: Nicht wir richten uns nach den Dingen, sondern die Dinge richten sich nach uns - d.h. sie lautet nicht so: Wir richten die Dinge nach uns. Doch dieses programmatische Bekenntnis, dass es einen aktiven Anteil der Dinge an sich gäbe, der selbst sich nach unserer Beschreibung ausrichte, wodurch eine Adäquation gesichert sei, läuft zentralen Gedankenschritten der kantischen Argumentation zuwider und bleibt so letztlich ungeklärt.

Zum einen ist und bleibt, das machen die Terminologie der Affektionstheorie und die Logik des „Ding an sich“ klar, Kant so Vertreter des Begriffs eines „ontologischen Realismus“91, der sich in Form eines Rests nicht gänzlich wegerklären lässt, wenn er auch keine Zwei-Welten-Lehre impliziert. Zum anderen aber verfehlt er eine vernunftgemäße Beschreibung realistisch gedachter Objektivität, indem er auf abstrakte Weise das An-sich und das Für-uns, d.h. Sein und Bestimmbarkeit, auseinanderhält, ohne zu sehen, dass bereits der Akt der Unterscheidung beider einen dritten Standpunkt neben dem Für-uns und dem An-sich voraussetzt, in dessen Metasprache, die den gemeinsamen Grund beider Sphären enthält, sich allein die Objektivität beider Realitätssphären formulieren ließe. Nur so kann der Fehler vermieden werden, die Logik der Sprache, die zum Objekt werden soll, immer zugleich im Rücken zu haben und damit eine rein interne Unterscheidung eines Begriffsschemas zu einer externen zu machen. ${ }^{92}$

91 Schon Fichte (Zweite Einleitung in die Wissenschaftslehre, GA I,4, S. 236, Fußnote), spricht von einem „Kantischen Realismus“. Vgl. auch Manfred Frank: „Was heißt ,frühromantische Philosophie?"،, in: Athenäum 19 (2009), S. 15-43, hier: S. 42. Gerade die Einarbeitung der ersten Rezension der KrV durch Garve in den „Göttingischen Anzeigen von gelehrten Sachen“ in die Prolegomena hat - in Abwehr des Idealismusvorwurfs im Sinne Berkeleys - zur zumindest punktuellen, jedoch nicht durchgehenden und systematisch-konsistenten Betonung der Existenzbehauptung, d.h. des Realismus des „Ding an sich“, geführt. Vgl. dazu Förster: Die 25 Jahre der Philosophie, S. 59-64.

92 Davidson hat in der Kritik des Dualismus von Schema und Inhalt genau dieses Paradox nachgezeichnet (Davidson: On the Very Idea of a Conceptual Scheme, S. 183-198). Vgl. auch Wolfgang Detel: Geist und Verstehen. Historische Grundlagen einer modernen Hermeneutik, Frankfurt am Main 2011, S. 380 ff. Dabei hat Detel aufgezeigt, dass die vollständige Inkommensurabilität verschiedener Begriffsschemata, hier der des An-sich und des Für-uns, undenkbar und 
Ist aber das zweite, weil Vorstellung an sich selbst [...] ihren Gegenstand dem Dasein $\mathrm{nach}$ nicht hervorbringt, so ist doch die Vorstellung in Ansehung des Gegenstandes alsdann a priori bestimmend, wenn durch sie allein es möglich ist, etwas als einen Gegenstand zu erkennen. (KrV, B 125)

Ein konsistenter Begriff von Realität muss es demnach schaffen, diese Dimensionen zu vereinen, ohne sie damit auf bloße Subjektivität des Für-uns zu reduzieren. Kants eigener „Grundsatze der durch gängi gen Bestimmung“ (KrV, B 599) des Seienden, demnach „alles Existirende [...] durchgängig bes ti m m t“ (KrV, B 601) sei, schmilzt zu einem „transzendentalen Ideal“ der Vernunft zusammen: d.h. zu einer ewig aufzusuchenden Einheit des in der Erscheinung real Gegebenen ${ }^{93}$. Zugleich aber, das zeigt die vorliegende Untersuchung, muss diese Einheit als formal gegeben immer schon vorliegen, damit auch die kantischen Unterscheidungen überhaupt sinnvoll sein können. Deshalb ist die Verlängerung der Bestimmtheit des Realen als Handlungen des Verstandes und der Vernunft hin zum „Ding an sich“ für Kant zugleich mit der Auslöschung von „Bestimmtheit überhaupt“ verbunden. Das „All der Realität (omnitudo realitatis)“, in welchem der „Allbesitz der Realität [...] eines Dinges a n sich selbst als durchgängig bestimmt vorgestellt" (KrV, B 604) wird, ist als Grenzwert allen Bestimmtseins „das Unbeschränkte“ (KrV, B 604), welches als Gesamt „alle[r] mögliche[n] Prädicate der Dinge“ (KrV, B 603) notwendig angenommen werden muss. Denn Bestimmungen als „wahre Verneinungen“ (KrV, B 604) - „omnis determinatio est negatio“ - können nur aufgrund eines vorgegebenen Unbeschränkten vollzogen werden, das alle Möglichkeiten der Bestimmung bei sich führt, selbst aber unbestimmt ist, um bestimmte Möglichkeiten nicht notwendig vorauszusetzen und damit auszulöschen. Der Realgrund eines letzten Gegebenen, den Kant im Beweisgrund Gottes noch objektiv gedacht hatte ${ }^{94}$, wird nun zur methodischen Annahme bestimmenden Denkens reduziert und die Realität des „Ding an sich“ als Begriff zu einem „Alles“, das zugleich in Bezug auf

damit sinnlos wäre. Allein nämlich um diesen Unterscheid von An-sich und Für-uns sinnvoll behaupten zu können, ist eine geteilte Basis beider Schemata notwendig (vgl. Detel: Geist und Verstehen, S. 386), welche in der vorliegenden Untersuchung als notwendig übergreifender Begriff des Realen entwickelt wird. Kants Theorie impliziert damit eine notwendige Metasprache, welche die Differenz von An-sich und Für-uns überspannt und sie so erst zu einer sinnvollen Differenz macht: Der Grund und Gehalt dieser Sprache aber ist das Reale selbst.

93 „Die durchgängige Bestimmung ist folglich ein Begriff, den wir niemals in concreto seiner Totalität nach darstellen können, und gründet sich also auf einer Idee, welche lediglich in der Vernunft ihren Sitz hat, die demn Verstande die Regel seines vollständigen Gebrauchs vorschreibt." (KrV, B 601)

94 Vgl. Förster: Die 25 Jahre der Philosophie, S. $92 \mathrm{f}$. 
die Bestimmung überhaupt „Nichts“ ist. Die wiederum materiale, individuelle und doch allgemeingültige Bestimmung unserer Wirklichkeitserfahrung, die nicht durch die transzendentale Ausstattung gesteuert ist, wird auf diese Weise, d.h. von einem real notwendigen völlig Unbestimmten des „Ding an sich“ her, wiederum gänzlich unerklärbar.

Auch das „Ich“ der „synthetischen ursprünglichen Einheit der Apperception“ kann sich nicht in seinem Sein (verstanden als Sein der Realität ${ }_{1}$ ), sondern nur in seinem Erscheinen selbst erkennen (KrV, § 25, B 157), d. h. sich nur als empirisches Ich, das sich selbst Erscheinung ist, auf sich wirklich beziehen und sich erfassen $^{95}$. Kants Unterscheidung von „Erkennen“ und „Denken“ wird hier besonders schmerzhaft, nämlich in existenzieller Weise, als Abgrund bedeutsam. Das Ich als Grund seiner objektkonstitutiven Prozesse bleibt sich selbst gegenüber nur notwendige Annahme und hypothetische Unterstellung. Das „Dasein“ des Ich an sich wird bei Kant nur als bloß gedachter Akt des Bestimmens gedacht, d.h. als letztbegründende (arché) und letztursächliche (causa sui) Form von „Bestimmtheit überhaupt“, nämlich als synthetische Einheit der Apperzeption. Diese muss als Identität des Bewusstseins in wechselnden Vorstellungen notwendig angenommen werden, um durch die Selbigkeit des Bewusstseins die Konstanz von Gegenständen sowie die Einheit ihrer Elemente und damit die Form von Etwas überhaupt für mich denken zu können. Deshalb ist das „Dasein“ des Ich nicht selbst wiederum wie ein Gegenstand in der Erkenntnis bestimmbar, weil das Muster aller synthetischen Prozesse im Ich a) Grundlage alles Bestimmens ist, also in jedem Bestimmen bereits vorausgesetzt ist ${ }^{96}$, und b) alles Bestimmen einen sinnlichen Stoff braucht, der aber bezüglich der synthetischen Einheit des Ich notwendig fehlt, sodass, wenn das Ich sich bestimmt, es sich notwendig als Er-

95 Marshall hat völlig recht, gegen die Zwei-Welten-Interpretationen des „Selbst“ bei Kant (empirisches Selbst vs. transzendentales und reines Selbst) zu argumentieren, dass „dividing the self is deeply un-Kantian“ (Marshall: Kant's One Self and the Appearance, S. 428) und dass vielmehr statt der Unterscheidung verschiedener Arten des Selbst bei Kant verschiedene Arten der Selbstrepräsentation des einen Selbst gemeint sind (Marshall: Kant's One Self and the Appearance, S. 426). Auch die vorliegende Arbeit geht von der „one-world intepretation“ (Marshall: Kant's One Self and the Appearance, S. 422) bezüglich des „Ding an sich“/Erscheinungswelt bzw. des Selbst aus. Das ändert jedoch nichts an dem Umstand, dass die Beschreibungen des jeweiligen Verhältnisses von Realitätsebene und Subjekt bzw. von den „Charakteren“ (Marshall: Kant’s One Self and the Appearance, S. 428) des Subjekts zu dessen Einheit widersprüchlich sind und sich nicht zu einer kohärenten Beschreibung einer Aspektvielfalt fügen; eben dies ist das (logische) Problem, nicht die sich daraus vielleicht ableitende Ontologie.

96 McDowell (Mind and World, S. 99): „the possibility of understanding experiences, ,from within', as glimpses of objective reality is interdependent with the subject's being able to ascribe experiences to herself; hence, with the subject's being self-conscious.“ 
scheinung bestimmt - „und ich habe also demnach keine Erkenntniß von mir wie ich bin, sondern bloß, wie ich mir selbst erscheine. “(KrV, B 158) Das Dasein des Ich als reines An-sich ist so bei Kant verschattet und eine reine Denknotwendigkeit, die notwendig keine Erkenntnis sein kann: Das Bewusstsein der „synthetischen ursprünglichen Einheit der Apperception“ richtet sich darauf, „nicht wie ich mir erscheine, noch wie ich an mir selbst bin, sondern nur daß ich bin.“ (KrV, B 157) Kant trennt in Bezug auf das Ich an sich also eine bloß denknotwendige Daseinsund Funktionsgewissheit von der Selbsterkenntnis ${ }^{97}$ : Das Ich an sich kann sich nur denken als etwas, das notwendig existiert, aber nicht, wie es an sich existiert. „[I]ch existire als Intelligenz, die sich lediglich ihres Verbindungsvermögens bewußt ist“ (KrV, § 25, B 158f.), denn alles andere, dessen ich mir von mir bewusst bin, betrifft das Ich als Erscheinung. Indem Kant die Aussagen über das Ich der synthetischen Einheit der Apperzeption als denknotwendige, aber erkenntnisfreie, rein begriffslogische Schlussfolgerungen deklariert, um den Hiatus von Realität $t_{1} /$ Realität $_{2}$ und dessen Erkenntnislimitationen zu retten, können Bestimmungen für die Realität ${ }_{1}$ formuliert werden, ohne dadurch in einen offensichtlichen Selbstwiderspruch zu geraten: auch wenn zugleich ihr epistemischer Status - so sind sie gültig als Analogien, wörtlich zutreffende Beschreibungen etc. undeutlich geworden ist. Der Grund aller transzendentalen Arbeit des Subjekts an den sinnlichen Daten ist so aber mehrfach grundlos geworden: a) in dem hermeneutischen Verbot, die körperlich-sinnliche Daseinsgewissheit des Ich als Ausdruck einer epistemisch gewissen Realität des Ich im Sinne der Realität ${ }_{1} \mathrm{zu}$ verstehen; b) in dem epistemischen Verbot, die Denknotwendigkeit des Ich der Apperzeption als Modus von Erkenntnis zu begreifen, durch welchen eine Form von Bestimmtheit generiert wird, die in transzendentalen Derivationen die Objektwelt der Erscheinungen strukturiert, in einer Überschreitung der Grenze von Realität $t_{1} /$ Realität $_{2}$ als Gegebensein von Bestimmtheiten der Ding-an-sich-Realität,

97 Vgl. die „Vorrede zur zweiten Auflage“, B S. XL-XLI, wo Kant in einer großen Fußnote zur Daseinsgewissheit des Ich Stellung nimmt und das ,intellektuelle Bewußtsein meines Daseins, in der Vorstellung Ich bin, welche alle meine Urteile und Verstandeshandlungen begleitet“, und welches reziprok durch die Gewissheit äußerer Dinge sich gestützt findet bzw. diese stützt, von einer „Bestimmung meines Daseins durch intellektuelle Anschauung“, welche einzig wirkliche Selbsterkenntnis wäre, unterscheidet. Gunnar Hindrichs hat hier eine sehr interessante Interpretation vorgelegt. Nach Hindrichs bedeutet das „Ich bin“ „kein blindes Sein, sondern die Vorwegnahme von Bestimmtheit“, welches eine „Charakteristik des Ichseins“ erlaubt. „Als Antizipation dessen, was in der vom ,Ich denke‘ gebundenen Ontologie zu stehen vermag, bestimmt sich die Erzeugung im Bezug auf das, was noch nicht ist. [...] ,Ich bin‘ besagt kein Ein-für-allemal meines Daseins, sondern das fortwährende Werden jener Sachhaltigkeit, die das, Ich denke‘ stets von Neuem zur Bestimmung bringt.“ (Gunnar Hindrichs: „,Ich denke“ und ,Ich bin““, in: Konzepte 3 (2017) S. 101-110, hier: S. 110) 
zu der das Substrat des „Ich denke“ gehört ${ }^{98}$. Somit wird auch hier deutlich, dass der Logik des Bestimmtseins überhaupt der Realität ${ }_{2}$ eine notwendige, aber bei Kant verschwiegene Tendenz anhaftet, diese Form von Bestimmtheit auf gleichen oder analogen Formen der Realität ${ }_{1}$ zu gründen. Realität muss demgemäß begriffslogisch als Geflecht unterschiedener und in der Unterscheidung in Begründungsverhältnissen aufeinander bezogener Weisen der Bestimmtheit begriffen werden, welches der Unterscheidung von An-sich und Für-uns bzw. den Weisen des transzendentalen Bestimmens notwendig vorgelagert ist. Genau das aber macht das System der kantischen Unterscheidungen vor allem in der abstrakten Form des Unterschieds, den er zur Anwendung bringt, unmöglich, auch wenn es stets darauf abzuzielen scheint. Hierin hat der hermeneutische „Trick“ Fichtes, zwischen „Geist“ und „Buchstaben“ der kantischen Philosophie zu differenzieren, seinen Grund ${ }^{99}$.

\subsubsection{Das Problem des „Ding an sich“}

Die Kritik an der Stellung des Subjekts zum „Ding an sich“ bei Kant kann als der Dreh- und Angelpunkt der „Überwindung“ Kants durch die Idealisten gesehen werden. Ihre Diskussion in der Forschung füllt beinahe ganze Bibliotheken. ${ }^{100}$ Dabei hat ein wesentlicher Diskussionsstrang die Kritik am „Ding an sich“ stets in

98 Es ist in diesem Rahmen nicht notwendig, die Lehre von der synthetischen Einheit der Apperzeption weiter zu untersuchen. Für die Frage nach den kategorialen Begriffen der Realität hat sie hier keinen darüber hinausgehenden Erklärungswert: Denn in ihr legt Kant einzig den letzten Grund aller Synthesen des Verstandes und der Vernunft, die Urform aller Synthesis, offen. Die Kategorien „Realität“ und „Wirklichkeit“ sowie die (widersprüchliche) Bestimmung der Realität ${ }_{1}$ stellen demgegenüber bestimmtere, mit weiteren notwendigen kategorialen Eigenschaften versehene Versionen begrifflicher Synthesis dar. Für diese bietet die abstrakte Grundform der Synthese, die das Mannigfaltige als Gehalte eines Bewusstseins bestimmt, keine weitere Aufklärungschance: Sie sagt einzig, dass alle Bewusstseinsinhalte qua ihrer „Bestimmtheit überhaupt“ notwendig durch Formen der Synthese gebildet werden, die in der Ursynthesis ihrer Zugehörigkeit zu einem Bewusstsein wurzeln. Darüber hinaus hat Marshalls Versuch, den Unterschied der Charaktere des Selbst (empirisches Selbst - transzendentales und reines Selbst) als Unterart des Gattungsunterschieds von „Ding an sich“/Erscheinungen zu verstehen, ebenfalls keine Auswirkungen auf die Probleme, welche die jeweiligen kategorialen Beschreibungen der Felder von Realität ${ }_{1}$ und Realität ${ }_{2}$ erzeugen (Marshall: Kant's One Self and the Appearance, S. 429 ff.).

99 Fichte: Zweite Einleitung in die WissenschaftsLehre, in: GA I,4, S. 209-271, hier: S. 231f. Vgl. dazu Horstmann: Die Grenzen der Vernunft, S. 47 f., $53 \mathrm{f}$.

100 Als kleine Forschungsübersicht vgl. die Diskussion und die Fußnotenhinweise bei Sandkaulen: Das leidige Ding an sich, und für den englischsprachigen Raum zuletzt Marshall: Kant's One Self and the Appearance/Thing-in-itself Distinction. 
der Form des Kausalitätsarguments vorgetragen, das spätestens in Hans Vaihingers Kommentar zur Kritik der reinen Vernunft kanonisch festgehalten worden ist. ${ }^{101}$ Dessen Pointe ist die Markierung des Verhältnisses von affizierendem „Ding an sich“ und Subjekt als Kausalverhältnis (Affektion des Subjekts durch das „Ding an sich“) und damit als ungebührliche Erweiterung einer rein auf die Welt der Erscheinung beschränkten Kategorie auf das noumenale „Ding an sich“. Diese Kritik, das hat Birgit Sandkaulen aufgezeigt, ist so nicht direkt dort zu finden, von wo sie die Idealisten (Schelling, Fichte, Hegel) entnommen zu haben glaubten ${ }^{102}$ bzw. ist dort nur ein untergeordneter, abgeleiteter Aspekt einer weitaus umfassenderen Kritik (siehe das Kapitel zu Jacobi): nämlich in Friedrich Heinrich Jacobis David Hume über den Glauben, oder Idealismus und Realismus. Ein Gespräch (1787) in der Beilage Über den transzendentalen Idealismus. ${ }^{103}$ Ernst Cassirer schließt noch an diese Quelleninterpretation an, wenn er Jacobis Verdienst gerade wesentlich darin sieht, die inneren Widersprüche des affizierenden „Ding“ bezüglich der Kausalität so scharf gefasst zu haben, dass danach Kants Lehre nicht ihrem Buchstaben gemäß stehenbleiben konnte. ${ }^{104}$ In diesem Anschluss an Jacobi lautet die Kritik demnach: Bereits die Unterscheidung zwischen „Ding an sich“ und Erscheinung selbst ist im Rahmen des Theorieprogramms eines transzendentalen Idealismus selbstwidersprüchlich, weil so eine materiale Realität außer der Erscheinung angenommen werden muss, um den Grund sinnlicher Affektionen einsichtig zu machen, zugleich aber alle Realität nur Erscheinungscharakter haben soll und deshalb „Kant von einem vom Ich verschiedenen Etwas nichts wissen dürfe, leider aber zu viel von ihm wisse.“105 „Der transzendentale Idealismus, so könnte Jacobi resümieren, kann nicht nur keinen Beweis für die Realität der Außenwelt liefern, konsequent gefaßt kann er nur das Gegenteil beweisen. "106 Diese Kritik übersieht allerdings, dass Kant transzendentalen Idealismus und empirischen Realismus programmatisch durchaus als Einheit zu denken versucht; nur gelingt dieses Zusammendenken eben nicht vollständig. Jacobis Kritik an Kants aufklärerischen und zugleich restriktiven Vorstellungen von „Realität überhaupt“ geht aber, wie gesagt, weit über den bloß kategorialen Begriff von Realität und seine Einteilungen hinaus; sie betrifft vor

101 Vgl. Sandkaulen: Das leidige Ding an sich, S. $179 \mathrm{f}$.

102 Vgl. Sandkaulen: Das leidige Ding an sich, S. 180-182.

103 Jacobi: David Hume, JWA 2,1, S. 5-112 [Beilage, S. 103-112], hier: S. 109 ff.

104 Ernst Cassirer: Das Erkenntnisproblem in der Philosophie und Wissenschaft der neueren Zeit (1907), Reprint, Bd. 3, Darmstadt 1995, S. 33.

105 Horstmann: Die Grenzen der Vernunft, S. 55. Zur interessanten Uminterpretation dieser Kritik bei Fichte vgl. ebf. Horstmann: Die Grenzen der Vernunft, S. 55.

106 Horstmann: Die Grenzen der Vernunft, S. 33. 
allem empirisch evidente Sachverhalte wie Freiheit, das Unbedingte und das Lebendige sowie die empirische unbedingte Gewissheit der Realität der Außenwelt überhaupt. ${ }^{107}$ Der Kausalitätsvorwurf wird eigentlich explizit zuerst im $A e$ nesidemus oder Über die Fundamente der von dem Herrn Professor Reinhold in Jena gelieferten Elementar-Philosophie (1792) von Gottlob Ernst Schulze entwickelt ${ }^{108}$ und schließlich dann bei Fichte ${ }^{109}$ aufgegriffen ${ }^{110}$. Hegel zieht daraus zum einen die Konsequenz, dass das „Ding an sich“ einen begriffsauflösenden Widerspruch von Selbstbeschreibung und Sein darstellt. Was nämlich programmatisch das Andere $\mathrm{zu}$ allem Bewusstsein sein soll, ist durch diese Bestimmung zugleich vollends bewusstseinsimmanent bestimmt und damit unproblematische Erscheinung im kantischen Sinn (vgl. GW 20, S. 80 f., § 44); bei Kant selbst ist dies im Widerspruch des „ganz unbestimmten Begriff[s]“ des „Ding an sich“ im Gegensatz zum „bestimmten Begriff“ [KrV, B 307] deutlich sichtbar. Als gewöhnlicher Fall kategorialer Bestimmung als unbestimmt kann es deshalb - und dort wird die Kausalität wieder ernst genommen - in Analogie zu Fichtes Nicht-Ich gesetzt werden: „Was bei Kant ,das Ding-an-sich“ heißt, das ist bei Fichte der Anstoß von außen, dieses Abstraktum eines Anderen als Ich, welches keine andere Bestimmung hat als die des Negativen oder des Nicht-Ich überhaupt.“ (TWA 8, S. 147, § 60 [Zusatz 2]) Schließlich fasst Schelling in seinen Münchner Vorlesungen Zur Geschichte der Neueren Philosophie die zentralen Vorwürfe an Kants „Ding an sich“ (Substanzform, Unbestimmtheitswiderspruch, Kausalitätsunterstellung) konzis zusammen $^{111}$ und prägt die polemische Formel „hölzernes Eisen“112 dafür. Strawson hat in seinem wirkmächtigen Kommentar zur Kritik der reinen Vernunft das Kausalitätsargument gegen Kant bestätigt: Es sei bezüglich der Kritik eine unabweisbare ,premise that all our ,outer perceptions are caused by things which exist independently of our perceptions and which affect us to produce those perceptions“113. Resümierend heißt es dann bei Strawson: „Experience is simply what emerges from the affecting relation, and all the distinctions we draw within

107 Vgl. dazu konzis Horstmann: Die Grenzen der Vernunft, S. 34-42.

108 Gottlob Ernst Schulze: Aenesidemus oder Über die Fundamente der von Herm Professor Reinhold in Jena gelieferten Elementar-Philosophie, hg.v. Manfred Frank, Hamburg 1996, S. 184 f. [263f.].

109 Johann Gottlieb Fichte: Zweite Einleitung in die Wissenschaftslehre für Leser, die schon ein philosophisches System haben, GA I,4, S. 209-271, hier: S. 235f.

110 Vgl. Sandkaulen: Das leidige Ding an sich, S. 180.

111 Vgl. Friedrich Wilhelm Joseph Schelling: „Zur Geschichte der Neueren Philosophie (1827)“, in: Ders.: Schriften von 1813-1830, Reprint, Darmstadt 1976, S. 283-482, hier: S. 364-367.

112 Schelling: Zur Geschichte der Neueren Philosophie, S. 366.

113 Strawson: The Bounds of Sense, S. 250. Strawson spricht davon, dass Kant dies ,beständig behaupte' (Strawson: The Bounds of Sense, S. 253f.) 
experiences are drawn within the sphere of what emerges from this relation. "114 Damit verfehlt Kant aber nach Stephen Houlgate gerade „the actual nature of being that is disclosed in our experience“115, wie es Hegel später in der Wissenschaft der Logik im spekulativen Denken begrifflich einfangen wird: „Hegel has proven that things relate to other things preciseley as they are in themselves. Their ownmost nature manifests itself in these relations and does not remain hidden from view. “116 Hegels Kritik am „Ding an sich“ als einem „Abstractum“ (GW 21, S. 47), so konstatiert Houlgate, besteht folglich auch nicht darin, dass das „Ding an sich“ ein „abstrakter Begriff“ [abstract concept ${ }^{117}$ sei, sondern nur der „Begriff eines abstrakten Objekts“ [concept of an abstract object] ${ }^{118}$ - „ein dem Denken fremdes und ässerliches“ (GW 21, S. 47). Gerd Irrlitz erkundet in seiner komplexen Zusammenfassung der historischen Quellen wie werkinternen Argumentationsstrukturen des gesamten „Ding an sich“-Komplexes bei Kant eine wesentliche Verwendungsweise des Begriffs ebenfalls als den „subjektfreie[n] Gegenstand als Ursache der Erscheinungen, ein materielles Substrat als letzter Affektionsgrund (noumenon im negativen Sinne)“119 zukommt und meint in Bezug auf die sich daraus ergebenden Widersprüche: „Ihn [Kant, C.W.] interessieren die Aporien des Dingbegriffes nicht“120. Auch die „Lösung“ des Problems, die Irrlitz im Antinomien-Kapitel des Dialektik-Teils der Kritik der reinen Vernunft angelegt sieht - dass das „Ding an sich“ als das „noch Unerkannte, und in der Konsequenz das asymptotisch Bekannte durch den Prozess der Verwandlung in ,Dinge für uns ““ als der „unendliche Erschließungsprogress der Erscheinungen, der tendenziell auch die Dinge an sich aufschließe“121, betrachtet werden müsse -, löst das Problem nicht wirklich, weil damit lediglich der Zusammenfall von Erscheinungswissen und noumenalem Wissen in eine unbestimmte, vielleicht nie erreichbare Zukunft verlegt, die Unterscheidung beider aber nicht angegriffen wird und so zugleich der mögliche Zusammenfall kategorial unmöglich erscheint. Eine ähnliche „Lösung“ deutet Robert B. Pippin in Bezug auf Brandoms Hegellektüre an, wenn Kant im Sinne der Kritik am „Mythos des Gegebenen“ so verstanden wird, als solle die ganze Rede von der Unerkennbarkeit des „Ding an sich“ nur ausdrücken, dass

114 Strawson: The Bounds of Sense, S. 255.

115 Stephen Houlgate: The Opening of Hegel's Logic. From Being to Infinity, West Lafayette, Ind. 2006, S. 131.

116 Houlgate: The Opening of Hegel's Logic, S. 341.

117 Houlgate: The Opening of Hegel's Logic, S. 135.

118 Houlgate: The Opening of Hegel's Logic, S. 339

119 Irrlitz: Kant-Handbuch, S. 172.

120 Irrlitz: Kant-Handbuch, S. 172.

121 Irrlitz: Kant-Handbuch, S. 172 f. 
Objekte deshalb nicht an sich selbst betrachtet werden können, weil unsere letzten begrifflichen Regeln „nicht empirisch abgeleitet sind“122, mithin nicht unmittelbar-abbildend in den Dingen selbst wurzeln, und dass sie verstanden werden müssen „nicht etwa aufgrund einer Erklärung, die bis zu etwas direkt in der Erfahrung Verfügbarem zurückverfolgt werden kann“123. Förster hingegen versucht das Kausalitätsargument zu entkräften ${ }^{124}$, und zwar im impliziten Anschluss an eine bereits von Jacobi kritisierte ,Verteidigung Kants, wonach Kausalität lediglich eine Uminterpretation des logischen Grund-Folge-Zusammenhangs sei. ${ }^{125}$ Kant behaupte mit der Verknüpfung von sinnlicher Rezeptivität und Noumenalität keine Ursache-Wirkungs-Beziehung und nehme somit keinen ungebührlichen Gebrauch der Kategorien in objektiver Weise vor, sondern analysiere lediglich eine Bedeutungsbeziehung innerhalb des Begriffs rezeptiver Sinnlichkeit, die „zwei in einem Begriffe nothwendig verbundene Bestimmungen [...] als Grund und Folge verknüpft [...] und zwar entweder so, daß diese Einheit als analytisch (logische Verknüpfung) oder als synthetisch (reale Verbindung), jene nach dem Gesetze der Identität [...] betrachtet wird“ (AA, 5, S. 111). Damit ist die eigene kantische Lesart des „Noumenon“ und seiner Konstruktionsregeln (KrV, B 344) reaktiviert. Förster hat sicher recht, wenn er anmerkt, dass die Komponente der Begriffsbedeutung hier für Kant eine zentrale Rolle spielt, auch dort, wo sozusagen notwendige Gedankenexperimente in Form des Noumenon angezeigt sind, um Elemente des Systems wie ,Erscheinung und ,Ding an sich“ überhaupt unterscheiden zu können. „Folglich muss das Ding an sich so gedacht werden, dass ein Wesen mit einer anderen, nicht-rezeptiven Anschauung es tatsächlich wahrnehmen und als wirklich erkennen könnte. "126 Försters Rettungsversuch übersieht aber m.E. zum einen, dass Kant (siehe Kap. 1.1.1) durchaus in kausalistischer Terminologie argumentiert, wo er das Zustandekommen von Empfindungen in Affektionsbegrifflichkeiten beschreibt, also keineswegs nur im Raum „analytischer“ Bedeutungserläuterung bleibt. Zum anderen ist nicht zu sehen, wie Kant sinnvollerweise die semantischen Beziehungen innerhalb des Begriffs der Sinnlichkeit erläutern kann, ohne sie zugleich notwendig als reale Funktionen

122 Robert B. Pippin: „Brandoms Hegel“, in: Hegel in der neuen Philosophie, hg.v. Thomas Wyrwich, Hegel-Studien, Beiheft 55, Hamburg 2011, S. 367-406, hier: S. 372.

123 Pippin: Brandoms Hegel, S. 372.

124 Förster: Die 25 Jahre der Philosophie, S. 117-120.

125 Vgl. Jacobi: David Hume, JWA 2,1, S. 50 - 52. Eine ganz ähnliche Gedankenfigur findet sich auch bei Nicholas Rescher: „Noumenal Causality“, in: Kant's Theory of Knowledge. Selected Papers from the Third International Kant Congress, hg.v. Lewis White Beck, Dodrecht/Boston 1974, S. $175-183$.

126 Förster: Die 25 Jahre der Philosophie, S. 120. 
einer realen Genese durch Affektion zu verstehen, d.h. als Verursachungsbeziehung. ${ }^{127}$ Unmissverständlich heißt es demgemäß in der Auflage A der KrV anhand des „Paralogismus der Idealität (des äußeren Verhältnisses)“:

[W]enn man äußere Erscheinungen als Vorstellungen ansieht, die von ihren Gegenständen, als an sich außer uns befindlichen Dingen, in uns gewirkt werden, so ist nicht abzusehen, wie man dieser ihr Dasein anders, als durch den Schluß von der Wirkung auf die Ursache, erkennen könne [...]. Nun kann man zwar einräumen: daß von unseren äußeren Anschauungen etwas, was im transzendentalen Verstande außer uns sein mag, die Ursache sei, aber dieses ist nicht der Gegenstand, den wir unter den Vorstellungen der Materie und körperlicher Dinge verstehen; denn diese sind lediglich Erscheinungen [...]. Der transzendentale Gegenstand ist, sowohl in Ansehung der inneren als äußeren Anschauung, gleich unbekannt. (KrV, A 372) $)^{128}$

Kant gesteht hier, im semantisch wertlosen Konjunktiv verbleibend, die Notwendigkeit ein, die Form der Ursache irgendwie in Bezug auf das „Ding an sich“ denken zu müssen bzw. richtiger: nicht völlig vermeiden zu können. Nur so nämlich - das hat Jacobi in der Beylage klar erkannt ${ }^{129}$ - ergibt die Rede von der Rezeptivität der Sinnesorgane überhaupt Sinn: $\mathrm{Zu}$ deren semantischem Genom gehört es, ein Anderes als Affizierendes benennen zu müssen, das „den äußeren Erscheinungen [...] zum Grunde liegt“ (KrV, A 379f.). Der Schluss auf äußere Dinge bezüglich ihrer inneren Wahrnehmung, „,indem ich diese als die Wirkung ansehe, wozu Etwas äußeres die nächste Ursache ist“ (KrV, A 368), ist mithin zwar nicht korrekt (denn die äußeren Dinge im Raum als Ursachen unserer Vorstellungen von ihnen sind zugleich nur im Raum in uns, d. h. als Erscheinungen; vgl. die von Kant erläuterte doppelte Bedeutung von „außer uns“, KrV, A 373), zugleich aber auch nicht einfach falsch (negativ: Denn die Unerweislichkeit des „Ding an sich“ verbietet es, auch Aussagen über ihr Nichtvorhandensein zu machen; positiv: Denn die Logik des Affiziertwerdens muss ein irgendwie unbekannt Affizierendes setzen). Ebenfalls in der Auflage A erörtert Kant dies zugleich an der platonischen Semantik von „Erscheinungen“, die notwendigerweise Erscheinungen von Etwas sein müssen, das unerkennbar als Gegenstand, d.h. intentionales Objekt bzw. ursächlicher Gehalt, überhaupt hinter ihnen liegt und zugleich in einer realen Wirkamkeit zu ihnen stehen muss, die Veranlassung (Ursache) wie Repräsentationalität (Grund) beinhaltet:

127 In diesem Sinne bemerkt Graeser, dass es bei Kant „das Ding an sich [ist], von dem das Subjekt affiziert wird“ (Graeser: Kommentar zur Einleitung zur Phänomenologie des Geistes, S. 46). 128 Zum Wechsel des Gebrauchs von „transscendental“ zwischen Auflage A und B, der sich hier manifestiert, vgl. Förster: Die 25 Jahre der Philosophie, S. $115 \mathrm{f}$.

129 Jacobi: David Hume, JWA 2,1, S. 108, 111. 
Nun sind aber diese Erscheinungen nicht Dinge an sich selbst, sondern selbst nur Vorstellungen, die wiederum ihren Gegenstand haben, der also von uns nicht mehr angeschaut werden kann, und daher der nichtempirische, d.i. transzendentale Gegenstand = X genannt werden mag. (KrV, A 109)

Es gehört demnach zur Bedeutung des Grund-Folge-Zusammenhangs von „Ding an sich" und Erscheinungen, sich in Form von Ursache-Wirkungs-Beziehungen zu verwirklichen. Empfindungen liegen nur vor, wo sie als rezeptive Reaktionen auf Noumena durch diese bewirkt werden: Anders ist die Bedeutung ihrer Existenz nicht denkbar. Deshalb gehört diese Kausalität auch zu ihrem semantischen Schlüssel. Das bspw. sieht auch Wilfrid Sellars in Empiricism and the Philosophy of Mind so, wenn er die kausale Grundbeziehung der außermentalen Realität auf das Bewusstsein als notwendig zu denken annimmt, um das Vorliegen von Sinnesdaten erklären zu können ${ }^{130}$, zugleich aber die Rechtfertigung (Geltung) der Bewusstseinsinhalte von deren kausalem Zustandekommen (Genese) gegen naturalistische Verkürzungen durch die Identifikation beider klar unterscheidet. Ebenso bestimmt Donald Davidson die Beziehung von Empfindungen auf Überzeugungen, d.h. von sinnlich-perzeptiven Gehalten auf begrifflich-propositionale Gehalte, als Beziehungen von „kausaler Art. Empfindungen lösen manche Überzeugungen aus und bilden in diesem Sinn die Basis oder das Fundament dieser Überzeugungen. “131 Sowohl zwischen objektiver Realität und den sinnlichpassiven Perzeptionsorganen des Subjekts als auch zwischen den Gehalten der Perzeption und den Gehalten von Gedanken müssen demnach kausale Wirkbeziehungen angenommen werden, die sich nicht sinnvoll auf die kategorial unterschiedene Grund-Folge-Beziehung reduzieren oder zurückführen lassen, wie es Förster für Kant vorschlägt. Kants nur scheinbar saubere Trennung von „Denken“ (Bedeutung) und „Erkennen“ (Bestimmen eines Objekts) darf dort nicht zum Argument werden, wo sichtbar ist, dass Kant sie selbst unterlaufen muss: Das scheinbar störungsfreie Nebeneinander des notwendigen Gedankenexperiments „Ding an sich“ (Noumenon) und seiner realen Unerkennbarkeit macht es sich zu leicht, wo notwendige Gedankenbestimmungen des „Ding an sich“ (Unerkennbarkeit, Ursache bzw. Gründe für Empfindungen) das Gewicht und die Funktion realer Erkenntnisse gewinnen. ${ }^{132}$ Hegels Kritik des Denkens bzw. Erkennens ,vor

130 Vgl. Blume: Sellars im Kontext der analytischen Nachkriegsphilosophie, S. XIII.

131 Donald Davidson: „Eine Kohärenztheorie der Wahrheit und der Erkenntnis“, in: Ders.: Subjektiv, intersubjektiv, objektiv, Frankfurt am Main 2004, S. 233-270, hier: S. 243.

132 Ähnlich gegen die ,Rettung' des kantischen Arguments argumentiert auch Frank, Idealismus und Realismus: S. 122; die Bedeutung der kausalen Grundannahme unterstreicht auch Markus 
dem Erkennen“, das sich nicht die Hände an den Geltungsbedingungen des Erkennens schmutzig machen will (vgl. GW 20, S. 50 f., § 10), scheint hier m. E. noch immer zuzutreffen. Kants transzendentale semantische Argumente sind zunächst einmal Behauptungen wie Erkenntnisaussagen auch; sie beanspruchen Geltung und geben Bestimmungen, auch wenn diese ihre Gründe in Denknotwendigkeiten, nicht in empirischen Daten haben sollen. Diesen klaren Gegenstandsbezug aufzuweichen, nur um Kant vor Widersprüchen $\mathrm{zu}$ bewahren, erscheint mir deshalb als nicht sinnvoll. Auch Schönrich weist dementsprechend deutlich auf den „kausalen Kontext“133 der Empfindungen hin und betont die „kausale Vorgeschichte einer Anschauung“134 bei Kant. Des Weiteren trifft er die wichtige Unterscheidung zwischen „Anschauungsvorkommnissen“ und „Anschauungsinhalt“135: Kausale Verursachung betrifft demnach nur die „Anschauungsvorkommnisse“; der „Anschauungsinhalt“ kann nämlich, wie im Fall von Halluzinationen oder Täuschungen, auch ohne kausale Verursachung entstanden sein und darf nur im Fall richtiger Wahrnehmung als repräsentationales Produkt der kausalen Verursachung gelten. Allerdings ändert dies nichts an dem Problem, ob und wie repräsentationale Gehalte in ihrer begrifflichen Form durch eine reale Begriffsbeziehung wie die der Kausalität gedacht werden müssen. Denn Halluzinationen können nur gedacht werden als nicht aktuell, aber notwendig in der Vergangenheit durch äußere Gegenstände verursachte Wahrnehmungsgehalte, die durch die reproduzierende Einbildungskraft wiederaufgerufen und höchstens neu kombiniert werden; es handelt sich hierbei um Täuschungen, d. h. um falsch repräsentierte Gehalte einer Verursachung. Zugleich stellt das Fehlen überzeugender „psycho-physischer Gesetze, die dem Anschauungsvorkommnis einen Ort in der Kausalkette zuweisen könnten“136, für die hier erörterte Fragestellung kein Problem dar: Die Frage nach der subjektinternen Kausalität zwischen der „Bewußtseinsmodifikation“ und dem „physikalisch beschreibbaren Körperereignis“137, also nach dem ebenfalls kausalen Zusammenhang zwischen somatischer Affektion des Körpers durch das „Ding an sich“ und dem Auftreten von mentalen Bewusstseinszuständen, mag zwar durchaus dahingehend mit der Frage nach der subjektexternen Kausalität zwischen „Ding an sich“ (Realität ${ }_{1}$ ) und Subjekt an sich verbunden sein, insofern es sich hier nicht um völlig verschiedene Arten von

Willaschek: „Der transzendentale Idealismus und die Idealität von Raum und Zeit“, in: Zeitschrift für philosophische Forschung 51/4 (1997), S. 537-564.

133 Schönrich: Externalisierung des Geistes, S. 133.

134 Schönrich: Externalisierung des Geistes, S. 133.

135 Schönrich: Externalisierung des Geistes, S. 133.

136 Schönrich: Externalisierung des Geistes, S. 134.

137 Schönrich: Externalisierung des Geistes, S. 135. 
Kausalität handelt. Dass aber im Faktum der Affektion eine (wie auch immer zu erklärende) Verursachungsbeziehung zwischen „Ding an sich“ und Subjekt (als wiederum inneres, aber auch nicht nur kausales Zusammenspiel von Körper und Geist) anzunehmen ist, zeigt Kant darin, dass der konkrete Weltbezug als Möglichkeit korrekter oder falscher Repräsentation von existierenden Sachverhalten sonst nicht sinnvoll zu denken ist. Deshalb ist Schönrich zuzustimmen, wenn er mit Gerold Prauss (Die Welt und wir) betont: „Repräsentierendes Mittel und repräsentierter Gegenstand sind keine separierbaren Relata einer äußeren Beziehung, sondern Momente einer prozessualen Einheit." ${ }^{138}$ Das aber heißt, einen Begriff des Realen zu entwickeln, welcher es erlaubt, unter dem Dach einer gemeinsamen Grundstruktur, die als organische Einheit gemeinsamer Bestimmbarkeit und Regelhaftigkeit begrifflich verfasst sein muss, äußeren Gegenstand und erfahrendes Ich zusammenzudenken. Der kantische „Anschauungsinternalismus“139, der „behauptet, dass uns Anschauungsvorkommnisse allein über ihren [subjektiven, C.W.] Inhalt zugänglich sind“140, und dass deshalb „dem repräsentationalen Inhalt der Lieferung [...] die Adresse des Lieferanten nicht aufgeprägt “141 sei, verfehlt diesen Zusammenhang notwendigerweise und vermag ihn nur als kausalistischen Widerspruch zu denken. Der „Anschauungsexternalismus“ greift jedoch erst dann vollständig, wenn er im Versuch, „die kausale Vorgeschichte der Entstehung einer Anschauung zur Festlegung ihres Gegenstandsbezugs“142 heranzuziehen, die Voraussetzung der gemeinsamen begrifflichen Grundstruktur akzeptiert, die das übergreifend Reale ausmacht. Erst so nämlich kommen die Glieder der kausalen Kette als im Rahmen eines gemeinsamen und nicht weiter fundierbaren Begriffsschemas überhaupt vergleich- und aufeinander beziehbare in den Blick.

Ebenso wenig reicht es zur Rechtfertigung Kants aus, darauf hinzuweisen, dass eine solche Kausalbeziehung der Affektion in den wechselseitigen Modi von Aktivität und Passivität zwischen Subjekt und „Ding an sich“ eine Logik von Substanzen voraussetzt, die von Kant für das Ich an sich selbst aber natürlich, wo es nicht als Erscheinung und damit als Gegenstand kategorialer Konstruktion erfasst wird, abgelehnt wird (in der Kritik der Paralogismen der rationalen Psychologie in der „Transzendentalen Dialektik“, KrV, B 407 f.). Vielmehr fügt dieses Argument der Kritik an Kant noch eine zweite Ebene hinzu: Nicht nur die Kausalität wird in der passiven Affektionsbeziehung des Subjekts ungebührlich auf

138 Schönrich: Externalisierung des Geistes, S. 137.

139 Schönrich: Externalisierung des Geistes, S. 134.

140 Schönrich: Externalisierung des Geistes, S. 134.

141 Schönrich: Externalisierung des Geistes, S. 134.

142 Schönrich: Externalisierung des Geistes, S. 134. 
das Verhältnis von Subjekt und „Ding an sich“ appliziert, sondern auch ihre Voraussetzung in der Form von Objekthaftigkeit, die im Substanzbegriff liegt. Schließlich ist auch der Versuch, aus der kausalen Affektion ein bloßes, in sich geschlossenes Gegebensein zu machen und somit die Notwendigkeit des Bezugs auf ein „Ding an sich“ auszulöschen, zum Scheitern verurteilt: Wie ist ein Gegebensein von Etwas für das Subjekt sinnvoll zu denken, wenn es nicht einen Grund dieses Gegebenseins gibt, der die Normativität dafür bereitstellt, dieses Gegebene richtig oder falsch, wahr oder unwahr zu repräsentieren, weil er im Gegebensein selbst repräsentiert ist? Alle diese Lösungsversuche scheinen mir nur Umformulierungen zu sein, um dem Problem zu entgehen, statt es zu lösen. Für eine Lesart, die für eine atemporale Kausalität plädiert und daher an Kants Behauptung festhält (nämlich, dass „Dinge an sich“ weder räumlich noch zeitlich sind, weil sie nicht in unseren Anschauungsformen enthalten sind) steht Allen Wood. ${ }^{143}$ Demgegenüber argumentiert Kenneth R. Westphal dafür, dass wenn Raum und Zeit nur menschliche Anschauungsformen sind, es logisch und metaphysisch auch möglich ist, dass den „Dingen an sich“ ebenfalls solche Eigenschaften inhärent sind, analog zu (den subjektiven Anschauungsformen) Raum und Zeit. Diese temporalen und zeitlichen Noumenal-Eigenschaften nennt Westphal „rspatiality“ and „r-temporality“144 - wobei „„“ für real bzw. für von den Anschauungsformen unabhängig steht. Westphal, so könnte man sagen, plädiert also für eine noumenale temporale Kausalität, die jedoch phänomenal atemporal ist, d.h. von den Anschauungsformen unabhängig. ${ }^{145}$ Eine solche Form der Kausalität ist anschlussfähig an Eric Watkins' Interpretation, der entgegen vieler Kantkommentatoren zeigt, dass Kants Kausalitätskonzept nicht dem humeschen Ereignismodell folgt (wonach ein bestimmtes Ereignis ein anderes bestimmtes Ereignis bloß verursacht), sondern von einer Kausalität von Substanzen ausgeht, die mit kausalen Kräften als zugleich begründende Fähigkeiten ausgestattet sind, die entsprechend ihrer Natur und ihrer Umstände selbst auferlegt sind:

[W] have seen that Kant neither does nor can acept Hume's event-event model of causality. Rather, with the benefit of an awareness of Kant's pre-Critical account of causality, we saw that Kant's texts and arguments commit him to a model of causality that involves substances exercising their causal powers so as to determine each other's states. ${ }^{146}$

143 Allen Wood: „Kant’s Compatibilism“, in: Self and Nature in Kant's Philosophy, hg.v. Allen Wood, Ithaca, New York 1984, S. 57-101.

144 Kenneth R. Westphal: Kant's Transcendental Proof of Realism, Cambridge 2004, S. 55.

$145 \mathrm{Vgl}$. zu Kants Kausalitätsmodell generell Eric Watkins: Kant and the Metaphysics of Causality, Cambridge 2005, insb. Kap. 4 („Kant’s Model of Causality“), S. 230-297.

146 Watkins: Kant and the Metaphysics of Causality, S. 296. 


\subsection{Zwischenbemerkung: Begriffsunterscheidungen}

„Realität“ bleibt für das Denken Kants die ständige Projektionsfläche seiner Erwägungen, und zwar so, dass oft derselbe Begriff (Wirklichkeit/Realität) zum einen für die Realitä̈ $t_{1}$, zum anderen für die Realität $t_{2}$ und dann sogar terminologisiert in Form der Kategorien benutzt wird. So gebraucht er z.B. den Terminus „wirklich“ („wirkliche Wesen“, KrV, § 2, B 37) in der „Transzendentalen Ästhetik“ zum einen synonym mit der Art des „Ding an sich“ (vgl. KrV, § 2, B 37), zum anderen aber auch im Sinne von ,Existenz' überhaupt, ganz gleich ob innerhalb der Erscheinungen oder an sich (vgl. KrV, §6, B 49, wo er vom „wirklichen Gegenstand" eindeutig im Sinne des ,Existierens' spricht). Kant konstatiert deutlich, dass die durch den Verstand und seine transzendentalen Formen konstituierten Gegenstände „auf etwas außer mir bezogen werden“ (KrV, § 2, B 38), d.h. in der natürlichen Einstellung des Subjekts immer so behandelt werden, als ob sie auf eine unabhängig von uns gegebene, fraglos als Existenz gesetzte Realität zutreffen. Damit wird das natürliche Denken als eines in ständiger Verwechslung (,Subreption“147) begriffen, denn es verwechselt Erscheinungen und Realität (vgl. auch KrV, § 8, B 63f.). Des Weiteren macht Kant klar, dass ein „empirischer Begriff“ ein solcher ist, „der von äußeren Erfahrungen abgezogen worden“ (KrV, § 2, B 38) ist. Doch auf welcher Grundlage soll eine solche Abstraktion möglich sein? Wie soll der empirische Begriff einer Sache mit der Sache übereinstimmen bzw. von dieser Sache seine empirischen Daten (sowohl die empirisch-allgemeinen als auch die empirisch-besonderen) erhalten, wenn sich nicht überprüfen lässt, wie diese Daten an sich beschaffen sind? Wie soll ein empirischer Begriff damit zum „Begriff“ werden? Kant müsste dafür eine in allen Subjekten prästabilierte Art der Konstruktion auch der empirischen Begriffe annehmen, ohne dass klar wäre, woher die besonderen Formen der Dinge im Subjekt kommen sollen.

In jedem Fall bezieht Kant bis in die „Transzendentale Logik“ hinein, die doch eigentlich eine terminologische Eindeutigkeit durch den Gebrauch der Begriffe „Realität“ und „Wirklichkeit“ als Kategorien anstrebt, die Begriffe „wirklich“, aber auch „Gegenstand“ oder „Objekt“ an einigen Stellen deutlich auf die Realität $t_{1}$. So spricht Kant bspw. in Bezug auf die empirische Empfindung von der „wirkliche[n] Gegenwart des Gegenstandes“ (KrV, B 74), die der Empfindung vorausgesetzt ist ${ }^{148}$. Weiterhin ist in der $\mathrm{KrV}, \S 21$, B 145 - stellvertretend für

147 Den positiven Begriff der „Subreption“ führt Kant in der Kritik der Urteilskraft im Zusammenhang mit der Analytik des Erhabenen ein (AA, 5, § 27, S. 257): als „Verwechselung einer Achtung für das Object statt der für die Idee der Menschheit in unserm Subjecte“.

148 „Wirklich“ ist hier in der Logik des Vorausgesetztseins deutlich auf die Sphäre des „Ding an sich“ bezogen. Das kategoriale „wirklich“ kann noch nicht gemeint sein, da es hier noch nicht 
zahlreiche andere Belegstellen - mit dem Ausdruck „Object“ das Ding an sich als Objekt gemeint und nicht das Objekt der Verstandessynthesis, dem doch erst Objektivität im Sinne der Miminalbedingungen von Gegenständlichkeit in der Erscheinung zukommt: „[...] sondern nur den Stoff zum Erkenntniß, die Anschauung, die ihm durchs Object gegeben werden muß, verbindet und ordnet.“

Nicht um diese Begriffsverwirrung zu steigern, sondern um sie sichtbar zu machen, ist es sinnvoll zu zeigen, dass Kant in der „Transzendentalen Ästhetik“ und in der „Transzendentalen Analytik“ mindestens sieben verschiedene Facetten der Bedeutung des Realitätsbegriffs benutzt, die zumeist einen funktionalen Sinn haben, d. h. bestimmte Hinsichten des Realitätskonzeptes handhabbar machen sollen. Diese Bedeutungsunterschiede gehen über den Unterschied von „Ding an sich“ und Erscheinung hinaus und verdeutlichen, dass Kant in der Kritik der reinen Vernunft auf der Suche danach ist, die verschiedenen Dimensionen des Begriffs von Realität, die ich zu Beginn dieses Kapitels unterschieden habe, selbst auch zu unterscheiden. Bevor ich zur Analyse des kategorialen Realitätsbegriffs ${ }_{2}$ in der „Transzendentalen Logik“ voranschreite, sollen deshalb diese Begriffsunterscheidungen ohne einen Anspruch auf Vollständigkeit, aber in übersichtlicher Darstellung, d. h. auch jenseits ihrer jeweiligen logischen Genese, kurz aufgeführt werden, um Kants Arbeit an diesem zentralen Begriffsproblem und die Prozesshaftigkeit deutlich zu machen.

Im Bereich der Realität des „Ding an sich“ (Realität $\left.{ }_{1}\right)$ benutzt Kant auch noch

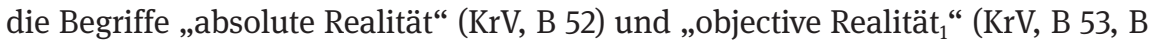
70). Darüber hinaus benutzt er sowohl in der Kritik der reinen Vernunft (siehe oben) als auch in den Prolegomena (Prol. § 13, Anm. III, S. 54 f.) dafür auch den Ausdruck „Wirklichkeit“/,wirklich“. 1) Die „absolute Realität“ meint dabei die Wirklichkeit des „Ding an sich“, wie es jenseits aller subjektiven Formen ist, und wird deshalb von Kant als Synonym für „Ding an sich“ benutzt. 2) Die „objektive Realität $_{(1)}$ “ hingegen bezeichnet eine Art Reflexionsbegriff. Kant benutzt ihn an der bezeichneten Stelle, um die Wirklichkeit des „Ding an sich“ zu markieren, die gemeint ist, wenn man fälschlicherweise von Eigenschaften der Erscheinung behauptet, sie würden auch jenseits der Erscheinung gelten und sie damit in „Schein“ verwandelt. An anderer Stelle (KrV, §6, B 49) spricht Kant auch von „objective[n] Bestimmung[en]“ als solchen, die Gegenständen jenseits aller allgemeinen konstitutiven Subjektivität zukommen; diese objektiven Eigenschaften seien „das Innere, was dem Objecte an sich zukommt“ (KrV, § 8, B 67), und zwar in Abgrenzung zu „bloße[n] Verhältnißvorstellungen“ (KrV, § 8, B 67) der Anschau-

wirksam ist, sondern lediglich seine Grundlage, die empfangene, gegebene Gegenwart der Materie, gemeint sein kann. 
ungsformen. Greifbar wird so im terminologischen Ausdruck das bereits erläuterte Problem, dass eine Art von Bestimmtheit des „Ding an sich selbst“ gedacht werden muss, für die es aber im kantischen System keine Stelle und keine mögliche Benennung gibt. 3) „Wirklichkeit ${ }_{(1)}$ “ meint hier die „Existenz der Sachen“ (Prol. §13, Anm. III, S. 55) an sich selbst, die von Kant vor allem im §13 der Prolegomena auch im Sinne des Daseins des „Ding an sich“ gebraucht wird.

Im Bereich der Realität der Erscheinungen (Realität ${ }_{2}$ ) lassen sich mindestens vier Bedeutungsnuancierungen unterscheiden: 1) Die „empirische Realität“ (KrV, $\S 7$, B 53) meint die objektive Gültigkeit und Allgemeinheit der Elemente und Bedingungen der Erscheinung; „real“ mithin die Markierung des intersubjektiven Geltungsanspruchs der bezeichneten Erfahrung. 2) Die „objective[] Realität ${ }_{2}$ “ (KrV, § 12, B 114) - die ich, um sie von der „objektiven Realität“ auf der Ebene der Realität ${ }_{1}$ zu unterscheiden, mit dem Index „2“ versehe - meint das Gegeben- und Wirksamsein (actualitas) eines Begriffs im Raum der Erscheinung, d.h. seine Aktualität und Gültigkeit für alle Subjekte jenseits bloßer Subjektivität ${ }^{149}$, und damit seinen Bedingungscharakter für „Erkenntnis“, die nur im durch schematische Adaption geregelten Zusammengehen von Begriff und Anschauung möglich ist (in diesem Sinne gehören „Erkenntniß“ und „objective Realität“ zusammen, vgl. KrV, B 194). Dies ist die „objective Gültigkeit“ der „subjective[n] Bedingungen des Denkens “ (KrV, § 13, B 122), wobei in der Bedeutung des „Objektiven“ hier die Bedeutungen der Allgemeingültigkeit (d.h. erzeugt durch allgemeingültige Formen der Subjektivität) und der Objekthaftigkeit zusammenfallen. Vor allem ab der „Transzendentalen Deduktion“ verwendet Kant gehäuft diesen Begriff der „Objektivität“ von Begriffen, weil erst sie gerade in ihrer notwendigen Gültigkeit für jedes Subjekt ein „Object d er Er fa h r ung “ (KrV, § 14, B 126) konstituieren: „Begriffe, die den objectiven Grund der Möglichkeit der Erfahrung abgeben“ (KrV, § 14, B 126). „Objektiv“ wird demnach als Bestimmung derjenigen subjektiven Bedingungen des Erkennens gefasst, die einen „Begriff vom Object“ ermöglichen, also die apriorischen Bedingungen von Objekthaftigkeit herstellen (vgl. KrV, § 18, B 139) ${ }^{150}$. Kategorien erhalten demnach ihre objek-

149 Vgl. zur Objektivität allgemeiner Subjektivität: KrV, B 117.

150 Zur notwendigen Allgemeinheit des Begriffs der Objektivität vgl. § 3 (KrV, B 44), wo Kant „R e a li ä t “ direkt so übersetzt: „d.i. die objective Gültigkeit“, und auch § 19 (KrV, B 142), wo die „objective Einheit gegebener Vorstellungen“ im Urteil als „n o th w e n di ge Ei in he it derselben“, d.h. als „ein Verhältniß, das o bj e ktiv g ültig ist“, bezeichnet wird - „,welches so viel sagen will als: diese beide [sic] Vorstellungen sind im Object, d.i. ohne Unterschied des Zustandes des Subjects, verbunden und nicht bloß in der Wahrnehmung (so oft sie auch wiederholt sein mag) beisammen.“ (KrV, B 142) Zur Objekthaftigkeit vgl. § 23 (KrV, B 148f.), wo Kant von der „Ausdehnung der Begriffe, über unsere sinnliche Anschauung hinaus“ spricht, als „bloße Gedan- 
tive Realität, indem sie durch ihre Anwendung auf die sinnliche Mannigfaltigkeit Gegenstände, verstanden als allgemeine Muster notwendiger Dinggestalt, ermöglichen (KrV, § 24, B 150 f.). 3) „Subjective Realität“ (KrV, § 7, B 53) meint die Wirklichkeit, d.h. die Existenz und notwendige Wirksamkeit bzw. Aktualität (Gegenwärtigkeit), von Elementen und Bedingungen der Erscheinung. Damit wird eher die selbstgegenwärtige, für das Bewusstsein des Subjekts eindringlich präsente Dimension der Realität der transzendentalen Elemente in der Erscheinung bezeichnet. 4) Wenn Kant von der Zeit als „wirkliche[r] Form der innern Anschauung“ (KrV, § 7, B 53) spricht, so ist ,wirklich“ dementsprechend als Wirksamkeit von Elementen und Bedingungen der Erscheinung zu verstehen. Deshalb ist „wirklich“ kein Gegensatz zu „Erscheinung“, sondern nur zu „Schein“ (KrV, § 8, B 69): „Denn in der Erscheinung werden jederzeit die Objecte, ja selbst die Beschaffenheiten, die wir ihnen beilegen, als etwas wirklich Gegebenes angesehen“ (KrV, § 8, B 69) ${ }^{151}$. Im Zuge dieser Differenzierung gelangt Kant bspw. in der „Transzendentalen Dialektik“ zu einer interessanten Unterscheidung bezüglich der Ideen: Wo man nämlich Ideen verkennt, wenn man sie „für Begriffe von wirklichen Dingen“ (KrV, B 671) nimmt, d. h. für Begriffe hält, die sich in empirisch erfahrbaren und potenziell aktualen Objekten in der Welt der Erscheinungen verwirklichen, aber eigentlich nur als „Analoga von wirklichen Dingen“ (KrV, B 702) betrachtet werden können, dort kann man ihnen durchaus eine „Realität“ (KrV, B 702) zugestehen. Dazu aber trennt man innerhalb dieses Begriffs den Aspekt der Allgemeingültigkeit von dem der Objekthaftigkeit ab: Denn auch Ideen besitzen eine intersubjektiv allgemeingültige Sachhaltigkeit als regulative Prinzipien der Vernunft. Der Begriff der Wirklichkeit erfüllt somit im engeren Sinn als einziger konstant die Funktion, das innerhalb der Erscheinungen als Einzelding oder Summe von Einzeldingen konkret Gegebene zu umfassen: Synonym für ihn kann dann vor allem an einzelnen Stellen der Begriff der „Natur“ (KrV, B 682) sein.

kenformen ohne objective Realität, weil wir keine Anschauung zur Hand haben, auf welche die synthetische Einheit der Apperzeption, die jene allein enthalten, angewandt werden, und sie so einen Gegenstand bestimmen können.“

151 Definition der Erscheinung: „Was gar nicht am Objekte an sich selbst, jederzeit aber im Verhältnisse desselben zum Subjekt anzutreffen und von der Vorstellung des ersteren unzertrennlich ist, ist Erscheinung“. (KrV, § 8, B 70, Fußnote). „Schein“ dagegen ist es, die Verhältnisse der Erscheinung für Verhältnisse der Dinge an sich zu nehmen (KrV, § 8, B 70, Fußnote). 


\section{3 „Auf Realität stoßen“: Realität ${ }_{2}$ in der „Transzendentalen Analytik“}

Es hat sich gezeigt, dass, mit Michael Devitt gesprochen ${ }^{152}$, Kant in Bezug auf die Realität $t_{1}$ notgedrungen einen Realismus vertritt, der weder konsequent durchsichtig noch begründbar ist („Feigenblatt-Realismus“), auch wenn er vielleicht im Rahmen der Probleme eines metaphysischen bzw. ontologischen Realismus noch die vernünftigste Option darstellt ${ }^{153}$ : „Kann man dieses wohl Idealismus nennen? Es ist ja gerade das Gegenteil davon. “(Prol. § 13, Anm. II, S. 49) Deshalb hat Hilary Putnam nachvollziehbarerweise seinen eigenen ontologischen Realismus in Richtung eines internen Realismus im Sinne Kants schrittweise revidiert ${ }^{154}$. Der begrifflichen Lücke für diese Realität ${ }_{1}$ entspricht nun invers das scheinbare kategoriale Überangebot für die Welt der Erscheinungen (Realität ${ }_{2}$ ), d.h. die Doppelung der kategorialen Form, mit welcher die grundsätzliche Strukturierungsleistung des transzendentalen Subjekts in realitätssetzender Hinsicht von Kant bedacht wird. Dass Kategorien überhaupt bei Kant realitätssetzend fungieren, liegt an der im Projekt der Transzendentalphilosophie grundsätzlichen Verbindung ihrer logischen Größe mit einem ontologischen Anspruch: zugleich die Form des Denkens wie die Form des Seienden in der Einheit der Erscheinung zu begründen. „Die Unterscheidung von Dasein (Wirklichkeit) und Realität ist systematisch in der Kategorientafel [...] fixiert“"155: Somit stellt sich aber die Frage nach der Funktion dieser Aufspaltung im Gefüge des kantischen Realitätskonzepts. Hans Heinz Holz hat bereits festgehalten, dass bei Kant in der Anlage der Kategorien „die alte Koppelung von Realität und Existenz [...] aufgehoben“'156 wird. Wo er (pauschal betrachtet) Existenz als „Dasein“ in die Kategorie der „Wirklichkeit“ auskoppelt, die zur Kategoriengruppe der „Modalität“ gehört, wird die Kategorie „Realität“ als Element der Kategoriengruppe „Qualität“ dafür frei, den doppelten

152 Michael Devitt: Realism and Truth, Oxford 1984, S. 22.

153 Vgl. Frank: Idealismus und Realismus, S. 19.

154 Vgl. Putnams Wendepunkt in: Hilary Putnam: „Realism and Reason“, in: Ders.: Meaning and the Moral Sciences, London 1978, S. 123-140.

155 Holz: Realität, S. 211.

156 Holz: Realität, S. 210. Beim Kant-Schüler Friedrich Schiller findet sich diese Koppelung allerdings noch in seinen 1795 veröffentlichten Briefen über die ästhetische Erziehung des Menschen: „Materie aber heißt hier nichts anderes als Veränderung oder Realität, die die Zeit erfüllt“ (Friedrich Schiller: „Über die ästhetische Erziehung des Menschen in einer Reihe von Briefen“, in: Ders.: Sämtliche Werke, Bd. 5, hg.v. Wolfgang Riedel, München 2004, S. 570 -669, hier: S. 604). Einen durch Empfindung erzeugten Inhalt überhaupt als Materie der intentionalen Bezugnahme zu haben, meint hier die „Realität des Daseins“ (Schiller: Über die ästhetische Erziehung, S. 605); damit greift Schiller anders als Kant auf den aristotelischen Hylé-morphé-Gedanken zurück. 
qualitätskategorialen Aspekt der „Dingheit“ („Etwas“; KrV, B 602) und der „Sachheit“ (essentia/Wesenheit/„Realität“; KrV, B 602) ${ }^{157}$ zu repräsentieren. „Alle positiven, in bejahenden assertorischen Sätzen aussagbaren Bestimmungen haben den Charakter der Realität“"158: Realität ist also erst einmal ganz allgemein die kategoriale Form, in der bei Kant dem Subjekt transzendental Bestimmtheit überhaupt (Sachheit) gegeben ist. Anders als Holz annimmt, ist damit jedoch keine Ambivalenz im Gebrauch des Wortes „Realität“ zu konstatieren. Denn die Bedeutung der „objektive[n] Gültigkeit“"159, also der Allgemeinheit des Inhalts als „real“, bildet gerade den notwendigen und integralen Aspekt, welcher die beiden Bedeutungen „Sachheit“ und „Dingheit“ in der Kategorie der „Realität“ zusammenhält ${ }^{160}$. „Real“ ist folglich dann eine Bestimmtheit, wenn sie aufgrund ihrer geltungsbezogenen Allgemeinheit für das Subjekt zum Element der „Dingheit“ der zu ihr gehörenden Sache wird, d.h. den Charakter des Objekthaften ${ }^{161}$ annimmt und das Objekt als konstante, integrale, je bestimmte Form einer Sache in der Erscheinung konstituiert. Kant erörtert dabei sowohl ,formale Vorbedingungen“ wie auch „materielle Vorbedingungen“162 von Dingheit, d.h. Objekthaftigkeit, die sich in den Kategorien sowie in den Formen ihres Verknüpftseins manifestieren. Die formalen Bedingungen für Objekthaftigkeit sind vor allem die Bestimmungen der Substanz und der Kausalität, von denen bereits gezeigt worden ist, inwieweit sie die Trennung der Sphären von Realität und Realität $_{2}$ immer schon überspannen:

Es soll möglich sein, die zeitlich veränderlichen beobachtbaren Prädikate widerspruchsfrei auf eine im Wandel der Prädikate beständige Substanz als Träger dieser Eigenschaften zu beziehen. Und es soll weiter möglich sein, die Veränderungen der Prädikate in der Zeit als kausale, naturgesetzliche Veränderung der Eigenschaften eines Objekts zu interpretieren. ${ }^{163}$

157 Holz: Realität, S. 211. Zum philosophiegeschichtlichen Hintergrund dieser Trennung vgl. Honnefelder: Scientia transcendens (dort zu Kant: S. 457-486).

158 Holz: Realität, S. 211.

159 Holz: Realität, S. 211.

160 Vgl. hierzu ausführlicher Günter Zöller: Theoretische Gegenstandsbeziehung bei Kant. Zur systematischen Bedeutung der Termini „objektive Realität“ und „objektive Gültigkeit“ in der „Kritik der reinen Vernunft“, Berlin 1984, v. a. S. 47-57.

161 „Kategorien [sind] folglich diejenigen reinen Synthesen auf Begriffe gebracht, die ein wie auch immer gegebenes Mannigfaltiges so zusammenfassen, dass ein Objekt desselben gedacht und folglich Urteile hierüber möglich werden.“ (Förster: Die 25 Jahre der Philosophie, S. 36) Kant sagt deutlich: Etwas wird „realisiert, d.i. zum Objekt gemacht“ (KrV, B 611).

162 Mittelstaedt: Der Objektbegriff bei Kant, S. $210 \mathrm{f}$.

163 Mittelstaedt: Der Objektbegriff bei Kant, S. 210. 
Als materielle Bedingung darf vor allem der „Grundsatze der durchgängigen Bestimmung“ gelten, welcher festlegt, dass „,von allen möglichen Prädicaten der Dinge, so fern sie mit ihren Gegenteilen verglichen werden, eines zukommen muß“ (KrV, B 599f.), und der bspw. die durchgängige Lokalisierbarkeit fordert.

Es ist also keine Zweideutigkeit, wenn festgestellt werden muss, dass „Realität [...] bei Kant sowohl die Affirmation im Urteil (die Annahme der positiven Gegebenheit des Urteilsinhalts) als auch das gegenständliche Korrelat des Urteils, das in dieses als sein Inhalt eingeht" ${ }^{164}$ meint. In Kants transzendentalem Idealismus sind die objektive Geltung der Bewusstseinsinhalte und der ontologische Sinn des Realitätsbegriffs (als ,Objektivität' in der ,Gegebenheit der Gegenstände`) funktionale Korrelate: Gegenstände sind Funktionen von Urteilen, eben weil die Begriffe, aus denen sie konstruiert sind, Funktionen von Urteilen sind ( $\mathrm{KrV}, \mathrm{B}$ $94)^{165}$. Wo der Begriff der Realität auf die Konstruktion des Gegenstands (und nicht

164 Holz: Realität, S. 211.

165 „Kant takes the judgment to be the minimal unit of experience (and so of awareness in his discursive sense) because it is the first element in the traditional logical hierarchy that one can take responsibility for.“ (Robert B. Brandom: Articulating Reasons. An Introduction to Inferentialism. Cambridge, Mass./London 2001, S.13) Demnach sind bei Kant Begriffe in der Tat definiert im Kontext von Urteilen und nur von deren Funktionsweise her zuallererst sinntragend: „Von [...] Begriffen kann nun der Verstand keinen andern Gebrauch machen, als daß er dadurch urteilt.“ (KrV, B 93) Das von Frege im Zuge der „sententialistischen Revision“ der Analytischen Philosophie entworfene „Kontextprinzip“, nach welchem „Wörter nur im Zusammenhang eines Satzes Bedeutung haben“ (Wolfgang Welsch: „Hegel und die analytische Philosophie. Über einige Kongruenzen in Grundfragen der Philosophie“, in: Jenaer Universitätsreden VI, hg.v. Klaus Manger, Jena 2005, S. 139-223, hier: S. 173) und welches die Umstellung der Sinnesdatentheorie auf die Protokollsatztheorie ermöglicht hat, findet sich demnach schon bei Kant. Schönrich (Externalisierung des Geistes, S. 128-132) hat konzis aufgezeigt, wie Kant einen usualistischen Begriff des Begriffs einführt, der den Gebrauchsaspekt besonders betont: als Gebrauchswissen von Regeln darüber, welche Teilbegriffe (Prädikatausdrücke) innerhalb eines Begriffs verbunden sind und folglich zur Repräsentation angewendet werden dürfen. Sellars darf hier als ,Schüler Kants gelten, wo er jede Form von Wissen als tatsachen-, d. h. potenziell urteilsförmig betrachtet , deshalb die „Sinnesdaten“, in denen ein Einzelgegenstand repräsentiert sein soll, als Kandidaten von Wissen ablehnt (Sellars: Empiricism and the Philosophy of Mind, S. 15-20, Abschnitte 3-6) und die sinnesdatentheoretische Idee einer „Form des Wissens [...] von Einzelgegenständen“ (Blume: Sellars im Kontext der analytischen Nachkriegsphilosophie, S. XII) anstatt von Tatsachen kritisiert. John McDowell wird diese Tradition fortsetzen, indem er aufgrund der kategorialen Unverträglichkeit des Wissens bzw. Erkennens von Tatsachen und der Idee bloßen Wahrnehmens einzelner Dinge bestreitet, dass hier eine Rechtfertigungsbeziehung zwischen beide treten könne, und stattdessen von der Beziehung einer „Entschuldigung“ [exculpation] spricht (McDowell: Mind and World, S. 27). Erneut wird hier das in Kap. 1.1 dargestellte Grundproblem sichtbar, die begriffslose und rein kausale (selbst in dieser Kausalität problematische) Bestimmung des Realen als Gegenstand unmittelbarer Empfindungen überhaupt in eine Logik des Realen einbauen zu 
auf den Gegenstand selbst) abzielt, kann dies nur geschehen, weil Kant Gegenständlichkeit an die Kondensation von notwendig gültigen Urteilen als epistemischem Kern von Objekten bindet. So wird Ontologie durch Epistemologie ersetzt: Die „Frage nach der Seiendheit des Seienden und nach der Realität des Realen [wird] zur Frage nach der Seiendheit und Realität des Begriffs und diese wiederum zur Frage nach der Möglichkeit der im Begriff erfaßten Einheit der Bestimmungen“166. Kant geht also den Schritt zur Grundlegung des Begriffs als Form von Realität überhaupt - aber er schränkt diese Realität auf die Sphäre der Erscheinungen ein und unterminiert so den Aspekt des Zusammenhangs, der in der Bestimmung des „Realen überhaupt“ gesetzt ist. Zugleich ist bei Kant, wie Dieter Henrich gezeigt hat, die „Analyse des Objektbegriffs“ bzw. „Kants Lehre von der Objektivität“ unausweichlich gekoppelt an seine „Lehre vom Selbstbewußtsein als einem Identitätsprinzip“167, die eine

notwendige Bedingung dafür [ist], daß eine Rechtfertigung des Objektivitätsanspruchs unserer Erkenntnis gelingt; auch die Untersuchung des Selbstbewußtseins muß auf eine eigenständige Analyse des Objektbegriffes rekurrieren. Eine zureichende Rechtfertigung, daß Erfahrung als wirkliche Erkenntnis von Objekten allgemein möglich ist, läßt sich nach Kant aber nur ausgehend vom Selbstbewußtsein gewinnen. ${ }^{168}$

Ausgehend vom Identitätsprinzip der transzendentalen Apperzeption als Grund aller Einheit überhaupt lässt sich deshalb zwar die Staffelung der Funktionsweisen von Einheit und Bestimmtheit im Raum der Erscheinung herleiten und begründen und mithin die Frage beantworten, ob die innere Konsistenz von Kants Idealismus $\mathrm{zu}$ beanstanden ist, aber die Frage nach der Reichweite, der Sinnhaftigkeit und dem Grund der Unterscheidungen zwischen den verschiedenen Realitätsbegriffen lässt sich vom Identitätsprinzip der transzendentalen Apperzeption aus nicht stellen, weil es innerhalb einer dieser Sphären fällt bzw. deren beschränkten Horizont ausmacht.

Das folgende Kapitel setzt sich zum Ziel, abseits historischer oder genetischer Erläuterungen zu Kants Deduktion der Kategorien auf Besonderheiten der Funktionsweise sowohl der Wirklichkeits- als auch der Realitätskategorie hinzuweisen, um diese in Beziehung zu den Problemen des Begriffs der Realität ${ }_{1}$ setzen zu können.

können, ohne naturalistische Verkürzungen vorzunehmen, die einfach das kausale Zustandekommen als Grund eines Bewusstseinsinhalts betrachten.

166 Honnefelder: Scientia transcendens, S. 444.

167 Henrich: Identität und Objektivität, S. 16.

168 Henrich: Identität und Objektivität, S. 17. 


\subsubsection{Wirklichkeit}

In Kants Urteilstafel ist Modalität (zu deren Kategoriengruppe „Dasein“ bzw. „Wirklichkeit“ als Einzelkategorie gehört) nicht eine Form der Eigenschaft einer Sache, sondern beschreibt die je besonders bestimmte Beziehung des Denkens auf den Begriff derselben ${ }^{169}$, d.h. die Art des Bejahens des Inhalts durch das Denken (KrV, B 100) ${ }^{170}$. „Wirklich“ bedeutet deshalb hier eine „logische[] Wirklichkeit“ (KrV, B 101), nämlich die der Setzung des Inhalts durch das Bewusstsein als wahr, d.h. daseiend im Sinne positiven und aktualen Gegebenseins in Form repräsentationalen Gehalts ${ }^{171}$. Die Quelle des Rechtsgrundes, diese Wirklichkeit behaupten zu können, ist die Empfindung, d. h. die tatsächliche Gegebenheit des Gegenstandes in der Wahrnehmung ${ }^{172}$ :

Das Postulat, die Wirklichkeit der Dinge zu erkennen, fordert Wahrnehmung, mithin Empfindung, deren man sich bewußt ist; zwar nicht eben unmittelbar von dem Gegenstande selbst, dessen Dasein erkannt werden soll, aber doch im Zusammenhang desselben mit irgend einer wirklichen Wahrnehmung (KrV, B 272). ${ }^{173}$

169 Vgl. Kant (Der einzig mögliche Beweisgrund vom Dasein Gottes, AA, 2, S. 72): „Es ist aber das Dasein [...] nicht sowohl ein Prädikat von dem Dinge selbst, als vielmehr von dem Gedanken, den man davon hat.“

170 Vgl. KrV (B 287, Fußnote), wo auch noch einmal erläutert wird, dass „Wirklichkeit“ im Sinne der Kategorie keine Eigenschaft der Dinge selbst betrifft, sondern die „Position des Dinges in Beziehung auf den Verstand“. Existenz ist mithin logisch kein Prädikat erster Ordnung, welches Gegenständen als Sacheigenschaft zukommt, sondern ein Prädikat zweiter Ordnung, welche „den Gegenstand in Beziehung auf meinen Begriff“ (KrV, B 627) setzt. Wirklichkeit als Modalität tut nichts als Eigenschaft dem Gegenstand hinzu bzw. macht seine durchgängige Bestimmtheit mit aus, sondern bestimmt einzig die Beziehung des Verstandes auf ihn: nämlich ob er in der Anschauung existent oder nicht-existent (aber möglich oder notwendig) ist. Das ist später die Grundlage der Kritik des ontologischen Gottesbeweises (KrV, B 619-630). Vgl. dazu Honnefelder: Scientia transcendens, S. $469 \mathrm{ff}$.

171 In der Kategorie „Wirklichkeit“ zeigt sich so die Tradition eines existenziellen Sinnes von „esse“ als „actus“ (energeia) im Gegensatz zur „potentia“ (Möglichkeit/dynamis).

172 Vgl. den $\S 76$ der Kritik der Urteilskraft, wo Kant für den menschlichen Verstand die Möglichkeit einer Sache dem Verstand, die Wirklichkeit hingegen der Anschauung zuordnet (Kritik der Urteilskraft, AA, 5, S. 401-403) und aufgrund der Trennung beider Erkenntnisstämme daraus ableitet, dass ,aus der bloßen Möglichkeit auf die Wirklichkeit gar nicht geschlossen werden könne“ (AA, 5, S. 402) - anders als ein anschauender Verstand (intellektuelle Anschauung), für den beides ineinanderfiele.

173 Vgl. KrV (B 273): ,[D]ie Wahrnehmung aber, die den Stoff zum Begriff hergibt, ist der einzige Charakter der Wirklichkeit.“ In der Unklarheit des Terminus „Charakter“ ist hier der ganze Problemzusammenhang der Realität $t_{1}$ in einer begrifflichen Markierung verdichtet. 
Die „negative Bedingung“ (KrV, B 189) der „Realität überhaupt“ ist die Widerspruchslosigkeit des Begriffs der Sache bzw. die Form ihrer Identität als formale Prinzipien des inneren Zusammenhangs des Begriffs; doch durch diese negative Bedingung wird nur die „logische Möglichkeit“ (KrV, B 303) derselben gesichert, nicht aber ihre „reale Möglichkeit“ (KrV, B 302) indiziert. Denn dafür ist es notwendig, dass „,der Begriff [...] sich auf ein Objekt beziehe, und also irgend was bedeute.“ (KrV, B 303) Wenn diese Objektbeziehung wiederum durch den gelingenden Zusammenhang mit einer Anschauung hergestellt und die reale Möglichkeit damit verwirklicht ist, greift die Kategorie der Wirklichkeit rein in Beziehung auf den Inhalt des Bewusstseins: „Das Reale äußerer Erscheinungen ist also wirklich nur in der Wahrnehmung und kann auf keine andere Weise wirklich sein.“(KrV, A 376)

Sichtbar wird hier die Verflechtung der Kategorie „Wirklichkeit“ als kategoriale Form der Realität ${ }_{2}$ mit den Bedingungen, aber auch Problemen der Realität und ihrer Gegenwärtigkeit im Bewusstsein. Denn den „Zusammenhang“ zu denken, den Kant hier unbestimmt andeutet, nämlich als sachmotivierte, kausal erzeugte und repräsentationale Anwesenheit des „Ding an sich“ in einer ihm angemessenen Repräsentation der es bezeugenden wirklichen Empfindung, ist eben das Problem der Realität $t_{1}$. Darüber hinaus erkennt Kant übrigens sogar einen Weg, „c o m pa r a tive a priori das Dasein“ (KrV, B 273) eines Dinges zu erkennen: „[...] wenn es nur mit einigen Wahrnehmungen, nach den Grundsätzen der empirischen Verknüpfung derselben (den Analogien), zusammenhängt.“ Die Wirklichkeit bspw. einer allgemeinen Kraft wie des magnetischen Feldes aus einzelnen empirischen Äußerungen zu schlussfolgern, muss als gültige Grundlage aller Naturwissenschaft in den wiederum gesetzmäßigen Zusammenhängen der Grundsätze des Verstandes begründbar sein. Quines berühmter Begriff empirischen Wissens als Netz, das nur an den äußeren Punkten mit der Wirklichkeit zusammenhängt, intern jedoch nach eigenständigen Regeln prozessiert und artikuliert wird, hat hier seine kantische Basis ${ }^{174}$.

Zugleich jedoch findet sich in diesem Zusammenhang, quasi als weitere Verdoppelung der grundsätzlichen Doppelung der Kategorien für das Reale, eine bedeutsame Spiegelung der Daseinskategorie. „Existenz“ bzw. „Dasein“ wird nämlich von Kant (allerdings ohne Erläuterung) an einer wichtigen Stelle auch als Verhältnisweise der 3. und 4. Kategoriengruppe in Bezug auf ihre Gegenstände gefasst (KrV, § 11, B 110). Deshalb heißen die 3. und die 4. Kategoriengruppe auch

174 Willard Van Orman Quine: „Two Dogmas of Empiricism“, in: Ders.: From a Logical Standpoint of View. Nine Logico-Philosophical Essays (1953), 2. Aufl., Cambridge, Mass./London 1980, S. 20 -46, hier: S. 42. 
„dy n a m i s c he [] Kategorien“ (KrV, § 11, B 95), und von ihnen wird gesagt, dass beide Gruppen zusammen als Einheit einer „Abteilung [...] auf die Existenz dieser Gegenstände [...] gerichtet“ sind (KrV, B 110). Das bedeutet, dass das „Dasein“ der Gegenstände im Raum der Erscheinungen erst dort beginnt, wo Gegenstände der Anschauung (d.h. solche, die bereits quantitativ und qualitativ bestimmt sind) nach „Relation“ (Substanzform mit Akzidenzien, Kausalitäts- und Gemeinschaftsverhältnissen) und „Modalität“ (d.h. im Hinblick auf ihre Daseinsweise) bestimmt sind, also dort, wo sich erst eine gewisse Komplexität des Objektbegriffs im Zusammenspiel seiner relationalen und modalen Qualitäten entwickelt hat ${ }^{175}$.

Kant unterscheidet damit also eigentlich (wenn auch mehr implizit als explizit) zwei Begriffe von „Dasein“ (Existenz/Wirklichkeit) im Raum der kategorialen Ordnung der Erscheinungswelt: 1) Dasein als Einzelkategorie der Modalität (Wirklichkeit), 2) Dasein als komplexe Kategorie zweiter Ordnung (Metakategorie bzw. „Abteilung“), die sich aus der gemeinsamen Wirksamkeit der 3. und der 4. Kategoriengruppe zusammensetzt und dabei eine Konfiguration von Kategorien meint, die erst in ihrer integralen Aktualität das Existenzial von Objekten bilden. Die Grundlage dieser Art von Wirklichkeit wird dabei durch die Voraussetzung gebildet, dass Objektivität im Sinne von Dasein abhängig ist von einer doppelten Bewegung der transzendentalen Gestaltung der sinnlichen Daten: zum einen als hinreichend mehrdimensionale innere Ausdifferenzierung der Elemente der Sache, zum anderen als hinreichend synthetische Verknüpfung der Elemente zur Sache ${ }^{176}$. Somit wird der Begriff des Objekts in seinem Dasein abhängig von einem bestimmten Grad der Komplexität seiner Struktur ${ }^{177}$, wobei Komplexität nach dem eben Gesagten als mehrdimensionale Einheit deutlich unterschiedener Elemente und damit im bestimmten Zusammenspiel des Unterschieds von Identität und Differenz bestimmt ist. So schreibt Kant:

Object aber ist das, in dessen Begriff das Mannigfaltige einer gegebenen Anschauung vereinigt ist. $(\mathrm{KrV}, \S 17, \mathrm{~B} 137)$

175 Zur grundsätzlichen Teleologie der Verstandeshandlungen auf die Erzeugung von objekthafter Komplexität vgl. KrV, § 15, B 129-131.

176 In der Kritik der Urteilskraft bestimmt Kant pointiert „Auffassung (apprehensio) und Zusammenfassung (comprehensio aesthetica)“ als Ur-Handlungen der Einbildungskraft zur Erzeugung eines objekthaften Bildes der Sache (§ 26, AA, 5, S. 251).

177 Vgl. Henrich (Identität und Objektivität), der beschreibt, wie bei Kant „objektive Realität“ an der Konstitution objekthafter Komplexität hängt. 
Die synthetische Einheit des Bewußtseins ist also eine objektive Bedingung aller Erkenntniß, nicht deren ich bloß selbst bedarf, um ein Object zu erkennen, sondern unter der jede Anschauung stehen muß, um für mich Object zu werden. (KrV, § 17, B 138) $)^{178}$

Das Objekt setzt für sein Dasein (Wirklichkeit) die „Synthesis überhaupt“ des Mannigfaltigen der Anschauung durch die synthetische Einheit der Apperzeption (Ich denke) im Verstand (,der selbst nichts weiter ist, als das Vermögen, a priori zu verbinden“, KrV, § 16, B 135) voraus. Jedes Objekt als „Objekt überhaupt“ ist damit in seinem Dasein von den ursprünglichen Operationen des Verstandes und ihrer je besonderen Qualität abhängig: Dasein ist das, was als mehrstufiger kumulativer Effekt aus dem Grad der Komplexität der Verstandeshandlungen hervorgeht. Das bloß in der Anschauung Gegebene hat deshalb noch kein Dasein als Objekt für uns, weil ihm die apriorische, „reine synthetische Einheit des Mannigfaltigen“ (KrV, B 177) (die der reine Verstandesbegriff leistet) sowie die bestimmte Einheit des Objektbegriffs (die erst der empirische Begriff leistet, indem er die Rahmenkonstruktionen des Verstandes mit besonderen Gehalten füllt) fehlen. Der Begriff des Daseins des Gegenstandes, seine Wirklichkeit im kantischen Sinne, fällt somit zusammen mit der Architektur eines besonderen Zusammenspiels der Verstandeshandlungen bzw. ihrer Aktualität, d.h. dem Gegebensein ihres jeweiligen Vollzuges: „[...] die Bedingungen der Möglichkeit der Erfahrung überhaupt sind zugleich Bedingungen der Möglichkeit der Gegenstände der Erfahrung und haben darum objective Gültigkeit in einem synthetischen Urtheile a priori.“ $(\mathrm{KrV}, \mathrm{B} 197)^{179}$

\subsubsection{Realität}

Es mag ein Anzeichen der oft beklagten Unordnung der nach langer Vorarbeit im „stillen Jahrzehnt“ hastig zusammengeschriebenen Kritik der reinen Vernunft sein, dass die wesentlichen Erläuterungen zur Kategorie der „Realität“ nicht in der Deduktion der Kategorientafel $\mathrm{zu}$ finden sind. Um die Funktionsweise der Kategorie bei der Arbeit zu sehen, ist ein Blick in den 4. Abschnitt des 3. Hauptstückes des zweiten Buches der „Transzendentalen Dialektik“ („Von der Unmöglichkeit eines ontologischen Beweises vom Dasein Gottes“) notwendig, der uns hier allerdings nicht interessiert. Um hingegen die begriffliche Form der Ka-

178 „Die transzendentale Einheit der Apperception ist diejenige, durch welche alles in einer Anschauung gegebene Mannigfaltige in einen Begriff vom Object vereinigt wird.“ (KrV, § 18, B 139)

179 Vgl. auch KrV, § 20, B 143. 
tegorie näher zu betrachten, muss man einen Blick in das Schematismuskapitel werfen; denn ungewöhnlicherweise finden sich erst hier Erläuterungen zum Begriff selbst.

Im Schematismuskapitel erläutert Kant die Kategorie der Realität zuerst im Hinblick auf die durch sie bestimmte „Sachheit“, wobei dafür grundlegend ist, dass sie „dasjenige also [ist], dessen Begriff an sich selbst ein Sein (in der Zeit) anzeigt“ (KrV, B 182). Als Kategorie einer „erfülleten, oder leeren Zeit“ (KrV, B 182) bezeichnet die Kategorie der Realität eben jene „Sachheit“ (KrV, B 182), die die Form eines Inhaltes überhaupt („Empfindung überhaupt“, KrV, B 182) als eines gegebenen mit einer bestimmten Größe meint (im Unterschiede zum Nicht-Sein als Nicht-Gegebensein bzw. mit der Größe 0). Zur „Sachheit“ der Realität gehört also „ein[] Grad oder Größe“ (KrV, B 182), d.h. die quantitative Bestimmtheit überhaupt. Diese ist in der Kategorie „Realität“ als Form angelegt ${ }^{180}$ und wird durch ihre Verbindung mit der Anschauung mit empirischem Gehalt gefüllt, weil diese stets in ihrem Gegebensein ein bestimmtes Etwas an Empfindung (Größe/Grad) mitbringt (sonst wäre sie leer und damit nicht gegeben).

Realität als Kategorie ist mithin die Form der „Quantität von Etwas“ (KrV, B 183) als reine Synthesis gegebener mannigfaltiger Empfindungsdaten mit der Bestimmung, „Etwas“181 und potenziell „anwesend“ (gegeben durch Anschauung) zu sein. Wie dabei das Realwerden eines Inhalts funktioniert, wird klar, wenn man näher betrachtet, wie Kant „das Schema einer Realität“ (KrV, B 183) erläutert, d.h. den funktionalen Übergang von der Data der Anschauung zur Kategorie. Dieses Schema wird bestimmt als „Quantität von Etwas, so fern es die Zeit erfüllt“ (KrV, B 183): also die Einheit einer bestimmten Gegebenheit („Etwas“) in der Verlaufsform zeitlicher Prozesse (,so fern es die Zeit erfüllt“) mit einem Umschlagprozess von Quantität in Qualität, nämlich das resultative Realsein als Kategorie der Qualität. Weiter heißt es:

Nun hat jede Empfindung einen Grad oder Größe, wodurch sie dieselbe Zeit, d.i. den innren Sinn, in Ansehung derselben Vorstellung eines Gegenstandes mehr oder weniger erfüllen kann, bis sie in Nichts ( $=0=$ negatio) aufhört. Daher ist ein Verhältniß und Zusammenhang, oder vielmehr ein Übergang von Realität zur Negation, welcher jede Realität als ein Quantum vorstellig macht; und das Schema einer Realität als der Quantität von Etwas, so fern es die Zeit erfüllt, ist eben diese continuirliche und gleichförmige Erzeugung derselben in der Zeit, indem man von der Empfindung, die einen gewissen Grad hat, in der Zeit bis zum Ver-

180 Die Kategorie „Realität“ gibt definitorisch folgende Form vor: Gegebensein eines „Etwas“ (KrV, B 602) mit bestimmter Größe.

181 Vgl. zur Bestimmung des „Etwas“ und seiner Vorgeschichte Honnefelder: Scientia transcendens, S. $444 \mathrm{f}$. 
schwinden derselben hinabgeht, oder von der Negation zu der Größe derselben allmählig aufsteigt. (KrV, B 182f.)

Das heißt: Das Schema, welches eigentlich nur die Funktionsstelle der Übersetzung zwischen Anschauung und Kategorie einnimmt, um „die Subsumtion [...], mithin die Anwendung der Kategorie auf Erscheinungen möglich“ (KrV, B 176) zu machen, zeigt hier erst den ganzen begrifflichen Zusammenhang der Kategorie „Realität“" auf, der in ihr eingefaltet liegt. „Realität“ meint demnach als reiner Begriff die Form des bestimmten, potenziell aktualen, d.h. durch Anschauung ermöglichten Gegebenseins von Etwas (,Realität ist E t w a s “, KrV, B 347), das durch Quantitätsänderungen bestimmt ist (d.h. real ist apriorisch Etwas, dessen „Sachheit“ eine bestimmte Größe in einer bestimmten Zeit einnimmt). Generell gründet die Möglichkeit dieses Etwas im „transzendentalen Ideal“ des „All[s] der Realität (omnitudo realitatis)“, aus dem es durch „Verneinungen [...] als Schranken“ (KrV, B 603f.) hervorgeht: „[...] die durchgängige Bestimmung eines jeden Dinges beruht auf der Einschränkung dieses All der Realität, indem Einiges derselben dem Dinge beigelegt, das übrige aber ausgeschlossen wird“ (KrV, B $605)^{182}$. Die Realität empirischer Objekte besteht in der Einschränkung der Allheit aller möglichen Dingprädikate auf diejenigen Prädikate, die diesen Objekten in der Erfahrung auch wirklich zukommen, wodurch ein negativ umrissenes partikulares Feld von Bestimmtheit entsteht: das „Etwas“ realer Objekthaftigkeit.

Dieses Etwas erscheint deshalb weiterhin als Zusammenhang von Quantität und Negation im Schema zeitlicher Veränderung, durch welchen die Bestimmtheit überhaupt als Fundament des Realseins gesetzt ist: Bestimmtheit heißt ein nach außen hin vorliegendes Begrenztsein (Negation) und ein nach innen hin als prinzipiell messbarer Inhalt bestehendes Gefülltsein (Quantität). Damit ist dieses Etwas schließlich auch noch in die Umschlagsfigur von Quantität in Qualität eingespannt: Das Etwas als qualitative Form des Realseins entsteht als Differenzial einer sich in zeitlicher Prozession qua negativer Begrenzung graduell entfaltenden quantitativen Größe. Auf dieser Definition der „Realität“ fußen dann bei Kant im Fortgang des Schematismuskapitels die Schemata der apriorischen Bestimmungen, die man die „sekundären apriorischen Realbestimmungen“ der 3. Kategoriengruppe (Relation) nennen könnte.

Wie schon für die Kategorie der „Wirklichkeit“ gilt somit auch für die Kategorie der „Realität“, dass sie eigentlich eine Zusammenhangskategorie ist, die sich

182 Der „Grundsatze der durchgängigen Bestimmung“ (KrV, B 599) für jedes empirische Ding ist das Prinzip der empirischen Realität der Objekte der Erscheinungen: Er meint, dass in Bezug auf den „Inbegriff aller Prädikate der Dinge überhaupt“ für jedes Ding prinzipiell angegeben werden kann, welches von zwei kontradiktorisch entgegengesetzten Prädikaten ihm zukommt. 
sinnvoll nur im nochmals gestuften bestimmten Zusammenhang von Einzelkategorien bzw. von Kategoriengruppen ergibt. Den engsten, d.h. internen Zusammenhang bilden die drei Kategorien der Gruppe „Qualität“ - Realität, Negation, Limitation -, weil gezeigt worden ist, wie „Realität“ als kategorialer Effekt aus dem Zusammenspiel von Negation und Limitation hervorgeht. Der etwas weitere, gleichwohl noch auf derselben Stufe vorliegende Zusammenhang (externer Zusammenhang ${ }_{1}$ ) besteht aus der Kategoriengruppe „Quantität“, da Kant „Realität“ deutlich in der bestimmten prozessualen Verknüpfung von Quantität und Negation begreift. Den weiteren Zusammenhang (externer Zusammenhang 2 ) schließlich bilden die Kategorien der Gruppe „Relation“, die im Schematismuskapitel aus der Kategorie „Realität“ heraus erläutert und folglich in ihrer Funktionsweise aus ihr abgeleitet werden ${ }^{183}$. Was Kant folglich im „Amphibolie“-Kapitel der Kritik der reinen Vernunft als reale Eigenschaft der „Substanz“ als der grundlegendsten Form des Gegebenseins von Etwas aufzeigt - „die innern Bestimmungen einer substantia phaenomenon im Raum [sind] nichts als Verhältnisse und sie selbst [ist] ganz und gar ein Inbegriff von lauter Relationen“ (KrV, B 321) -, gilt ebenso für die Logik des reinen Begriffs der Realität selbst.

\subsubsection{Die Transgressivität der Realitätsbegriffe}

Es ist deutlich geworden, dass die Kategorien des Realen (Wirklichkeit und Realität) zu ihrer Bestimmung und Funktion sich notwendig selbst in Richtung auf die Beziehung $\mathrm{zu}$ anderen Kategorien oder in Beziehung auf sich selbst als andere

183 Kant nämlich definiert das „Schema der Substanz“ wie auch das „Schema der Ursache und der Causalität“ (KrV, B 183) stets als Modifikationen „des Realen“ (KrV, B 183). Er zeigt damit, inwiefern zum einen die Kategorien der Kategoriengruppe „Relation“ (KrV, B 183) nur in Bezug auf die Kategorie der Realität (die wiederum ein Zusammenhang von Realität, Negation und Limitation ist) gedacht werden können. Zum anderen zeigt er, dass die Kategorie der Realität die Kategorien der „Substanz“ (KrV, B 183) und der „Kausalität“ (KrV, B 183) als logische Entfaltungen ihrer eigenen Konfiguration bereits enthält. Denn: Substanz als „Beharrlichkeit des Realen in der Zeit“ (KrV, B 183) ist nur eine besondere Modifikation der Kategorie der Realität, nämlich die Bestimmtheit „Beharrlichkeit“ (KrV, B 183) als besondere Qualität quantitativer Veränderung überhaupt, die ja als Form von Realität bestimmt worden war (vgl. KrV, B 249-253, wo im Einzelnen die Kategorie „Substanz“ erläutert und dafür immer wieder auf das „Reale“ als Substrat bzw. das „Dasein“ als Substanz Bezug genommen wird). „Das Schema der Ursache und der Causalität eines Dinges überhaupt“ (KrV, B 183) als das „Reale, worauf, wenn es nach Belieben gesetzt wird, jederzeit etwas anderes folgt“ (KrV, B 183), ist eine nähere Bestimmung der Zeitfolge quantitativer und qualitativer Veränderung überhaupt, wie sie in der Kategorie der Realität bereits gesetzt ist; ebenso das „Schema der Gemeinschaft (Wechselwirkung)“ (KrV, B 183) als „Zugleichsein der Bestimmungen“ (KrV, B 183) der Substanzen. 
Kategorie überschreiten müssen. Kant nimmt so (nicht intendiert) die platonische Einsicht der symploké aus dem Sophistes auf, nämlich dass manche kategorialen „Begriffe sich gegeneinander [...] in Hinsicht auf Mischung verhalten“184, indem sie „durch einander hindurchgehen“"185, also ihre Teilhabe an anderen Begriffen eine notwendig $\mathrm{zu}$ denkende Funktion ihrer eigenen Bestimmung ist. Diese Überschreitung verdoppelt sich im Hinblick auf die kategoriale Doppelung von „Realität“ und „Wirklichkeit“. So wie sich die Kategorie „Realität“, wie angezeigt, notwendig verzweigt und den ihr zugeordneten scharf begrenzten Platz innerhalb der Ordnung der Kategorien überschreitet, verhält sich auch die Kategorie „Wirklichkeit“. Es ist bereits gezeigt worden, wie auch „Dasein“ (Wirklichkeit) als Metakategorie zweiter Ordnung ihren Platz im Raum der vierten Kategoriengruppe überschreitet, indem sie sich in einen zweiten Begriff von ihr verdoppelt, der als Zusammenhang der dritten und der vierten Kategoriengruppe von Kant gedacht wird („Abteilung“ der Wirklichkeit, Kap. 1.3.1).

Hinzu kommt schließlich bezüglich der Kategorie „Wirklichkeit“ eine zweite innere Verdopplung, welche die Verknüpfung zwischen Realität ${ }_{2}$ und Realität ${ }_{1}$ überhaupt andeutet und sozusagen als spiegelbildliche Gegenseite der Überschreitungsbewegung erscheint, welche bezüglich der Realität $t_{1}$ als deren notwendiger Bezug auf objektive Formen des Bestimmtseins (Kap. 1.1) und damit auf objektive begriffliche Funktionen gezeigt wurde. Denn diese „Wirklichkeit“ als „Dasein“ muss als begriffliche Form objektseitig (im „Ding an sich“) immer schon vorliegen, um das Vorliegen überhaupt schon der allerersten Stufe von Realität in der Empfindung bzw. Anschauung erklären zu können. Die Form des Gegebenseins überhaupt, welche dem besonderen Gegebensein von sinnlichen Data als aktuelle „Mannigfaltigkeit“ zugrunde liegt und damit vorhergeht und die Kant im kategorialen Begriff „Dasein“ meint, bildet den Anfang und das Ende des transzendentalen Baus der Realität: die notwendig zu denkende erste Form, um das Gegebensein von sinnlichen Daten zu ermöglichen, wie auch die letzte kategoriale Verbindung, um den Zusammenhang der dritten und der vierten Kategoriengruppe im Begriff „Wirklichkeit“ zu schließen. Schließlich muss das Mannigfaltige der Anschauung für die Empfindung „wirklich“ sein, um nachfolgend durch die Kategorie der Realität als „real“ bestimmt werden zu können. Die spätere Kategorie der „Wirklichkeit“ beruht damit auf der ihr vorausgehenden „Wirklichkeit“ der Realität $t_{1}$, die im Raum der Anschauungen als eine heteronome, nicht

184 Platon: Sophistes, S. 127 [254a]. 185 Platon: Sophistes, S. 145 [259a]. 
denkbare dem Subjekt eingefügt wird. ${ }^{186}$ Das zeigt auch Kants Bestimmung des Schemas der Kategorie „Wirklichkeit“: „Das Schema der Wirklichkeit ist das Dasein in einer bestimmten Zeit“ (KrV, B 184) - eine Definition, die exakt das beschreibt, was eigentlich vor allen Kategorien und Schemata bereits die Form des Inhalts der Realität ${ }_{1}$ in der Empfindung ausmacht.

Erneut wird das zentrale Dilemma bezüglich der Ordnung der Begriffe des Realen in Kants Philosophie deutlich. Realität ${ }_{1}$ („Ding an sich“) und Realität (Kategorien von Realität/Wirklichkeit) sind bei Kant zum einen absolut getrennt gedacht, weil sie nicht integrierbar oder begrifflich vermittelbar sind, sondern zwei verschiedenen Welten und Wissensformen zugehören („Ding an sich“ - Erscheinungen). Zum anderen aber bedingen sie einander, indem die Kategorien „Realität“ und „Wirklichkeit“ der Erscheinungswelt nur zu verstehen sind von einem Begriff von Wirklichkeit aus, der ihnen als je verschiedene objektive Form von Bestimmtheit immer schon vorausgehen muss, damit sie überhaupt Bedeutung haben können. Der komplexe Begriff der Realität ist - das hat ,unfreiwillig‘ auch die verwirrende Multiplizierung der Begriffe des Realen gezeigt (Kap. 1.2) dem logischen Moment seines Einsetzens immer schon vorgängig, weil er auch auf der Ebene seines bloßen Begriffs jede verstandesmäßige Eingrenzung auf einen logischen Ort immer schon überschreitet und sich vielmehr als auf multiple Orte des systematischen Begriffszusammenhangs verteilt zeigt ${ }^{187}$. „Bestimmtsein

186 Kant nennt nicht umsonst die Grundbegriffe im Anschluss an die Tradition der kategorialen Analyse seit Platon (Sophistes) und Aristoteles (Kategorienschrift) „unauflösliche Begriffe“ und meint, „daß es unvermeidlich sei, in der Zergliederung auf unauflösliche Begriffe zu kommen, die es entweder an und für sich selbst oder für uns sein werden“ (Immanuel Kant: Untersuchung über die Deutlichkeit der Grundsätze der natürlichen Theologie und Moral, AA, 2, S. 273-303, hier: S. 280). Ein solcher Begriff ist der des „Daseins“: „Wenn man einsieht, daß unsere gesamte Erkenntnis sich doch zuletzt in unauflöslichen Begriffen endige, so begreift man auch, daß es einige geben werde, die beinahe unauflöslich sind, das ist, wo die Merkmale nur sehr wenig klarer und einfacher sind, als die Sache selbst. Dieses ist der Fall bei unserer Erklärung von der Existenz. Ich gestehe gerne, daß durch dieselbe der Begriff des Erklärten nur in einem sehr kleinen Grade deutlich werde“ (Immanuel Kant: Der einzig mögliche Beweisgrund zu einer Demonstration des Daseins Gottes, AA, 2, S. 63-165, hier: S. 73f.).

187 Dass Kant an einer Stelle der Kritik der reinen Vernunft in Bezug auf das „Ich denke“ der synthetischen Einheit der Apperzeption (KrV, B 423, Fußnote) zusätzlich noch einen anderen Begriff von „Existenz“ (Dasein) in Anschlag zu bringen versucht, der allen Empfindungen und Begriffen vorausgehen soll, zeigt überdeutlich, wie ihm dieses Problem der Vorgängigkeit des Realen zumindest im Feld bestimmter Problemfälle seiner Theorie bewusst gewesen ist. Denn die Existenzgewissheit des Ich als in der Erfahrung evidente Gegebenheit, die zugleich aber keinen Erkenntnischarakter haben kann (vgl. zu dieser Verschattung des Ich als Korrelat zur Verschattung des „Ding an sich“ als je letzte Gründe von Kants Systematik Jacobi: David Hume, JWA 2,1, S. 110), ist zugleich für die Architektur des Systems notwendig: Das transzendentale Selbstbe- 
überhaupt“ in der Form des Realen lässt sich nicht isolierend auf einen abstrakten kategorialen Begriff zusammenkürzen, sondern ist sich im Sinne von Heideggers absoluter Erschlossenheit des Seinsverständnisses ${ }^{188}$ und natürlich im Sinne von Hegels Dialektik von Nachgängigkeit und Vorgängigkeit (vgl. Hauptteil II) immer schon selbst (vor)gegeben, um überhaupt gedacht werden zu können ${ }^{189}$. Hegel

wusstsein muss als evident begründet werden, um die aus ihm abgeleitete transzendentale Einheit, welche wiederum die Einheitsfunktionen von Urteil und Begriff begründet, sichern zu können. Existenz aber kann an dieser Stelle kein Begriff sein: weder ein Prädikat erster Ordnung, das Dingen zukommt (denn das Selbstbewusstsein ist keine Substanz), noch ein Prädikat zweiter Ordnung (denn es ist auch kein Begriff von sich). Kant weicht deshalb auf ein Selbstgefühl aus, dessen Evidenz im eigenen Vollzug liegt: Existenzgewissheit ist erstens keine logische Schlussfolgerung aus dem Satz „Ich denke“ (hier missversteht Kant den cartesianischen Impetus als Schluss). Zweitens ist sie keine „unbestimmte empirische Anschauung, d.i. Wahrnehmung“, weil sie „vor der Erfahrung vorher[geht]“: Sie drückt eine solche nur aus. „Eine unbestimmte Wahrnehmung bedeutet hier nur etwas Reales, das gegeben worden und zwar nur zum Denken überhaupt, also nicht als Erscheinung, auch nicht als Sache an sich selbst (Noumenon), sondern als Etwas, was in der Tat existiert und in dem Satze: Ich denke, als ein solches bezeichnet wird.“ Die Tradition dieses „Selbstgefühls“ wird die romantische Philosophie nach Kant aufnehmen (vgl. Manfred Frank: Selbstgefühl. Eine historisch-systematische Erkundung, Frankfurt am Main 2002); bereits bei Fichte aber steht der Versuch an, den sich selbst begründenden Grund allen Wissens in einer anderen Wissensform, der des intuitiven Wissens des Ich von sich, zu suchen. Gegen die These, dass Kant ursprünglich (d.h. seit dem Duisburgschen Nachlass 1775 bis zur KrV 1781) ein substanztheoretisches Modell der Apperzeption erwogen hat, wie sie Wolfgang Carl vertritt, plädiert Rolf-Peter Horstmann für ein „dynamisch-prozessuales Modell“ (Rolf-Peter Horstmann: „Kant und Carl über Apperzeption“, in: Kant in der Gegenwart, hg.v. Jürgen Stolzenberg, Berlin/ New York 2004, S. 131-147, hier: S. 141). Die Konstitution der Einheit der Apperzeption erfolgt nur im Vollzug des Aufnehmens von gehaltvollen Vorstellungen in das als Einheit gedachte Subjekt, das insofern nicht als ein besonderes substanzielles Objekt vorgestellt werden kann. Das „Ich“, das ,in der Tat existiert“ (KrV, B 423, Anm.) ist vielmehr ein Akt, der nur stattfindet, wenn Vorstellungen gegeben sind, von welchen wir „abgesondert, niemals den mindesten Begriff haben können“ (KrV, A 364). Zu einer ähnlichen dynamisch-prozessualen Deutung der Einheit der Apperzeption, welche die Einheit als numerische Identität in der Zeit auffasst, vgl. Béatrice Longuenesse: „Kant on the Identity of Persons“, in: Proceedings of the Aristotelian Society 107 (2007), Teil 2, S. 149-167. Siehe auch McDowells Interpretation des „Ich denke“ in Mind and World (S. 99f.): „When [Kant] introduces the self-conscioussness that he argues to be correlative with awareness of objective reality, he writes of the ,I think that must be able ,to accompany all my representations ' [...]. It [I] has nothing to do with the substantial identity of a subject who persists as a real presence in the world she perceives. The subjective temporal continuity that is a counterpart to experience's bearing on objective reality shrinks to the continuity of a mere point of view, not, apparently, a substantial continuant.“

188 Martin Heidegger: Sein und Zeit, Tübingen 2001, S. 5 [§ 2].

189 Welchen zentralen Stellenwert für das „Reale“ das Moment der Vorgängigkeit bzw. der Unabhängigkeit des Realen von der „Konstruktion“ durch das Subjekt bei Kant einnimmt, zeigt sich daran, dass die ältere, ontologische Lesart des transzendentalen Idealismus heute wohl nicht 
wird dieser Selbstrelationalität des Realen als Modus seiner begriffslogischen Entfaltung über das Netz kategorialer Abgrenzungen hinweg noch den gleichsam ,inneren“ Aspekt hinzufügen, dass auch „Ansichsein“ (Selbstbeziehung/Identität) und „Beziehung auf Anderes“ (Unterschied) ${ }^{190}$, die bereits Platon im Sophistes (hier als Vorgänger des kantischen Isolationsdenkens) unterschieden ( $\alpha$ ủं $\alpha \alpha \theta$

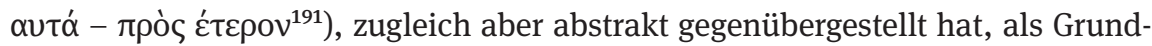
formen der Relationalität realer Gegenständlichkeit nur in ihrer wesenhaften Verknüpfung als Identität im Unterschied zu denken sind: „Ja, wenn nun einer nachwiese, daß das Ähnliche selbst unähnlich oder das Unähnliche ähnlich werde, das wäre, glaube ich, ein Wunder." ${ }^{192}$ Realität, so wird deutlich, ist in der Gesamtheit ihrer Begriffsform eine komplexe Kategorie zweiter Ordnung, die der kategorialen Isolation und ihrer horizontalen Reihung widerstreitet und deshalb in anderer Form in das System der Grundbegriffe integriert werden muss: nämlich in der Weise, wie auch das Verhältnis ihrer inneren Grundbestimmungen - als Identität im Unterschied bzw. Selbstunterscheidung des Identischen - zu denken ist. Gerade der reine kategoriale Begriff des Realen zeigt an, wie problematisch die abstrakte Isolation von Begriffsformationen ist und wie wenig sie sich eignet, die auch im ,bloßen' Begriff des Realen residierende Lebendigkeit seiner Entfaltung zu erfassen. ,Lebendig“ ist nicht nur das, was der Begriff des Realen als Inhalt zu erfassen sucht: Lebendig ist auch die Matrix seiner Begriffsform selbst. Erst die

mehr zu halten ist: Die von Kant dargestellten Synthesen von Anschauungen und Verstandesfunktionen können nicht so verstanden werden, als würden sie den Gegenstand ihrer Erkenntnis zuallererst konstituieren. Die epistemische Lesart hingegen, die sich an deutliche Formulierungen Kants anlehnt (KrV, A 92; vgl. zum Unterschied beider Lesarten Thomas Grundmann: „Was ist eigentlich ein transzendentales Argument?“, in: Warum Kant heute? Systematische Bedeutung und Rezeption seiner Philosophie in der Gegenwart, hg.v. Dietmar H. Heidemann, Kristina Engelhard, Berlin/New York 2004, S. 55f.), markiert die doppelte ontologische Unabhängigkeit der Gegenstände der Erfahrung. Ontologisch unabhängig vom Subjekt ist natürlich das „Ding an sich“; ontologisch unabhängig vom Subjekt ist aber laut Kant auch der Gegenstand der Erscheinung. Apriorische Bedingungen des Gegenstandes sind demnach „subjektabhängige Eigenschaften des ontologisch unabhängigen Gegenstandes“ (Grundmann: Transzendentales Argument, S. 56). Freilich hat Kant m.E. nicht hinreichend klar aufgezeigt, was hier unter „ontologisch unabhängig“ verstanden werden soll und in welcher Weise diese beiden ontologischen Ebenen aufeinander bezogen sind. Vgl. zur „Theorie der apriorischen Voraussetzung“ näher Anton Friedrich Koch: Wahrheit, Zeit und Freiheit. Einführung in eine philosophische Theorie, Paderborn 2006, sowie Ders.: Versuch über Wahrheit und Zeit, Paderborn 2006.

190 „[D]aß, was verschieden ist, [ist] dies, was es ist, notwendig in Beziehung auf ein anderes“ (Platon: Sophistes, S. 133 [255d]).

191 Platon: Sophistes, S. 133 [255c].

192 Platon: Parmenides, 129c. 
Hegel'sche Kategorienlehre löst diesen Anspruch allerdings begrifflich ein. ${ }^{193}$ Zugleich wird deutlich, dass Kants Neubegründung der Metaphysik als Wissenschaft im Raum ihrer konstitutiven Entzweiungen nicht nur eine - explizit gemacht - erkenntniswidrige Überschreitung von Begriffen durch sich selbst kennt: nämlich die der Ideen über den Anwendungsbereich der Erfahrung hinaus auf „Dinge an sich“194. Auch im Bereich des Verstandes haben zumindest die Kategorien des Realen die starke Tendenz, Begriffsverhältnisse einzugehen und so gerade die innere Überschreitung des Verstandes (d. h. seiner sauberen kategorialen Isolationen) $\mathrm{zu}$ inszenieren, die zugleich ein Abbild der notwendig $\mathrm{zu}$ denkenden äußeren Überschreitungen ist, durch welche sonst weder Subjektivität noch Objektivität sinnvoll zu denken sind.

Das gedrängte Fazit dieser kritischen Kantlektüre lautet deshalb: Es ist nicht möglich, die begrifflichen apriorischen Grundmuster des Realseins überhaupt als Minimalbedingungen der bestimmten Aktualität eines Vorhandenen so zu verstehen, als würden sie einer an sich völlig begriffslosen, unbestimmten und unbestimmbaren Materie der Empfindung a) nur nachträglich, b) nur subjektivtranszendental und c) abstrakt isoliert in einzelnen Kategorien hinzugefügt. Der Impuls der erscheinungsinternen Kategorien des Realen, inferenzielle Begriffszusammenhänge einzugehen und sich nur in diesen bestimmen zu lassen, also sich selbst nur in Beziehung auf Anderes bzw. vorausgesetzt als Anderes zu entfalten, durchwirkt alle Versuche, das Reale als Form zu begreifen. Auch im Verhältnis von Subjektivität und Außenwelt ergibt sich so die Denknotwendigkeit, ein Mindestmaß an Vernunftgemäßheit, d.h. begrifflicher Präformation in verwandten Formen im Objekt bzw. als Objekt („Ding an sich“) immer schon vorauszusetzen, um ihre sekundäre Applikation durch das Subjekt überhaupt sinnvoll und konsistent denken zu können. Extrem pointiert formuliert: Wo Begriffe durch Subjekte auf ein unabhängig von ihnen Reales angewendet werden sollen, muss Begrifflichkeit als dieses Andere und in diesem Anderen bereits vorliegen. „Soll ferner die Erfahrungs-Kontrolle von subjekt-unabhängigen Tatsachen erfolgen, die jedoch nur als begrifflich bestimmter Erfahrungsinhalt zur Verfügung stehen, wodurch geschieht dann die fragliche Erfahrungs-Kontrolle?“195: Es ist

193 Zur Lebendigkeit des Begriffs bei Hegel, der sich nur verstehen lässt, wenn man das an ihm unverzichtbare Moment der Bewegung markiert, vgl. die Habilitationsschrift von Annette Sell: Der lebendige Begriff. Leben und Logik bei G.W.F. Hegel, Alber-Reihe Thesen, Bd. 52, München 2013. 194 Eine Stelle aus der ersten Auflage der KrV besagt, dass „eben darin Philosophie besteht, seine Grenzen zu kennen.“ (KrV, B 755)

195 Wilhelm Lütterfelds: „Kant in der gegenwärtigen Sprachphilosophie“, in: Warum Kant heute? Systematische Bedeutung und Rezeption seiner Philosophie in der Gegenwart, hg.v. Dietmar H. Heidemann, Kristina Engelhard, Berlin/New York 2004, S. 150 -177, hier: S. 174. 
eben jene Frage, die zur Lösung der Aporie des Außenweltbezugs nahelegt, dass begriffliche Muster als immer schon zugleich präponiert-ontologische wie postponiert-epistemische Bedingungen von Realität zu verstehen sind. Dass im $k a-$ tegorialen Begriff des Realen, wo er nicht in auflösende und sinnwidrige Widersprüche geraten will, die begrifflichen Muster desselben so gedacht werden müssen, dass sie im Anderen des Objekts immer schon selbst vorhergehen müssen, um danach ${ }^{196}$ applikativ-konstruktiv durch das Subjekt in Form intentionaler Subjektivität wirksam sein zu können, ohne dabei bloß dieselben zu sein und deshalb im Erkennen einfach nur nachträglich abgebildet zu werden, stellt das Problem des ontologischen Unterschieds von Subjekt und Objekt mit Kant ins Zentrum des kategorialen Nachdenkens über „Realität überhaupt“. Es ist Kants großes Verdienst, im Rahmen seiner Kritik der metaphysischen Ontologie und ihrer Transformation in Epistemologie durch eine Fülle von scharfen Argumentationen und schwierigen Begriffsentwicklungen dieses Problemfeld in vorher ungeahnter Komplexität herausgearbeitet zu haben.

Jetzt wird schlussendlich auch deutlich, in welche Richtung die ausführliche Kritik an der Affektionstheorie des „Ding an sich“ sowie die Diskussion seiner Forschungsprobleme zielt. Das Problem dieses Gedankens nämlich ist viel weniger ein ungebührlicher Gebrauch der Kategorie der Kausalität, der zu einer „fälschlichen Überdehnung des Theorierahmens“197 führt, zugleich aber den „Theorierahmen der transzendentalen Reflexion“"198 voraussetzt und bekräftigt. Mit Jacobis weitaus radikalerer Kritik in der Beylage, wie sie von Birgit Sandkaulen in Absetzung vom bloß lokalen Kausalitätsargument herausgearbeitet worden ist, sind es vielmehr die begrifflichen Voraussetzungen bzw. Prämissen von Kants Konzept von Wahrnehmung und Sinnlichkeit, die die Geltungsbedingungen der Erkenntnistheorie und ihre funktionale Einheit gefährlich unterlaufen. Kant entwirft, wie wir gesehen haben, zwei begriffliche Ebenen der einen begrifflich zu beschreibenden Realität, die er als Zusammenhang entwickeln will (als zwei komplementäre Beschreibungen von Realsein), die sich aber zugleich nicht konsistent als Aspekte einer Realität zusammenbringen lassen. Die Prämisse des Begriffs der „Sinnlichkeit“ bildet den Beschreibungsbereich von $\mathrm{R}_{1}$ als Teilaspekt der vollständigen Beschreibung des kategorialen Begriffs der Realität so aus, dass er sich in die Regeln der „Begriffsbildung überhaupt“, die allein der Beschreibungsbereich $\mathrm{R}_{2}$ zugleich festlegt, nicht integrieren lässt. Denn die mit dem spezifischen Realsein der Gegenstände von $\mathrm{R}_{1}$ notwendig einhergehenden Be-

196 „Danach“ in einem logischen, nicht in einem zeitlichen Sinn.

197 Sandkaulen: Das leidige Ding an sich, S. 188.

198 Sandkaulen: Das leidige Ding an sich, S. 188. 
stimmungen widersprechen den Bestimmungen der Gegenstände von $\mathrm{R}_{2}$ : Um durch das Subjekt transzendental und empirisch bestimmt werden zu können, müssen die durch Affektion der „Dinge an sich“ gelieferten Informationen zuvor schon subjektunabhängig bestimmt sein, was sie aber nicht sein können, da alle begriffliche und protobegriffliche Bestimmtheit einzig in $R_{2}$ erzeugt wird. Das notwendig zu denkende Realsein der „Dinge an sich“ als affizierende Gegenstände außerhalb der transzendentalen Bedingungen von Subjektivität meint deshalb mehr als bloße abstrakte Existenz: Der ihnen zugeordnete kategoriale Begriff von Realsein enthält die beiden Bestimmungen „unabhängiges Vorausgesetztsein“ und ,an sich Bestimmtsein“ - damit aber die Voraussetzung einer subjektvorgängigen begrifflichen Form und eines sich in verschiedene Areale unterscheidenden einen Raums der „Begriffsförmigkeit überhaupt“.

Es ist damit deutlich geworden, dass denknotwendig der Begriff der Realität der affizierenden Dinge von $\mathrm{R}_{1}$ selbst wiederum eine begriffliche Strukturierung voraussetzt, d. h. eine vorausgesetzte Bestimmtheit so an sich haben muss ${ }^{199}$, dass daraufhin und als normativer Hintergrund die begrifflichen Operationen von $\mathrm{R}_{2}$ als andere zu diesen erfolgen können. Hier liegt auch die eigentliche Kritik Jacobis an Kants „Ding an sich“200: dass diese Idee affizierter Sinnlichkeit und nachfolgender begrifflicher Formierung von repräsentationalen Gehalten den Modus einer Rezeptivität voraussetzt, der Gegenstand und transzendentale Subjektivität als außer sich, vorgängig, gleichursprünglich und notwendig realbestimmt denken muss. Deshalb soll im nächsten Kapitel diese Jacobi-Kritik, die durch die hier vorliegende Interpretation gewissermaßen gestützt wird, kurz untersucht werden. Allerdings sind hier zugleich Einsichten formuliert worden, die weit über Jacobi hinausgehen. Um nämlich den Unterschied von $R_{1} / R_{2}$ als den von begrifflichen Teilaspekten desselben Wirklichkeitsbegriffs zu beschreiben, der die evident-erfahrungsgegebene und deshalb denknotwendige Differenz von subjektvorgängiger Erfahrungsgrundlage und nachfolgender Beschreibung, begriffsvorgängigen Gegenständen und deren nachfolgender begrifflicher Konzeptualisierung erfasst, muss angesichts der begrifflichen Konsequenzen aus dem Gedanken sinnlicher Affizierung sowie in Bezug auf die begriffliche Form der Einheit beider Aspekte von $R_{1} / R_{2}$, zu einer vollständigen und konsistenten kategorialen Beschreibung von „Realität überhaupt“ eben der Inhalt des Unterschieds, den der Unterschied $\mathrm{R}_{1} / \mathrm{R}_{2}$ bildet, als negiert vorausgesetzt werden. Denn das für Affizierungsbezie-

199 In den Prolegomena sagt Kant deutlich, dass „Erscheinungen doch jederzeit eine Sache an sich selbst voraussetzen und also darauf Anzeige tun, man mag sie nun näher erkennen oder nicht.“ (Prol. §57, S. 142) Damit ist nochmals die Voraussetzungs- und Verweisstruktur in der Grenzbestimmung von $\mathrm{R}_{2}$ und $\mathrm{R}_{1}$ deutlich markiert.

200 Sandkaulen: Das leidige Ding an sich, S. 184-186. 
hungen notwendige Realsein der Gegenstände innerhalb von $R_{1}$ muss als die Begriffsförmigkeit bereits vorausgesetzt gedacht werden, die mithilfe des Unterschieds von $R_{1} / R_{2}$ bei Kant erst als nachfolgend beschrieben wird und innerhalb der Kategorie „Realität“ als alleinige Form von transzendentalem „Realsein überhaupt“ erscheint: An-sich-Bestimmtsein nämlich. Die Begriffsförmigkeit des transzendentalen Realseins bestreitet (negiert) jede Möglichkeit vorgängigen Bestimmtseins der Gegenstände von $R_{1}$ - und setzt sie doch zugleich implizit voraus, um störungsfrei arbeiten zu können. Die durch den Begriff rezeptiver, affizierter Sinnlichkeit präsupponierte begriffsförmige Realität der Gegenstände in $\mathrm{R}_{1}$ wird in $\mathrm{R}_{2}$ implizit als notwendig begriffsförmig vorausgesetzt und zugleich explizit bestritten, um darauffolgend allein von den Leistungen transzendentaler Subjektivität begrifflich gesetzt werden zu können. Damit aber ist eben der Begriff realer Bestimmtheit, der das kategoriale „Realsein“ in $\mathrm{R}_{2}$ ausmacht, als sich selbst vorausgehend bzw. als Abstoßen seiner von sich selbst gedacht - d.h. als Gegensatz in sich selbst, indem er sich in seiner jeweiligen Negation gerade erhält und festigt. Die hier zur Beschreibung dieses Sachverhalts verwendete Hegel'sche Begrifflichkeit deutet bereits darauf hin, welche spekulativen Möglichkeiten zur Verfügung stehen, um auf dieses Verhältnis begrifflich volllständiger als bei Kant rückgreifen zu können. 